Gerión. Revista de Historia Antigua

ISSN: 0213-0181

https://dx.doi.org/10.5209/geri.74783

\title{
Il duovirato nei municipia italici: contributo allo studio della fase finale del processo di municipalizzazione nell'Italia centrale e meridionale
}

\author{
Simone Sisani ${ }^{1}$
}

Recibido: 24 de junio de 2020 / Aceptado: 18 de noviembre

Riassunto. Il contributo analizza in forma sistematica i casi noti di municipia retti da duoviri all'interno delle regiones augustee $I$-VII, con lo scopo di offrire una lettura in chiave strutturale della diffusione del duovirato municipale in area italica: l'analisi consente di formulare ipotesi sulle ragioni storiche del ritardo istituzionale manifestato da alcune aree della penisola, dove il processo di municipalizzazione giunge a pieno compimento soltanto a cavallo tra l'età cesariana e l'età augustea.

Palabras clave: Cesare; duoviri; municipia; praefecturae; quattuorviri; Silla.

[en] The Duovirate in Italian Municipia: Contribution to the Study of the Final Phase of the Municipalization Process in Central and Southern Italy

Abstract. The contribution analyzes systematically all known cases of municipia governed by duoviri within the Augustan regiones I-VII, aiming at offering a structural reading of the diffusion of municipal duovirate in the Italic area: the analysis allows to formulate hypothesis on the historical reasons for the institutional delay manifested by some areas of the peninsula, where the process of municipalization is fully accomplished only between the Caesarian and the Augustan ages.

Key words: Caesar; Duoviri; Municipia; Praefecturae; Quattuorviri; Sulla.

Sommario: 1. Il duovirato come esito del riassetto istituzionale di municipia quattuorvirali. 2 . Il duovirato come esito della promozione a municipia di realtà vicane. 3. Il duovirato come esito della tardiva costituzione a municipia di comunità semi-autonome sorte su antico ager Romanus. 4. Il duovirato come esito della tardiva costituzione a municipia di antiche civitates foederatae. 5. I municipia duovirali in Italia: le dinamiche storiche di un ritardo istituzionale. 6. Appendice: attestazioni "anomale" del quattuorvirato. 7. Bibliografia.

Cómo citar: Sisani, S. (2021): Il duovirato nei municipia italici: contributo allo studio della fase finale del processo di municipalizzazione nell'Italia centrale e meridionale, en Gerión 39/1, 41-93.

Università dell'Aquila.

E-mail: simone.sisani@univaq.it

ORCID: 0000-0002-8752-6931 
A Giulio Beloch, nel $150^{\circ}$ anniversario del suo arrivo in Italia.

All'interno della descrizione geografica dell'Italia centrale e meridionale (regiones $I-V I I),{ }^{2}$ Plinio elenca -attingendo ai registri ufficiali di età augustea- circa 350 civitates dotate di piena autonomia amministrativa: di esse, escludendo la trentina di coloniae civium Romanorum dedotte entro il II sec. a.C., ${ }^{3}$ oltre 300 dovettero conoscere una fase propriamente municipale. Nell'ambito di queste ultime comunità, conosciamo l'assetto magistratuale originariamente assunto in sede di constitutio per poco più di 180 municipia ${ }^{4}$ che possiamo convenientemente distinguere - al netto delle eventuali modifiche statutarie intervenute nel corso del tempo- in tre gruppi: municipia retti da quattuorviri (circa 120), municipia retti da duoviri (circa 50), municipia retti da collegi magistratuali non omologati allo schema quattuorvirale/ duovirale (circa 15).

Da tempo la critica moderna ha letto tale varietà di soluzioni come lo specchio dei diversi momenti storici in cui dovette realizzarsi la promozione municipale dei singoli centri, giungendo ad una schematizzazione ormai assurta a paradigma: ${ }^{5}$ le costituzioni "anomale" caratterizzerebbero i centri promossi a municipia già prima della guerra sociale, il quattuorvirato i municipia nati a seguito della generalizzata promozione delle vecchie comunità federate (latine e italiche) in virtù della lex Iulia del 90 a.C., il duovirato infine i municipia "tardi", la cui costituzione -o ricostituzione- risulterebbe cioè non anteriore all'età cesariana (per l'esattezza, secondo l'opinione dominante, al 49 a.C.). Tali postulati, seppure nella sostanza certamente da accogliere, necessitano di alcuni correttivi, quand'anche limitati a rilevare le rare ma comunque significative eccezioni alla regola, concernenti da un lato i casi di adozione del quattuorvirato tanto in municipia nati da comunità già incluse nell'ager Romanus prima della guerra sociale quanto in municipia ricostituiti in età post-cesariana, ${ }^{6}$ dall'altro le attestazioni di schemi magistratuali anomali in municipia posteriori al 90 a.C. ${ }^{7}$

$\mathrm{Al}$ di là di questo aspetto, a me pare che negli studi moderni non siano state di fatto indagate le ragioni stesse alla base di questa varietà amministrativa, che non è automaticamente spiegabile solo in termini cronologici. Ciò è vero in particolare

Plin. HN 3.50-74, 95-114. Qui e altrove in questo contributo, anticipo in forma necessariamente sintetica e non argomentata i risultati di un mio studio di prossima pubblicazione, dedicato al riesame globale della struttura espositiva e del valore documentario dei libri geografici della Naturalis Historia pliniana, volto a valorizzare i dati in essi contenuti ai fini della ricostruzione degli assetti amministrativi locali in Italia e nelle province occidentali.

3 Per un loro censimento si vedano gli elenchi forniti da De Ruggiero 1896, 98-130, e Pais 1923-1925 (cf. Degrassi 1971 [1959], 84-86), da aggiornare per quanto riguarda le coloniae di Abellinum, Heba e Pollential Urbs Salvia, dedotte in età graccana: cf. Sisani 2015, 82-90.

4 Si veda il quadro completo delle attestazioni -relative complessivamente a circa 240 comunità a statuto municipale o coloniario- riassunto nella tabella in calce al contributo, frutto dello spoglio delle basi di dati per l'epigrafia latina (Epigraphik-Datenbank Clauss-Slaby e Epigraphic Database Roma). Il quadro che offro va a correggere e ad aggiornare le liste di Beloch 1926, 488-522: fino ad ora, a mia conoscenza, le uniche prodotte con analogo intento sistematico.

Si veda per tutti Laffi 2001 [1973].

Su questi casi cf. infra, in appendice.

Come a Peltuinum (praefecti iure dicundo e aediles) e a Trebula Mutuesca (octoviri): sui due casi cf. Sisani 2010, 188-191, 193-199. 
per quanto riguarda la nascita e la diffusione del duovirato municipale: ${ }^{8}$ se infatti i rari casi di conservazione di magistrature di marca tendenzialmente epicoria possono essere ragionevolmente intesi come l'eredità della maggiore autonomia giuridica e amministrativa di cui godevano i municipia in età anteriore alla guerra sociale, ${ }^{9}$ e se per contro la grande diffusione del quattuorvirato non fa altro che tradire l'applicazione sistematica delle nuove linee-guida elaborate subito dopo il 90 a.C. allo scopo di uniformare il processo di generalizzata municipalizzazione della penisola, ${ }^{10}$ i municipia duovirali risultano un fenomeno di non facile inquadramento, per quanto attiene alle ragioni da un lato del ritardo nella loro costituzione, dall'altro dell'introduzione di una nuova struttura magistratuale senz'altro omologa ma comunque distinta dall'assetto quattuorvirale che di fatto accomuna tutti i municipia più precoci, e aderente piuttosto ad uno schema originariamente elaborato in funzione delle realtà coloniarie.

In un precedente contributo ho già affrontato nello specifico gli aspetti cronologici della nascita del duovirato come magistratura municipale. ${ }^{11} \mathrm{Ne}$ ribadisco sinteticamente le conclusioni, in particolare per quanto attiene all'inapplicabilità del terminus post quem del 49 a.C. di norma collegato in dottrina all'introduzione della nuova prassi: a mio avviso, essa dovette invece affermarsi fin dal 59 a.C. in connessione con la riattivazione del processo di municipalizzazione in Italia, nel quadro programmatico della legislazione agraria promossa da Cesare durante il suo primo consolato. In questa sede vorrei presentare una rinnovata analisi dell'intera questione, a partire da una lettura in chiave strutturale della diffusione del duovirato in area italica: ${ }^{12}$ un fenomeno che abbraccia -come vedremo- situazioni storicoistituzionali piuttosto diverse, di fatto accomunate unicamente da un generico ritardo nel consolidamento (o nel rinnovamento) della forma municipale.

\section{Il duovirato come esito del riassetto istituzionale di municipia quattuorvirali}

Pare opportuno, in primo luogo, isolare i casi in cui il duovirato non rappresenta la struttura magistratuale originaria assunta all'atto stesso della municipalizzazione, ma è invece il frutto del riassetto istituzionale di municipia precedentemente retti da quattuorviri. L'esempio più antico è senza dubbio quello di Tarentum: municipium costituito all'indomani della guerra sociale e inizialmente retto da quattuorviri, sostituiti da duoviri già intorno all'80 a.C. a seguito del confezionamento dello

$8 \quad$ Si era correttamente posto il problema -sull'onda degli studi del Beloch-già Degrassi 1962 [1960], le cui pur cursorie riflessioni offrono ancora, sul piano storico, importanti suggestioni.

Su questo aspetto rimando ora a Sisani 2021b.

10 Sisani 2016, con l'ipotesi che tali linee-guida siano state fissate da una lex Cornelia (Cinnae) "municipalis" dell' $86-85$ a.C.

11 Sisani 2018, 60-70. Rimando a questo contributo anche per le attestazioni di duoviri (in tutti i casi nude dicti) di età anteriore alla guerra sociale: magistrati con potestas edilitaria caratteristici di alcune comunità latine-Aesernia, Aquileia, Ariminum, Cora, Setia; dubbi i casi di Ardea (cf. AE 1955, 194a) e di Paestum (cf. HNI 1241)- e delle coloniae civium Romanorum (Antium, Croto, Luna, Puteoli, Volturnum), sporadicamente documentati anche in contesto federato (Falerii Novi) e municipale (Fidenae).

12 Escludo da questa analisi l'area cisalpina (regiones VIII-XI), solo parzialmente toccata dalla promozione del 90 a.C. e fino al 42-41 a.C. ancora inquadrata in regime provinciale: sugli sviluppi amministrativi locali in questo settore della penisola - e più in generale sulla diffusione del quattuorvirato e del duovirato municipali in ambito provinciale- si veda ora Sisani 2018. 
statuto locale. ${ }^{13}$ Il cambio di magistratura è in questo caso certamente da intendere come il prodotto della contributio tra il neonato municipium di Tarentum e la colonia di Neptunia, dedotta in loco in età graccana: ${ }^{14}$ il duovirato municipale tarentino è cioè null'altro che il segno del prevalere, al momento della compiuta municipalizzazione del centro, del modello offerto dai preesistenti organi amministrativi del nucleo coloniario locale.

Al di là di questo precedente, condizionato dalle peculiari vicende storicoistituzionali del centro, gli altri esempi noti di passaggio dal quattuorvirato al duovirato non sembrano risalire ad epoca anteriore all'età augustea e parrebbero sempre essere il prodotto di interventi volti al globale riassetto amministrativo e territoriale di singoli municipia, configurabili nei termini di autentica ricostituzione statutaria: in questi casi, la scelta della forma duovirale -canonica per i municipia già a partire dall'età cesariana- è condizionata essenzialmente dal contesto storico in cui si colloca la nuova constitutio. La natura di questi fenomeni di ricostituzione è ben illustrata dalle vicende di Perusia, ${ }^{15}$ dove il duovirato sostituisce l'originario quattuorvirato nella tarda età augustea, all'atto -documentato da esplicite testimonianze epigrafiche ${ }^{16}$ - della restitutio del municipium, che nel 40 a.C. era stato privato dell'intero territorio a seguito delle dure misure repressive promosse da Ottaviano al termine del bellum Perusinum. ${ }^{17}$ La restitutio contemplò senza dubbio la riattribuzione al centro di un proprio ager, eventualmente ridefinito rispetto ai suoi confini originari: un atto che, in ogni caso, dovette configurarsi a tutti gli effetti come una seconda constitutio del municipium, espressa dalla contestuale assunzione del nuovo titolo di Augusta Perusia. ${ }^{18}$

Non è da escludere che gli interventi augustei abbiano direttamente coinvolto, oltre a Perusia, anche i contermini centri di Arna e Vettona, senza dubbio gravitanti durante la fase sovrana nell'orbita della metropoli etrusca. ${ }^{19}$ Entrambi i municipia risultano retti da duoviri, le cui attestazioni epigrafiche non risalgono tuttavia ad epoca anteriore all'età augusteo-tiberiana. ${ }^{20}$ Se l'iscrizione dei due centri in una tribù (la Clustumina) distinta da quella di Perusia (la Tromentina) assicura dell'autonomia amministrativa di questo territorio a partire almeno dagli anni successivi alla guerra sociale, la relativa rarità di municipia duovirali in area etrusca e umbra spinge ad intendere anche il duovirato di Arna e di Vettona come l'esito del mutamento da un originario seppur non direttamente attestato assetto quattuorvirale.

Dinamiche analoghe, per quanto attiene almeno alle ricadute sul piano statutario prodotte da interventi di riassetto territoriale, sono prospettabili anche nel caso di Marruvium. ${ }^{21}$ Il municipium -al pari degli altri presenti in area marsa ${ }^{22}$ - risulta

13 Secondo quanto si ricava dalla lex municipii Tarentini: cf. Laffi 2007 [2004], che tuttavia pretende di collocare il cambio di magistratura in età cesariana (così anche Cappelletti 2011, 132-133), postulando un significativo intervallo di tempo -a mio avviso del tutto improbabile: cf. Sisani 2016, 39-40- tra la costituzione del municipium e l'elaborazione del suo statuto.

14 Plin. HN 3.99: cf. Sartori 1953, 90-96.

15 Ho diffusamente trattato il caso in Sisani 2011 b (cf. Sisani 2011c), con analisi di tutte le testimonianze.

16 CIL XI 1923a-d (cf. SupplIt 30 (2018), nrr. 2-5, 215-218): Augusto / sacr(um) / Perusia restituta.

17 D.C. 48.14 .6 .

18 CIL XI 1924, 1929-1931 (cf. SupplIt 30 (2018), nrr. 17-19, 236-243).

19 Cf. Sisani 2009.

20 Arna: CIL XI 5614. Vettona: CIL XI 7970; AE 1996, 653b. Cf. Zuddas 2017, 130.

21 Su questo caso si veda ora Letta 2019.

22 Anxa, Antinum e Lucus Angitiae: tutti municipia costituiti con certezza o probabilità subito dopo il 90 a.C. ed 
inizialmente retto da quattuorviri, documentati fino almeno all'età tiberiana; ${ }^{23}$ ad epoca certamente successiva risalgono invece tutte le iscrizioni con menzione di duoviri, apparentemente già attestati intorno alla metà del I sec. d.C. ${ }^{24} \mathrm{~A}$ fronte di queste indicazioni cronologiche, pare verosimile collegare la modifica della struttura amministrativa agli interventi di bonifica del lago del Fucino realizzati da Claudio e rinnovati sotto Traiano e Adriano, ${ }^{25}$ che dovettero produrre un significativo ampliamento delle superfici coltivabili ${ }^{26}$ e conseguentemente rendere necessaria una ridefinizione delle pertiche municipali circostanti.

Come nel caso di Perusia, la ricostituzione statutaria della civitas marruvina -tradita dal cambio di assetto magistratuale- parrebbe direttamente discendere dalle modifiche apportate ai suoi limiti territoriali: ricostituzione che è stata a volte letta nei termini di una promozione coloniaria del centro. ${ }^{27}$ La questione -cui si lega quella relativa all'effettiva portata, sul piano della ridefinizione degli assetti locali, degli interventi attuati nell'area a partire dall'età claudia- ruota intorno alla corretta attribuzione di una iscrizione di II sec. d.C. proveniente dal vicus di Supinum, ${ }^{28}$ dove è fatta menzione di un duovir di un non specificato municipium da identificare o con la stessa Marruvium o con Lucus Angitiae. In tutti i casi, l'iscrizione costituisce un forte indizio per postulare la sopravvivenza in quest'area di un assetto di marca municipale, riformato per quanto riguarda lo schema magistratuale a seguito degli interventi di cui si diceva, che in termini territoriali dovettero coinvolgere tutte le comunità affacciate sul Fucino: oltre a Marruvium e Lucus Angitiae, la stessa Alba Fucens. ${ }^{29}$ È invece poco probabile che tali interventi abbiano prodotto ricadute anche sui più eccentrici municipia marsi di Antinum e di Anxa, ${ }^{30}$ i quali significativamente mantengono ordinamento quattuorvirale fino almeno al II sec. d.C. ${ }^{31}$

in ogni caso entro l'età augustea, come assicura l'elenco trasmesso da Plinio (HN 3.106: Marsorum Anxatini, A(n)tinates Fucentes, Lucenses, Marruvini). La testimonianza -che si è cercato ripetutamente di correggere e piegare in funzione di ipotesi moderne (cf. Buonocore - Firpo 1998, 266-268), ma che stando alla lettera del testo attesta chiaramente l'esistenza di quattro distinti municipia- rende impraticabile l'idea di attribuire a Claudio la constitutio del municipium di Lucus Angitiae (come postulato da Letta - D'Amato 1975, 287-300), che tra l'altro può vantare una attestazione del quattuorvirato (CIL IX 3894) risalente già ai decenni finali del I sec. a.C.

23 Le attestazioni più recenti sono costituite da CIL IX 3664 e 7678.

24 CIL IX 3669. Cf. CIL IX 3683, 3697 e 7812.

25 Fonti e discussione in Buonocore - Firpo 1998, 169-180.

26 D.C. 60.11 .5 ; cf. Suet. Claud. 20.2.

27 Cf. Buonocore - Firpo 1998, 183-186. Il centro di Marruvium, in ogni caso, è indicato come municipium nel Liber Coloniarum (256 L.).

28 CIL IX 3855 (cf. Letta - D'Amato 1975, nr. 145, 237-240): D(is) M(anibus) s(acrum) / Blaesiae Q.f. Mel/fidi P. Cas[t]rici[u]s / +f. Gnom[- - -]s II/vir i(ure) d(icundo) [- - -]/+ opt[- - -] / munici[p- - -] (etc.). Dalla stessa località proviene anche una attestazione del quattuorvirato (CIL IX 7811), databile nei decenni finali del I sec. a.C.

29 Cf. LC 253 L. (in relazione ad una terminatio dell'ager Albensis realizzata nel 149 d.C.). Tale intervento, in ogni caso, non dovette comportare modifiche statutarie: è pur vero che Alba Fucens acquisirà durante l'età imperiale statuto coloniario (con conseguente introduzione del duovirato: CIL IX 7920)., ma la promozione è sicuramente successiva al 168 d.C., quando il centro risulta ancora retto da quattuorviri (CIL IX 3950).

30 Il centro, di incerta identificazione, può essere a mio avviso localizzato in corrispondenza dell'odierna Scanno: la presenza di un municipium in quest'area - di norma, ma senza reali basi, attribuita all'ager Sulmonensis- è indiziata da diverse testimonianze epigrafiche relative a decuriones (CIL IX 3088, 3093) e a un quattuorvir (CIL IX 7143) della tribù Sergia, che non vi è ragione di ritenere di provenienza aliena.

31 Antinum parrebbe in ogni caso vantare una isolata attestazione del duovirato (CIL IX 3841, nota solo da tradizione manoscritta), databile al II sec. d.C. L'irreperibilità dell'iscrizione impedisce tuttavia di verificarne la 
Un ulteriore possibile caso di riassetto amministrativo concerne il municipium di Verulae, inizialmente retto -al pari delle altre comunità erniche (Aletrium e Ferentinum) rimaste federate fino alla guerra sociale-da quattuorviri. ${ }^{32}$ Una iscrizione del 197 d.C. pone il problema dell'eventuale attestazione del duovirato, ${ }^{33}$ che la provenienza della lapide e la sintassi del testo spingono in effetti a ritenere rivestito in loco. La ricostituzione del municipium potrebbe collocarsi durante il principato di Nerva, come suggerisce una notizia del Liber Coloniarum, che attribuisce a questo imperatore - promotore di una rinnovata politica di assegnazioni agrarie in Italia ${ }^{34}$ una qualche modifica del regime statutario dell'ager Verulanus. ${ }^{35}$

Di più problematico inquadramento, soprattutto sul piano cronologico, è il caso di Aceruntia, ${ }^{36}$ municipium lucano coincidente con la comunità degli Aceruntini (regio III) che Plinio colloca erroneamente nel Bruzio: ${ }^{37}$ il centro ha restituito due diverse attestazioni di magistrati locali, una (databile alla prima metà del I sec. a.C.) relativa a quattuorviri ${ }^{38}$ l'altra (di cronologia incerta, ma difficilmente posteriore alla primissima età imperiale) a duoviri ${ }^{39} \mathrm{~A}$ fronte della possibilità di riferire entrambi gli interventi edilizi ricordati dalle due epigrafi allo stesso complesso termale -e con il conforto offerto dalla cronologia senza dubbio risalente del primo testo- verrebbe anche in questo caso da postulare una modifica statutaria, sopravvenuta in un'epoca e per ragioni impossibili da precisare: si potrebbe eventualmente sospettare una qualche relazione con la deduzione in età triumvirale della colonia di Venusia, assai prossima al centro, ${ }^{40}$ il cui impianto dovette come di norma comportare importanti ricadute sugli assetti territoriali locali.

Un analogo passaggio dal quattuorvirato al duovirato è infine postulabile nel caso senz'altro peculiare di Clusium, dove le testimonianze epigrafiche documentano tanto quattuorviri quanto duoviri, che si è creduto di poter assegnare a due fasi distinte della vita istituzionale del centro: i primi all'età tardo-repubblicana e augustea, i secondi all'età imperiale. ${ }^{41}$ Tale ricostruzione si scontra con quanto ora ricavabile

lettura, che già l'erudito Domenico De Sanctis -l'ultimo ad aver potuto esaminare la lapide, ormai illeggibilesospettava doversi emendare per quanto attiene alla carica municipale: non IIvir(o) ma IIIIvir(o).

$32 \quad E D R 166151$ (del pieno I sec. a.C.).

33 CIL X 5796: L. Alfio L.f. Cor(nelia)/Valentino II/vir(o) II q(uin)q(uennali), p(atrono) m(unicipii) V(erulanorum), / curat(ori) rei p(ublicae) col(oniae) / Casinatium et / patrono ordo / seviralium et / Augustalium ob / merita eius (etc.).

34 Plin. Ep. 7.31.4; D.C. 68.2.1. Cf. Keppie 1984, 104-105.

35 LC 239 L.: Verulae, oppidum muro ductum: ager eius limitibus Gracchanis in nominibus est adsignatus, ab Imp. Nerva colonis est redditus.

36 Cf. Chelotti 2015.

37 Plin. $H N$ 3.73: la confusione è causata dall'attestazione nel Bruzio dell'idronimo Acheron, che Plinio ha erroneamente collegato all'onomastica degli oppidani Aceruntini. Per la stessa regio III, un errore analogo riguarda i Cosilinates, omessi dall'elenco alfabetico delle comunità lucane dell'entroterra (Plin. HN 3.98) evidentemente perché ritenuti coincidenti con gli abitanti del Consilinum castrum già citato nella descrizione della costa bruzia (Plin. HN 3.95).

38 EDR 163266: P. Baius L. f. Ruf(us), M. Lucius M. f. +[- - - / IVvir(i) balneum, ahena, fistu[las], / labrum, castellum, piscin[am] / d(e) d(ecurionum) s(ententia) f(aciunda) c(uraverunt) eid(em)que probar[unt].

$39 C_{\text {CIL I }}^{2} 1693$ (cf. EDR 163267), perduta: M. Satrius M. [f. - - -], / Cn. Pompeius [- f. - - -] / IIviri it(erum) [quinq(uennales)?] / piscinam re[ficiundam de] / dec(urionum) sent(entia) co[er(averunt) id(em)que prob(averunt)?].

40 Il territorio della colonia venusina doveva estendersi, in direzione di Aceruntia, almeno fino all'odierna Forenza, come assicura il rinvenimento in questa località di una attestazione epigrafica $(A E 2016,314)$ menzionante un duovir della tribù Horatia.

${ }^{41}$ Pack - Paolucci 1987, 164-171, con censimento delle testimonianze. 
da iscrizioni di recente pubblicazione, che da un lato documentano l'esistenza di duoviri già in età triumvirale ${ }^{42}$ dall'altro parrebbero attestare già per l'età protoaugustea lo statuto coloniario del centro. ${ }^{43}$ La soluzione mi sembra imposta dalla giusta valutazione della testimonianza di Plinio, che nella lista alfabetica delle civitates della regio VII elenca come comunità distinte i Clusini Veteres e i Clusini Novi. ${ }^{44}$ Occorrerà dunque postulare la coesistenza, fino almeno all'età augustea, di due diverse realtà amministrative: il municipium di Clusium, costituito subito dopo la guerra sociale e regolarmente retto da quattuorviri, e una colonia dedotta nel suo territorio verosimilmente in età sillana, retta come atteso da duoviri. ${ }^{45} \mathrm{Il}$ fatto che quest'ultima magistratura si renda visibile soprattutto in età imperiale, unitamente alla contestuale scomparsa delle attestazioni di quattuorviri, può semmai denunciare la sopravvenuta riunificazione amministrativa delle due comunità in età postaugustea, con il prevalere degli istituti -non necessariamente dello statuto- di marca coloniaria. ${ }^{46}$

Al di fuori di questi esempi, tutti gli altri casi noti di passaggio dal quattuorvirato al duovirato sono collegabili all'elevazione del centro a colonia, vuoi a seguito dello stanziamento in loco di veterani nel corso del I sec. a.C., vuoi a titolo puramente onorifico durante l'età imperiale..$^{47}$ L'unico caso dubbio è rappresentato da Trebula Balliensis, municipium retto da quattuorviri fino almeno all'età augustea ${ }^{48}$ che vanta una isolata e assai tarda attestazione del duovirato: ${ }^{49}$ non è da escludere che anche qui il cambio amministrativo sia dovuto all'acquisizione, nel corso dell'età imperiale, dello statuto coloniario..$^{50}$

Restano infine da discutere le vicende affatto peculiari dei centri di Praeneste e Paestum, che conoscono anch'essi una parentesi municipale dove l'assetto duovirale è il frutto della conservazione -come, in certo modo, nel caso già illustrato di Tarentum - di precedenti regimi magistratuali di marca coloniaria. Entrambi i centri dovettero essere elevati a municipia già all'indomani della guerra sociale:

42 EDR 176019 (cf. Caracciolo 2018b, nr. 5, 261-262): [- P]edio Sex. f. / IIvir(o) / [qui]nq(uennali) quart(um).

43 AE 2017, 437 (cf. Caracciolo 2018b, nr. 4, 259-261): L. Firmius L. f. Clu(stumina) / Pollio quinquen(nalis) / c(oloniae?) C(lusinorum?), tribunus militum / legion(um) XII Gallicae / et Quartae.

44 Plin. HN 3.52. Un caso analogo, sempre in Etruria, è quello di Arretium, che nell'elenco pliniano figura "scissa" in tre comunità -Arretini Veteres, Arretini Fidentiores, Arretini Iulienses- da identificare nell'ordine con gli originari abitanti del municipium e con i nuclei coloniari dedotti in loco in età sillana e in età cesariana: cf. da ultimo Firpo 2009.

45 Secondo l'ipotesi già a suo tempo formulata da Degrassi 1962 [1949], 112-113. Sulla questione si veda da ultimo Caracciolo 2018a, 21-24, che tuttavia -ma senza nuovi argomenti- esprime scetticismo relativamente all'ipotesi di una deduzione coloniaria sillana.

46 Il centro, in ogni caso, parrebbe documentare statuto coloniario ancora nel corso dell'età imperiale, giusta la menzione di un patronus col(oniae) -piuttosto che col(legii)- nell'iscrizione CIL XI 2114 (cf. EDR 149195): - - - - - / [- - pra]et(ori) XV pop(ulorum) / [- - - tribu]n(o) coh(ortis) I vig(ilum) / [- - patron]o col(oniae?) C(lusinorum?) (etc.), databile genericamente al I-II sec. d.C.

47 Per un censimento di questi casi restano validi gli elenchi di De Ruggiero 1896, 98-130, e di Pais 1925, 352403, da leggere alla luce delle puntualizzazioni di Degrassi 1962 [1949] (cf. Degrassi 1971 [1959], 86-89, 92). Più recentemente, sulle deduzioni di età sillana cf. Santangelo 2007, 147-157; su quelle cesariane e triumviraliaugustee cf. Keppie 1983; sulle promozioni post-augustee cf. Keppie 1984. Alla luce delle ultime acquisizioni epigrafiche, la lista va aggiornata tenendo conto della colonia verosimilmente sillana di Vibinum (AE 1980, 267; AE 1991, 518) e delle promozioni post-augustee di Aesernia (CIL IX 6760), Alba Fucens (CIL IX 7933, 79407941), Lanuvium (AE 1945, 80), Volaterrae (AE 1994, 612).

$48 \quad C I L$ X 4562.

$49 \quad$ CIL X 4559 (del pieno IV sec. d.C.).

50 Cf. in questo senso Degrassi 1962 [1949], 163. 
una promozione che, almeno nel caso di Paestum, è confermata dalle attestazioni di quattuorviri in emissioni monetali databili all'inizio del I sec. a.C. ${ }^{51}$ Lo statuto municipale venne precocemente annullato in età sillana dalla deduzione in loco di due coloniae: deduzione certa nel caso di Praeneste, più che probabile -sebbene non suffragata da testimonianze esplicite- nel caso di Paestum, dove le più antiche attestazioni di duoviri risalgono già alla prima metà del I sec. a.C. ${ }^{52}$ A partire da questo momento, il duovirato resta la magistratura propria dei due centri, che pure al principio dell'età imperiale dovettero riacquisire statuto municipale: $:^{53}$ verosimilmente durante il principato di Tiberio, come attesta almeno nel caso di Praeneste una notizia trasmessa da Aulo Gellio. ${ }^{54}$ La riforma statutaria ebbe in ogni caso durata effimera, dal momento che nel corso dell'età imperiale entrambi i centri torneranno ad assumere veste coloniaria: Paestum già sotto Vespasiano (con il titolo di Colonia Flavia Prima), ${ }^{55}$ Praeneste al più tardi sotto Commodo. ${ }^{56}$

\section{Il duovirato come esito della promozione a municipia di realtà vicane}

La marca duovirale caratterizza anche alcuni municipia tardivamente costituiti a seguito della promozione di precedenti vici, ricompresi fino all'acquisizione dell'autonomia amministrativa all'interno dei territoria di comunità vicine. Si tratta di casi interessanti, i quali documentano le modifiche apportate nel corso del I sec. a.C. al programma elaborato negli anni successivi alla guerra sociale, che inizialmente -nel rispetto, evidentemente, degli assetti territoriali preesistenti- non doveva contemplare l'autonomia di questi centri.

Gli esempi certi riguardano Cereatae Marianae e Misenum, due vici in origine ricadenti il primo nell'ager di Arpinum, ${ }^{57}$ il secondo in quello di Cumae. ${ }^{58} \mathrm{Nel}$ caso di Cereatae Marianae, la promozione a municipium sembrerebbe relativamente precoce, dal momento che le prime tracce di una amministrazione locale risalgono già alla metà del I sec. a.C.. ${ }^{59}$ si potrà allora pensare ad un intervento promosso dallo stesso Cesare, eventualmente orientato dalla volontà di dare lustro al luogo di nascita di Gaio Mario. ${ }^{60}$ La promozione di Misenum ha invece carattere senza dubbio funzionale e dovette realizzarsi al principio dell'età augustea, in connessione

\footnotetext{
HNI 1242, 1244-1246, 1248-1249.

Keppie 1983, 153-155; cf. Sisani 2018, 63, nota 155.

Praeneste: cf. CIL XIV 2889 (Genius municipii), 2941 (patronus municipii), 3004 (patronus municipii). Paestum: cf. AE 1996, 471 (patronus municipii); Mello - Voza 1968, nr. 69a, 107-108 (municipes).

54 Gell. NA 16.13.5: Praenestinos autem refert [scil. Hadrianus] maximo opere a Tiberio imperatore petisse orasseque, ut ex colonia in municipii statum redigerentur, idque illis Tiberium pro referenda gratia tribuisse, quod in eorum finibus sub ipso oppido ex capitali morbo revaluisset.

55 AE 1975, 251.

56 CIL XIV 2922.

Cf. Plut. Mar. 3.

Cf. D.H. 7.3.2, 12.1.9; Liv. 24.13.6.

CIL I $\mathrm{I}^{2} 2537$ (duoviri); CIL I I 3101a (senatus).

60 Cf. Giovagnoli 2018. Resta il dubbio se la promozione risalga già al 59 a.C., nel quadro delle leges Iuliae agrariae, o non piuttosto al 46 a.C., se volessimo riferire alla constitutio di Cereatae Marianae la notizia riportata in Cic. Fam. 13.11: Nam constituendi municipi causa hoc anno aedilem filium meum fieri volui et fratris filium et $M$. Caesium, hominem mihi maxime necessarium: is enim magistratus in nostro municipio [scil. Arpinum] nec alius ullus creari solet.
} 
con la creazione della base militare della flotta pretoria. ${ }^{61}$ Anche in questo caso la promozione, come assicura la documentazione epigrafica, assunse forme municipali: Misenum acquisirà infatti statuto coloniario solo più tardi, nell'avanzata età imperiale. $^{62}$

I due casi rappresentano esempi forse non isolati di creazione, durante l'età cesariano-augustea, di nuove realtà amministrative da centri precedentemente privi di qualunque forma di autonomia. Dinamiche analoghe a quelle ora illustrate sono infatti prospettabili anche per altri municipia duovirali, la cui prossimità a importanti realtà coloniarie porta a credere originati dalla promozione di centri inizialmente aggregati, in sede di deduzione, alle pertiche delle vicine coloniae.

Un primo possibile caso è quello di Fabrateria Vetus, la cui tardiva costituzione a municipium -realizzatasi al più tardi nel corso dell' età augustea ${ }^{63}$ - è appunto indiziata dall'assetto magistratuale di marca duovirale, le cui attestazioni epigrafiche non risalgono ad epoca anteriore al III sec. d.C. ${ }^{64}$ sebbene le prime tracce dell'acquisita autonomia amministrativa siano già rintracciabili in una iscrizione risalente all'inizio dell' età imperiale. ${ }^{65}$ La comunità era entrata nell'orbita romana nei decenni finali del IV sec. a.C. ${ }^{66}$ e non è escluso che essa abbia ottenuto la cittadinanza (inizialmente sine suffragio) già nel 329 a.C., contestualmente ai Privernates. ${ }^{67}$ Il suo territorio non dovette rimanere estraneo alla deduzione nel 124 a.C. -all'indomani della distruzione di Fregellae- della colonia di Fabrateria Nova, ${ }^{68}$ fondata a breve distanza dall'oppidum volsco. La stretta relazione tra i due centri, pur non coincidenti a livello topografico, è chiaramente suggerita dalla denominazione della nuova fondazione, giustificabile solo ove si postuli un diretto coinvolgimento della vecchia comunità nel riassetto territoriale conseguente alle pratiche di deduzione. La circostanza - unitamente al fatto che l'esistenza di due distinte Fabrateriae è attestata

$61 \quad$ Reddé 1986, 186-197.

62 Misenum documenta statuto municipale fino almeno al pieno II sec. d.C. (CIL X 1593; AE 2000, 344); il titolo di colonia è attestato solo dal III sec. d.C. (CIL X 3674, 3678). Un analogo passaggio da municipium a colonia è stato prospettato anche in relazione a Cereatae Marianae, ma il frustulo epigrafico attestante tale titolatura - $A E$ 1988, 284 (da Strangolagalli), all'apparenza risalente alla prima età imperiale- è più convenientemente attribuibile ad altro centro: Frusino o forse meglio Fabrateria Nova.

63 Cf. Plin. $H N 3.64$.

${ }^{64} A E$ 1979, 140-141. Una ulteriore ma finora misconosciuta menzione del duovirato, anch'essa di III sec. d.C., è da rintracciare in CIL X 5657: [.] Septimio L.f. Tro(mentina) Herm[.]/[.]I IIvir(o) q(uin)q(uennali), pat(rono) mun(icipii) Fabra[t(eriae)] / Vet(eris) (etc.), dove in inizio 1. 2 si insiste a voler leggere [I]IIVIR. La presenza sulla pietra di un segno di interpunzione tra [.]I e IIVIR spinge piuttosto a restituite le 11. 1-2 nella forma [.] Septimio L.f. Tro(mentina) Herm[e]/[t]i IIvir(o) q(uin)q(uennali): viene così a cadere la supposta presenza del quattuorvirato a Fabrateria Vetus, per altro in se stessa problematica, perché qualora ammessa risulterebbe di fatto coeva alle locali attestazioni di duoviri.

65 CIL X 5655: [- - -] Rufo dict(atori) patr(i), / [- - -] fratribus, / [- - - coniugi?] castissimae / vac. / [- - -] aed(ilis) F(abrateria) N(ova) iter(um) l(ege) P(etronia) / [ - - F(abrateria) Ve]ter(e) bis v(ixit?) a(nnis?) vac. / [- - - ]+ [- - ]. Risulta problematica l'apparente menzione di un dictator, che mal si concilia tanto con gli sviluppi istituzionali del centro quanto più in generale con le forme magistratuali documentate in area volsca. A meno di non postulare che tale magistratura sia stata rivestita in altro municipium (ad esempio Aricia o Lanuvium), si potrebbe riferire il titolo ad una carica sacerdotale (per un possibile confronto si veda il dictator di CIL XII 4378, da Narbo Martius), omologa alle preture sacrali documentate in varie comunità romane (Sisani 2002, 488-489): uno stringente parallelo, per l'uso assoluto della titolatura, è offerto dal praetor -nude dictus, ma certamente sacrorum - attestato ad Aletrium (CIL X 5832: cf. Galli - Gregori 1998, 20-21).

66 Liv. 8.19.1-3.

67 Liv. 8.21.10.

68 Vell. 1.15.4. 
unicamente da Plinio e dalla documentazione epigrafica di età imperiale ${ }^{69}$ - rende percorribile l'ipotesi che la deduzione del 124 a.C. abbia portato all'annullamento dell'autonomia amministrativa del centro più antico, inglobato dalla pertica della colonia e pienamente sottoposto alla sua giurisdizione fino alla riattribuzione, tra l'età cesariana e l'età augustea, di un proprio statuto municipale.

L'intrinseca verosimiglianza di questo quadro invita a riflettere sulle vicende storico-istituzionali anche di altri municipia duovirali, accomunati dalla loro collocazione in aree interessate dall'impatto fortemente destrutturante degli interventi sillani. È questo il caso, in particolare, dei municipia campani di Herculaneum e Surrentum, entrambi retti da duoviri e costituiti forse già durante l'età cesariana, le cui vicende -che possiamo immaginare speculari- sono ricostruibili a partire dalle meno avare informazioni relative al primo centro.

Herculaneum venne certamente coinvolta nei fatti della guerra sociale, ${ }^{70}$ che in area vesuviana ebbero come è noto esiti particolarmente pesanti anche sul piano dei successivi sviluppi istituzionali locali: un caso emblematico è quello di Stabiae, definitivamente cancellata come realtà amministrativa dall'azione militare di Silla nell' 89 a.C. ${ }^{71}$ ed apparentemente integrata nell'agro nucerino. ${ }^{72}$ Che anche Herculaneum abbia inizialmente subito una sorte analoga è suggerito dal modo affatto peculiare con cui il centro è richiamato da Strabone ${ }^{73}$ che assegna ad esso la qualifica di ppoúpiov, equivalente di lat. castellum ed allusiva ad una realtà vicana piuttosto che urbana. ${ }^{74}$ Giusta l'idea che per questa sezione della sua opera il geografo attinga in special modo a Posidonio e dunque descriva il contesto dei decenni iniziali del I sec. a.C. ${ }^{75}$ avremmo la conferma del mancato sviluppo amministrativo del centro, che possiamo ritenere attribuito nell'81 a.C. alla pertica coloniaria di Pompeii. In ogni caso, a differenza di Stabiae, Herculaneum finì col tempo per acquisire statuto municipale, verosimilmente già prima dell'età augustea: le più antiche attestazioni epigrafiche di duoviri parrebbero di fatto risalire alla metà circa del I sec. a.C., ${ }^{76} \mathrm{e}$ non è dunque da escludere che la constitutio del municipium sia da attribuire già a Cesare. Giusta questa ipotesi, si potrebbe istituire uno strettissimo parallelo con le vicende del non distante centro di Calatia, attribuito alla giurisdizione di Capua da Silla ${ }^{77}$ e ricostituito come entità amministrativa autonoma tra il 47 e il 44 a.C., ${ }^{78}$

69 Cicerone menziona la comunità (Cluent. 192) e il centro (Fam. 9.24.1) senza offrire alcuna specificazione. Anche Strabone (5.3.9) sembrerebbe del resto conoscere un'unica Fabrateria.

70

1 Plin. HN 3.70: In Campano autem agro Stabiae oppidum fuere usque ad Cn. Pompeium L. Catonem cos. pr. Kal. Mai., quo die L. Sulla legatus bello sociali id delevit, quod nunc in villam abiit.

72 Secondo quanto suggerisce la proiezione costiera dell'ager Nucerinus -tra Pompeii e Surrentum-in Plin. HN 3.62: cf. Ruffo 2015, 11.

73 Str. 5.4.8.

74 Cf. Sisani 2017, 120-123.

75 Lasserre 1967, 10-25.

76 AE 1960, 277 (cf. EDR 74255): +++++++[- - -] / [-] Marcius Phi[lippus] / duovir(i) prim[i] / [f]aciundum [cur(averunt)] / [ei]sdemque pro[b(averunt)]; CIL I² 1625: M. Spurius M. f. / Men(enia) Rufus IIvir / i(ure) $d$ (icundo) macellum d(e) s(ua) p(ecunia) f(aciendum) c(uravit) eid(em)q(ue) pro(bavit). Entrambi i testi sono redatti su marmo (non è chiaro se greco o lunense), ma almeno il secondo -necessariamente il più recente dei due- presenta tratti paleografici piuttosto risalenti, che orientano per una cronologia difficilmente posteriore agli anni Quaranta del I sec. a.C.

77 LC 232 L.: Calatia, oppidum muro ductum: (...) coloniae Capuensi a Sulla Felice cum territorio suo adiudicatum olim ob hosticam pugnam.

78 Cic. Att. 16.8.1; Vell. 2.61.1-2; App. BC 3.164-165. 
salvo poi tornare a far parte dell'agro capuano - al pari di Casilinum- entro l'età augustea. $^{79}$

Meno chiare risultano le vicende di Surrentum, a partire dal ruolo giocato dal centro durante la guerra sociale, ${ }^{80}$ così come maggiormente incerta è anche l'epoca dell'acquisizione della piena autonomia amministrativa, le cui tracce epigrafiche non sono in questo caso anteriori all'età augusteo-tiberiana. ${ }^{81}$ Resta comunque percorribile l'ipotesi che anche questo centro sia stato inizialmente attribuito, in età sillana, al territorio di una comunità vicina: forse la stessa colonia di Pompeii, se non -al pari di quanto prospettato per Stabiae-il municipium di Nuceria.

Un ultimo caso, affatto peculiare, di tardiva promozione municipale di una comunità vicana, connotato da tratti di marcata artificialità, è quello di Trebula Mutuesca: ${ }^{82}$ in origine un semplice vicus verosimilmente ricadente all'interno

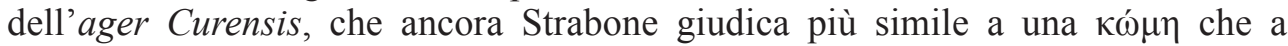
una $\pi$ ó $\lambda \iota_{\zeta}{ }^{83}$ L'autonomia amministrativa dovette sopravvenire nel corso dell'età augustea $^{84}$-complice forse la volontà di valorizzare la presenza in loco di un celebre santuario di Feronia- e venne apparentemente realizzata attribuendo al neonato municipium un territorio ritagliato dai contermini agri curense e reatino: il che spiega la compresenza, tra i municipes trebulani, di tribules della Sergia (tribù di Cures) e della Quirina (tribù di Reate). Il carattere artificiale della constitutio è ulteriormente accentuato dall'assetto amministrativo locale, che contrariamente a quanto atteso per un municipium "tardo" non aderisce allo schema duovirale: Trebula Mutuesca risulta infatti retta, a partire dall'età augustea, da un collegio di octoviri ${ }^{85}$ che richiama la struttura magistratuale tipica delle praefecturae dell'alta Sabina e dell' ager Praetutianus ${ }^{86}$ e che proprio ad essa dovette ispirarsi, nell'intento forse di rivestire l'operazione di una patina di antichità, in linea con i gusti antiquari così caratteristici dell'età augustea.

Come si vede, la tardiva promozione statutaria di realtà vicane ha di norma come esito la nascita di nuovi municipia, e tuttavia la stessa prassi informa anche alcuni casi di deduzioni coloniarie effettuate per così dire in vacuo: un ricorso assolutamente inusuale nel I sec. a.C. ma da postulare in relazione almeno alla colonia cesariana (poi augustea) di Lucus Feroniae, nonché verosimilmente a quella triumvirale di Faliscum.

79 Su questi casi cf. Keppie 1983, 52-53, 143-147. Calatia e Casilinum non figurano nella lista augustea delle civitates della regio I consultata da Plinio, che relativamente al secondo centro (cf. Plin. $H N$ 3.70) attesta esplicitamente la sua scomparsa come entità amministrativa.

80 L'occupazione del centro da parte degli insorti sembrerebbe ricavabile da App. BC 1.186.

$81 \quad$ CIL X 688.

82 Cf. Sisani 2011a, 692-693.

83 Str. 5.3 .1 (dove il centro è significativamente accostato ad Eretum, vicus anch'esso ricompreso nell'ager Curensis e mai assurto a dignità municipale). La natura vicana dell'insediamento è assicurata, per il II sec. a.C., dai due tituli Mummiani di provenienza locale CIL I² 627: L. Mummius co(n)s(ul) / vico.

84 Cf. Plin. HN 3.107.

85 Sisani 2010, 193-199.

86 Ho trattato diffusamente il tema in Sisani 2010; si veda ora anche Curchin 2016, 27-46. Octoviri come magistrati di una praefectura sono attestati nel I sec. a.C. ad Amiternum, Nursia e Interamnia Praetuttiorum, e sono postulabili a Reate. Non rientrano invece in questa categoria gli octoviri di Plestia (CIL XI 5621: di età tardorepubblicana; $A E$ 1991, 646: della prima età imperiale e relativa ad un personaggio di condizione libertina), che ora sono propenso a intendere come membri di un collegio sacerdotale: il centro umbro appare infatti regolarmente retto da quattuorviri (CIL XI 5619) e dovette essere promosso a municipium già all'indomani della guerra sociale. 
Il sito santuariale di Lucus Feroniae, ricadente in origine all'interno del territorio di Capena ${ }^{87}$ fu selezionato nel 46 a.C. per una deduzione coloniaria a favore dei veterani di Cesare, la cui pertica venne ricavata assemblando parti degli agri veiente e capenate: ${ }^{88}$ la circostanza spiega la necessità di iscrivere i coloni in una nuova tribù (la Voltinia), distinta -caso a mia conoscenza unico nel quadro delle assegnazioni effettuate in Italia a beneficio di veterani-da quelle originariamente presenti nell'area (la Stellatina nell'ager Capenas, la Tromentina nell'ager Veientanus). La fondazione cesariana, retta come di consueto da duoviri, ${ }^{89}$ assunse il titolo di Colonia Iulia Felix e venne successivamente rinforzata in età augustea. ${ }^{90}$

Più complesse da ricostruire sono le vicende relative all'ager Faliscus. ${ }^{91}$ L'esistenza di una colonia triumvirale-augustea in quest'area è assicurata dall'elenco pliniano $^{92}$ e confermata dal Liber Coloniarum, ${ }^{93}$ che ne assegna la deduzione ai triumviri e ne specifica la titolatura (Colonia Iunonia Falisca). La deduzione dovette interessare non Falerii Novi -che restò municipium (retto da quattuorviri) fino almeno al II sec. d.C. ${ }^{44}$ - ma il vecchio sito di Falerii Veteres: è quanto deve ricavarsi dalla menzione, in Strabone, di due distinte comunità, $\Phi \alpha \lambda \varepsilon ́ p$ seconda delle quali certamente da identificare con Falerii Veteres. ${ }^{96}$ Non esistono elementi che facciano sospettare, prima dell'età triumvirale, dell'autonomia amministrativa di quest'ultimo centro, che dopo i fatti del 241 a.C. dovette ridursi a semplice vicus - mera appendice del celebre santuario di Iuno Curitis,${ }^{97}$ dal quale senza dubbio deriverà alla futura deduzione l'epiteto Iunonia - integrato nel territorio della nuova Falerii sorta lungo la via Amerina. Se è così, anche la Colonia Falisca può considerarsi dedotta in vacuo, ma in questo caso la nuova realtà amministrativa non risultò duratura: è infatti probabile che l'unità territoriale del distretto sia stata recuperata grazie all'intervento di Gallieno, onorato localmente come redintegrator

87 Su questo caso cf. Keppie 1983, 168-169. L'originaria pertinenza territoriale del sito è esplicitamemte affermata da Livio (27.4.14-15; 33.26.8) ed è suggerita anche dalla notizia relativa alla deduzione cesariano-augustea contenuta nel Liber Coloniarum (216 L.: Colonia Capys [scil. Capenas]: pro aestimio ubertatis et natura locorum sunt agri adsignati), da riferire con tutta evidenza non alla stessa Capena ma appunto a Lucus Feroniae. Cf. Cic. Fam. 9.17.2: Veientem quidem agrum et Capenatem metiuntur (...).

L'attestazione più antica è costituita da $C I L \mathrm{I}^{2} 3338 \mathrm{~b}$.

90 Il centro figura nell'elenco delle coloniae triumvirali-augustee della regio VII riportato da Plinio (HN 3.51): che la nuova deduzione si debba non ai triumviri ma ad Augusto è suggerito dal titolo di Augustini che Agennio Urbico (46 L.) assegna ai suoi abitanti.

91 Cf. Keppie 1983, 170-172.

92 Plin. $H N 3.51$.

$93 \quad$ LC $217 \mathrm{~L}$.

94 CIL XI 3103, 3125; cf. CIL VIII 4249.

95 Str. 5.2 .9 (cf. Solin. 2.7; Steph. Byz. 656 M.). La mancata menzione delle due Falerii in Plinio -che sembra ignorare l'esistenza del municipium di Falerii (Novi), assente dalla lista di Plin. HN3.52- si deve verosimilmente all'errata collazione, da parte dell'erudito, tra la lista delle coloniae triumvirali-augustee e l'elenco alfabetico delle civitates della regio VII, al cui interno l'eventuale sequenza *Falisci (scil. Faliscum), Falerienses (scil. Falerii) cognomine Etrusci (notazione funzionale a distinguere questa comunità dagli omonimi Falerienses "piceni" della regio V: cf. Plin. HN 3.111) potrebbe essere stata fraintesa come allusione ad un unico centro: (colonia) Falisca (...) quae cognominatur Etruscorum (Plin. HN 3.51).

96 Come assicura D.S. 14.96 .5 (in relazione ai fatti del 395 a.C.). È quanto suggerisce anche la toponomastica

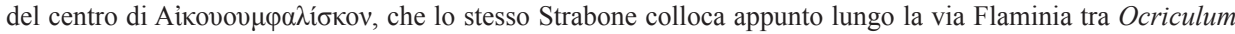
e Roma. Sulla questione si veda Di Stefano Manzella 1990 (da scartare l'idea dello studioso che Falerii Novi - civitas foederata fino al 90 a.C.- nasca come colonia di diritto latino: cf. sul punto Sisani 2018, 63-64).

97 Cf. Ov. Am. 3.13. 
coloniae Faliscorum, ${ }^{98}$ al quale può essere attributo il riaccorpamento, sotto una rinnovata veste coloniaria, delle due Falerii.

\section{Il duovirato come esito della tardiva costituzione a municipia di comunità semi-autonome sorte su antico ager Romanus}

I casi appena illustrati hanno tutti, in certo modo, carattere di eccezionalità, costituendo altrettanti interventi di modifica - dettati da esigenze di volta in volta diverse, ma sempre di natura contingente-al programma di municipalizzazione della penisola compiutamente elaborato in età cinnana. Di tutt'altra natura sono i casi in cui il ritardo nella costituzione a municipia di determinate comunità ha carattere per così dire strutturale, riguardando tutti quei centri che nei decenni successivi alla guerra sociale erano rimasti transitoriamente congelati in assetti istituzionali di rango inferiore. Le norme di interesse municipale riportate dalla tabula Heracleensis - da riferire ad una lex municipalis di portata generale, elaborata a Roma tra 1'86 e l'85 a.C. con lo scopo, tra gli altri, di offrire ai constitutores le linee-guida per il confezionamento degli statuti locali dei nuovi municipia ${ }^{99}$ - contemplano infatti non solo centri dotati di piena e compiuta autonomia (coloniae e municipia), ma anche comunità semi-autonome, distinte dai primi per il diverso grado di sviluppo delle strutture amministrative locali: da un lato le praefecturae, che rappresentano quadri censitari autonomi (al pari di coloniae e municipia) ma dove la giurisdizione locale è ancora amministrata da delegati del pretore, ${ }^{100}$ dall'altro i fora e i conciliabula, dotati di rudimentali organi magistratuali (con competenze di marca tipicamente edilitaria) ma dipendenti a livello censitario e giurisdizionale da centri vicini di rango superiore. ${ }^{101}$

Il carattere tendenzialmente transitorio di questi assetti è in ultima analisi implicato dal fatto che la normativa trasmessa dalla tabula Heracleensis riconosce alle comunità "minori" una propria individualità istituzionale, nonché -possiamo supporre- territoriale. ${ }^{102}$ Ciò significa che la loro futura promozione a municipia, se non prevista, non doveva comunque risultare già in partenza esclusa, pur se implicitamente vincolata al verificarsi di determinate condizioni: essenzialmente, lo sviluppo di una forma propriamente urbana funzionale alla creazione di strutture centralizzate di gestione dei rispettivi territoria, la cui mancata realizzazione avrebbe potuto condurre nel tempo all'assorbimento di tali comunità all'interno di realtà amministrative contermini già organicamente strutturate in forma municipale. ${ }^{103}$

Tali agglomerati secondari erano in larga misura presenti soprattutto all'interno dell'antico ager Romanus, in particolare nelle aree fatte oggetto tra il IV e il II sec. a.C. di interventi di colonizzazione viritana, che come è noto non erano accompagnati dalla creazione di nuove realtà urbane. È il caso ad esempio dei fora, che almeno in Italia sembrerebbero sempre fondati da Roma -tendenzialmente lungo il percorso

\footnotetext{
CIL XI 3089-3090.

Sisani 2016, 29-47.

Sisani 2010, 175-191.

Sisani 2011a, 581-594.

Cf. Sisani 2011a, 564-566.

Sisani 2011a, 592-594.
} 
delle viae publicae - in funzione di nuclei coloniari romani presenti nei territori annessi. ${ }^{104}$ Gli elenchi trasmessi da Plinio attestano l'esistenza, nelle regiones I-VII, di almeno nove municipia nati da precedenti fora: ${ }^{105}$ nessuno di essi documenta assetto quattuorvirale, mentre il duovirato è direttamente attestato a Forum Popilii nella regio I, Forum Novum ${ }^{106}$ nella regio IV, Forum Sempronii e (dubitativamente) Forum Flaminii ${ }^{107}$ nella regio VI, Forum Clodii nella regio VII. La documentazione epigrafica non consente di puntualizzare l'epoca della loro costituzione a municipia, che dovrà in ogni caso risalire al più tardi all'età augustea ma che non è escluso si collochi almeno in alcuni casi già in età cesariana o triumvirale: è quanto postulabile almeno per Forum Popilii, dove la più antica attestazione di duoviri parrebbe risalire ancora agli ultimi anni dell'età repubblicana. ${ }^{108}$

Più in generale, il ritardo nello sviluppo della forma municipale caratterizza l'intero comparto coloniale dell'ager Gallicus et Picenus, ${ }^{109}$ interessato nel 232 a.C. dal massiccio programma di assegnazioni viritane promosso da Gaio Flaminio e ancora alla metà del I sec. a.C. in larga parte organizzato in praefecturae. ${ }^{110}$ La tardiva costituzione di municipia in quest'area è confermata dalla pressoché uniforme diffusione di assetti amministrativi di marca duovirale, direttamente documentati a Forum Sempronii, Ostra e Suasa nell'ager Gallicus ${ }^{111}$ e a Cingulum, Cupra Maritima, Cupra Montana, Planina, Ricina, Septempeda e Trea nell'ager Picenus. ${ }^{12}$ La relativa frequenza di attestazioni magistratuali risalenti al pieno I sec. a.C., ${ }^{113}$ nonché le vicende istituzionali di Cingulum, ${ }^{114}$ suggeriscono con forza di collocare almeno l'avvio del processo di municipalizzazione in quest'area già in età cesariana, verosimilmente in connessione con le misure varate nel 59 a.C. ${ }^{115}$

Lo stesso assetto magistratuale caratterizza anche i municipia sabini di Amiternum e Nursia, nati in età augustea da precedenti praefecturae, dove l'originario ottovirato viene sostituito al più tardi al principio del I sec. d.C. da duoviri, ${ }^{116}$ che almeno a Nursia assumono la titolatura "ibrida" di octoviri duovirali potestate e octoviri

104 Sisani 2011a, 559-581.

105 Per un censimento completo dei casi cf. Sisani 2011a, 571-572.

106 Il quattuorvir attestato dal frammento epigrafico SupplIt 5 (1989), nr. 17, 183-184, dovette gerire la carica in altro centro

107 Resta incerto se l'iscrizione $A E$ 1988, 502 debba essere attribuita a questo centro, o non piuttosto a Hispellum: cf. Zuddas 2019, 255.

108 AE 2014, 329.

109 Cf. Sisani 2007, 68-72, 132-135.

110 Come attesta, relativamente almeno all'ager Picenus, Caes. Civ. 1.15.1-2. Per l'età immediatamente anteriore alla guerra sociale cf. Cic. Rabir. 22.

111 In quest'area l'unico municipium certamente retto da quattuorviri è quello di Sentinum: cf. infra.

112 Resta incerto il caso di Falerio, elevata a colonia -come assicura la mancata menzione di tale status in Plinio (cf. Keppie 1983, 182-183)- o prima dell'età triumvirale (in età graccana come la contermine Pollentia/Urbs Salvia?) o in età post-augustea, ed in ogni caso entro la prima età imperiale (cf. $A E$ 1960, 256): giusta la seconda eventualità, a favore della quale gioca l'assunzione di un assetto magistratuale distinto da quello caratteristico delle più antiche fondazioni coloniarie di area picena (tutte rette da praetores), almeno alcune attestazioni di duoviri (come CIL IX 5444) potrebbero risalire ancora alla precedente fase municipale.

113 Cupra Maritima: CIL I² 1917; InscrIt XIII/1, nr. 7, 243-248; Planina: SupplIt 22 (2004), nr. 15, 156-157; Trea: SupplIt 18 (2000), nr. 3, 174-175.

114 Alludo all'intervento di constitutio dell'oppidum ad opera di Labieno ricordato da Caes. Civ. 1.15.2, da far risalire quasi certamente al 59 a.C.: cf. Sisani 2011a, 583-584.

115 Su tutto questo si veda ora Sisani 2018, 68-70.

116 Sui due casi si veda, con censimento completo delle attestazioni, Sisani 2010, 199-207. 
aedilicia potestate. Anche questi casi riguardano un'area di antica colonizzazione viritana, popolata da cittadini romani fin dai decenni subito successivi alla conquista, nel 290 a.C., della Sabina e del territorio pretuziano. ${ }^{117}$ Rispetto all'ager Gallicus et Picenus, va tuttavia rilevato il maggior ritardo nello sviluppo delle forme municipali in questo distretto: ciò vale non solo per Amiternum e Nursia, ma anche per Reate, ancora una praefectura negli anni finali del I sec. a.C., ${ }^{118}$ e per Interamnia Praetuttiorum, che Frontino -in riferimento ad un contesto storico apparentemente coincidente con l'età triumvirale- considera ancora un semplice conciliabulum, solo successivamente promosso a municipium. ${ }^{119}$ Almeno nel caso di quest'ultimo centro, gli sviluppi amministrativi vennero fortemente condizionati dalla deduzione in loco di una colonia, verosimilmente di età sillana, che andò apparentemente ad affiancarsi alla comunità locale piuttosto che integrarla. Le concorrenti attestazioni di octoviri (del conciliabulum ${ }^{120}$ e di duoviri (della colonia) ${ }^{121}$ risalenti alla prima metà del I sec. a.C. prospettano il perdurare fino almeno all'età cesariana di una comunità "doppia", la cui tardiva integrazione amministrativa poté eventualmente condurre alla creazione di un municipium duovirale. ${ }^{122}$

La diffusione di questo assetto magistratuale in aree di antica colonizzazione viritana permette di spiegare le rarissime attestazioni del duovirato municipale in Etruria, apparentemente limitate -tolto il caso di Forum Clodii-ai municipia di Veii e Visentium. La constitutio augustea del municipium veiente, testimoniata dalla titolatura assunta dal centro (Municipium Augustum Veiens), ${ }^{123}$ potrebbe anche in questo caso rappresentare l'esito della tardiva strutturazione amministrativa di un comparto coloniale non urbanizzato, ${ }^{124}$ ma non è da escludere che l'intervento di Augusto si configuri piuttosto come restitutio di un municipium già esistente. ${ }^{125} \mathrm{Nel}$ caso di Visentium, si può invece essere ragionevolmente certi che il municipium nasca dalla promozione, in età cesariano-augustea, di un originario conciliabulum, sorto forse già al principio del II sec. a.C. nel territorio di antica pertinenza vulcente incamerato da Roma un secolo prima ed apparentemente interessato all'indomani del conflitto annibalico da assegnazioni agrarie, così come dalla deduzione della colonia di Saturnia (183 a.C.) e più tardi -verosimilmente in età graccana- di quella di Heba. ${ }^{126}$

In questa stessa chiave andranno forse spiegati, in area laziale, i casi di Ulubrae e di Aefula. Il primo centro, come assicura la sua ascrizione tribale, sorse nel

\footnotetext{
Sisani 2013a.

118 Sisani 2010, 216-219. Sull'assetto magistratuale di marca quattuorvirale, assunto dal municipium in età flavia, cf. infra, in appendice.

119 Frontin. 18-19 L. (=2.10 G., cf. comm. in Frontin. 2.18 G.): Huius soli ius quamvis habita oratione divus Augustus de statu municipiorum tractaverit, in proximas urbes pervenire dicitur, quarum ex voluntate conditoris maxima pars finium coloniae est attributa, aliqua portio moenium extremae perticae adsignatione inclusa, sicut in Piceno fertur Interamnatium Praetuttianorum quandam oppidi partem Asculanorum fine circumdari. [Quod si ad haec revertamur, hoc conciliabulum fuisse fertur et postea in municipii ius relatum]. Sulle vicende storicoistituzionali del centro cf. Sisani 2010, 207-210.

120 CIL IX 5067; cf. anche CIL IX 5158.

121 CIL I² 1905-1906, 3296.

122 Durante l'età imperiale il centro risulta retto da duoviri (cf. $A E$ 1912, 144; EDR 115916), ma resta incerto il suo statuto, che in una iscrizione del II sec. d.C. $(A E$ 1998, 416) figura ancora nella forma municipium et colonia Interamnatium Praetuttianorum.

123 CIL XI 3797, 3805, 3808, 3809.

124 Cf. Liverani 1984 e Soricelli 2007.

125 Per un possibile coinvolgimento del centro nei fatti del bellum Perusinum cf. Jones 1963.

126 Sulla colonizzazione di questo distretto cf. Sisani 2011a, 616-619.
} 
territorio conquistato ai Volsci nel 389 a.C. ed inquadrato fin dal 358 a.C. nella tribù Pomptina ${ }^{127}$ a seguito evidentemente della sua assegnazione a coloni romani. Lo statuto duovirale è certo, ${ }^{128}$ ma non è sicuro se esso debba essere riferito ad una realtà municipale piuttosto che coloniaria, come potrebbe suggerire una per altro ambigua notizia del Liber Coloniarium. ${ }^{129}$ Per quanto riguarda Aefula, una piccola realtà amministrativa autonoma stretta tra gli agri tiburtino e prenestino, la struttura magistratuale di tipo apparentemente duovirale ${ }^{130}$ spinge anche in questo caso a postulare una tardiva costituzione a municipium del centro, in origine verosimilmente un conciliabulum sorto nel territorio sottratto da Roma a Tibur e Praeneste nel 338 a.C., ${ }^{131}$ alla conclusione della guerra latina, e che possiamo ritenere anch'esso fatto oggetto di assegnazioni viritane.

Tolti i territori coloniali, all'interno dell'antico ager Romanus la marca duovirale caratterizza anche due comunità verosimilmente naturalizzate già prima della guerra sociale, che almeno nella prima metà del I sec. a.C. non parrebbero tuttavia strutturate in forma di municipia: Atina e Casinum. La naturalizzazione delle due comunità -e di quelle, contermini, di Allifae e Venafrum- è correntemente ritenuta un esito dell'annessione, nel 268 a.C., della frangia occidentale del territorio sannitico: ${ }^{132}$ l'ipotesi, senza dubbio percorribile, è basata essenzialmente sulla possibilità di attribuire a tutti questi centri l'originario status di praefecturae, senza tuttavia poter con certezza determinare - tolto il caso della praefectura atinate, senza

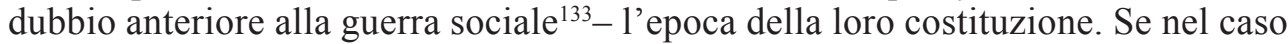
di Allifae e Venafrum resta in dubbio l'esistenza stessa di una fase municipale, ${ }^{134}$ in ogni caso precocemente annullata dalle deduzioni coloniarie effettuate in loco tra l'età sillana e l'età cesariana, ${ }^{135}$ Atina e Casinum permasero nella condizione

127 Taylor 1960, 50. Sul centro si veda ora Garofalo 2017.

128 Le attestazioni epigrafiche della carica (CIL X 6489; $A E$ 1995, 291) non sono in ogni caso anteriori all'età imperiale; l'unica iscrizione forse risalente ancora agli anni finali dell'età repubblicana è $C I L$ X 6490, menzionante un praefectus Ulubris iure dicundo, verosimilmente un sostituto temporaneo dei magistrati locali.

129 LC 239 L.: Ulubrae, oppidum: a triumviris erat deducta, postea a Druso Caesare est †inruptum [scil. interruptum?], ager eius in nominibus est adsignatus. Esclusa l'idea di una deduzione triumvirale, smentita dal silenzio di Plinio, si potrebbe eventualmente pensare ad una colonia sillana o (meno probabilmente) cesariana, poi ricondotta in età augustea o tiberiana -giusto l'emendamento al testo- alla condizione di municipium.

130 L'unica traccia epigrafica della locale amministrazione è offerta da un frammento di fasti consolari $(A E 1996$, 518: anni 120-121 d.C.) rinvenuto in contesto di reimpiego a breve distanza da Villa Adriana, che per la menzione di duoviri non può essere riferito al municipium quattuorvirale di Tibur: si è pensato ad una pertinenza prenestina o trebulana (cf. Sciarretta 1996, 102-104), ma sta di fatto che Aefula rappresenta una migliore candidata, essendo senza dubbio la realtà municipale più prossima al luogo di rinvenimento.

131 Cf. Liv. 8.14.9.

132 Humbert 1978, 244-250.

133 Cf. Cic. Planc. 32, 47.

134 I due centri sono qualificati come praefecturae in Fest. 262 L. Non dimostra una loro successiva promozione a municipia la menzione degli agri allifano e venafrano in Cic. Leg. Agr. 2.66 e Planc. 22, pur nel loro accostamento ad altre realtà a statuto certamente municipale.

135 Allifae -il cui statuto coloniario è attestato epigraficamente per l'età imperiale ma che non figura nella lista delle coloniae triumvirali-augustee trasmessa da Plinio: le assegnazioni di età triumvirale richiamate dal Liber Coloniarium (231 L.) avranno piuttosto avuto carattere viritano (cf. Keppie 1983, 62-63)- dovette essere dedotta verosimilmente in età sillana, o al più tardi cesariana. Nel caso di Venafrum (Keppie 1983, 138-139), le attestazioni di due diverse titolature -Colonia Iulia (CIL X 4875, di età tardo-repubblicana) e Colonia Iulia Augusta (CIL X 4894, di età augusteo-tiberiana)- fanno sospettare che una prima deduzione abbia avuto luogo in età cesariana (forse già nel 59 a.C.: cf. LC 239 L.), successivamente rinforzata dopo Azio. 
di praefecturae fino alla metà del I sec. a.C.: ${ }^{136}$ la successiva trasformazione in municipia portò in entrambi i casi all'assunzione di un assetto magistratuale di tipo duovirale. ${ }^{137}$

Casi analoghi, ma di inquadramento maggiormente problematico, potrebbero essere rappresentati da Trebula Suffenas, in territorio equo, e da Treba, che credo sia invece da ascrivere al comparto ernico. ${ }^{138}$ Il primo centro è certamente retto da duoviri, le cui attestazioni non sono tuttavia anteriori all'età imperiale:139 la constitutio a municipium dovette in ogni caso realizzarsi entro il 43-42 a.C. ${ }^{140}$ Qualche incertezza grava sull'assetto magistratuale del secondo centro, ${ }^{141}$ al quale può essere tentativamente riferita la menzione del duovirato in una iscrizione di provenienza anagnina, ${ }^{142}$ postulando che tutte le cariche rivestite dall'onorato, curator rei publicae Trebanorum, siano state gerite appunto a Treba: municipium da ritenere costituito (o ricostituito) solo in età augustea, almeno a giudicare dall'epiteto Augusta attribuitogli da Frontino. ${ }^{143}$

Nel caso di entrambi i centri, la vera questione aperta è quella relativa al loro status in età anteriore alla guerra sociale. Per quanto riguarda Trebula Suffenas, l'ipotesi di identificare nei suoi abitanti -piuttosto che in quelli di Trebula Balliensis-

136 Per Atina cf. Cic. Planc. 19, 21 (54 a.C.); per Casinum cf. CIL I² 1544 (metà del I sec. a.C.): C. Futio C.f. [- - -] / parenti pra[efecturae] / C[a]sina[tes d(ecurionum) d(ecreto)?]. Relativamente a quest'ultima iscrizione, la nuova proposta di restituzione (già ventilata da Molle 2016, 105-110) è di fatto obbigata, perché è l'unica a dare un senso al testo, superando le difficoltà implicate dalla corrente lettura parenti, pra[ef(ecto)] C[a]sina[tium] (nuovamente riproposta in Cerrone - Gallo 2016, 151-152).

137 Le attestazioni più antiche sono offerte per Atina da CIL $\mathrm{I}^{2} 1533$ (apparentemente da datare nei decenni finali del I sec. a.C.), per Casinum da CIL X 5159 (del 40 a.C.). Sugli sviluppi amministrativi dei due centri cf. Solin 2007 (Atina) e Solin 2013, 2016 (Casinum): relativamente a Casinum, continuo a ritenere che il pr(aetor) attestato da $C I L \mathrm{I}^{2} 1545$ (forse ancora risalente alla fase della praefectura) non sia un magistrato cittadino ma urbano (cf. Sisani 2011a, 725).

138 Contrariamente a quanto postulato, tra gli altri, da Humbert 1978, 218-219. Ma la pertinenza ernica è fortemente suggerita sia dall'inserimento del centro nella regio $I$ augustea (piuttosto che nella regio $I V$, dove sono invece collocate tanto Trebula Suffenas quanto la res publica Aequiculorum), sia dalla sua prossimità alle comunità di Capitulum Hernicum e di Afilae (quest'ultima solo apparentemente assente dagli elenchi pliniani, ma da identificare con l'anonima civitas ex agro Hernico cognominata di Plin. HN 3.63).

139 Una possibile attestazione di età repubblicana è forse restituita dall'iscrizione frammentaria SupplIt 4 (1988), nr. 34, 168-169: [- - -]++ [- - ] / [- - - Ma]rciu[s -f. duo]viri / [- - ei]dem [q(ue) pr]ob(arunt) / [- - -]++ [- - -].

140 AE 2009, 296: cf. Granino Cecere 2007

141 Non offre certezze a riguardo la sottoscrizione magistratuale presente nell'iscrizione trebana CIL XIV 3449 (del 192 d.C.), recante le formule onomastiche al genitivo di due personaggi privi di titolatura, ma che già il Dessau proponeva di identificare con una coppia di duoviri.

142 CIL X 5928 (II sec. d.C.): P. Vegellio P. f. Pub(lilia) Primo / eq(uiti) R(omano), IIvir(o), q(uaestori) alim(entorum), cur(atori) pec(uniae) / annon(ariae), q(uaestori) aerar(ii) arcae pu/b(licae), cur(atori) r(ei) p(ublicae) Trebanorum (etc.). Che il duovirato sia stato gerito ad Anagnia è virtualmente escluso dall'assetto magistratuale di tale municipium, ancora nel II sec. d.C. retto da praetores (cf. CIL X 5919, 5920): la presunta lettura IIvir in una iscrizione coeva nota solo da tradizione manoscritta -CIL X 5932 (cf. AE 2012, 329): D(is) M(anibus) / [- - ge]neri / pientissimo Esopus / IIvir [- - ] et Daphne / bene merenti fecerunt / qui vixit ann(is) XXXV[- - ], m(ensibus) VI- sarà da correggere in VIvir [Aug(ustalis)] (cf. EDR 32650), coerentemente con la probabile condizione libertina del personaggio che rivestì la carica.

143 Frontin. Aq. 93. Contrasta con una cronologia così avanzata l'attestazione di censores in CIL XIV 3451: A. Titius L.f., M. Vergilius M.f. cens(ores) d(e) s(enatus) s(ententia) //M.Vergilius M.f., A. Titius L.f. ce(n)s(ores), purtroppo perduta ma databile al più tardi nel pieno I sec. a.C. La testimonianza potrebbe avvalorare l'ipotesi di un municipium di antica costituzione poi rifondato da Augusto, ma può anche essere letta come il segno della iniziale dipendenza del centro, a fini censitari, da una comunità vicina, postulando che i censores menzionati nel testo siano ad esempio magistrati di Anagnia o di Aletrium. 
i Trebulani cui Roma concesse la civitas sine suffragio nel 303 a.C. ${ }^{144}$ è in stridente contrasto con la durissima sorte inflitta l'anno precedente al nomen Aequorum, quasi interamente cancellato ed apparentemente relegato dopo questa data all'interno della sola valle del Salto. ${ }^{145}$ Treba, se veramente ernica e non equa, potrebbe per contro far parte insieme ad Afilae e a Capitulum di quelle comunità minori che insieme ad Anagnia vennero naturalizzate nel 306 a.C. ${ }^{146}$ Non è tuttavia da escludere che in questo come nell'altro caso si sia piuttosto di fronte a conciliabula sorti in territori confiscati da Roma, tra il 306 e il 304 a.C., alle popolazioni vinte ed assegnati in forma viritana a cittadini romani, inquadrati fin dal 299 a.C. all'interno della tribù Aniensis creata in quell'anno, che accomuna tutti i centri-Trebula Suffenas, Afilae, Treba- situati lungo l'alta valle dell'Aniene. ${ }^{147}$

\section{Il duovirato come esito della tardiva costituzione a municipia di antiche civitates foederatae}

All'interno dell'antico ager Romanus, il ritardo degli sviluppi municipali pare sempre essere, in ultima analisi, l'esito di strategie amministrative risalenti ad epoca ancora anteriore al I sec. a.C. Meno trasparenti sono le ragioni di tale ritardo in aree rimaste federate fino alla guerra sociale, dove il processo di municipalizzazione avrebbe potuto - e almeno teoricamente dovuto- concludersi nel giro di pochi anni dalla concessione nel 90 a.C. della cittadinanza romana alle singole comunità locali. Analizzando la distribuzione dei municipia duovirali nati con certezza o probabilità dalla promozione di antiche civitates foederatae, emerge in primo luogo la possibilità di distinguere nettamente due aree di distribuzione: una "centro-settentrionale", dove le rare attestazioni -in territorio umbro, equicolo e peligno- costituiscono presenze decisamente isolate, l'altra "meridionale", dove si concentra senza dubbio il maggior numero di occorrenze, addensate essenzialmente in territorio sannitico e lucano (fino a lambire l'Apulia e la Campania) e accomunate dalla cronologia postulabile per la constitutio municipale, da circoscrivere virtualmente in tutti i casi all'età cesariana.

Gli esempi centro-settentrionali, appunto a causa della loro sporadicità, non si lasciano inquadrare in sistema. Almeno per quanto riguarda l'area umbra, essi potrebbero anzi essere in relazione a territori già popolati da cives Romani anteriormente alla guerra sociale: eventualmente a seguito delle iniziative coloniarie attuate al principio del II sec. a.C. ${ }^{148}$

144 Liv. 10.1.3. Riferisce la notizia ai Ballienses De Sanctis 1953-1964 [1907-1923], II, 322, nota 134; vi legge invece una allusione ai Suffenates Taylor 1960, 56-57 (seguita da Humbert 1978, 218-219).

145 Cf. Liv. 9.45.5-18.

146 Liv. 9.43.24: Anagninis quique arma Romanis intulerant civitas sine suffragii latione data. Cf. Humbert 1978, 212-216.

147 Taylor 1960, 56-57.

148 Su queste iniziative -finalizzate alla sistemazione dei veterani della guerra annibalica- e sulle aree interessate cf. Sisani 2007, 135-138: in particolare, occorrerà distinguere le assegnazioni in Apulia e nel Sannio, riservate ai soli veterani della campagna africana, da quelle attuate a beneficio dei veterani di Spagna, Sicilia e Sardegna, dedotti evidentemente in altre aree della penisola. Su tutta la questione si veda ora, diffusamente, Bellomo 2020 (che tuttavia sembra ignorare quanto da me già scritto sull'argomento). 
Nell'Umbria appenninica, ${ }^{149}$ il duovirato è attestato con certezza a Matilica ${ }^{150} \mathrm{e}$ forse a Tadinum: ${ }^{151}$ non prima, in entrambi i casi, dell'età imperiale. In mancanza di informazioni sulla storia dei due centri è difficile formulare ipotesi concrete sulle ragioni del ritardo negli sviluppi municipali, che in entrambi i casi potrebbe in qualche modo derivare dall'impatto destrutturante della conquista romana in quest'area. Ciò vale in particolare per Matilica, se non interna senza dubbio assai prossima al comparto coloniale dell'ager Gallicus et Picenus, la cui ascrizione alla tribù Cornelia fa sospettare un diretto coinvolgimento dell'area nel programma di assegnazioni attuato al termine della guerra annibalica. ${ }^{152}$ La stessa Tadinum parrebbe nascere lungo la via Flaminia solo al principio del II sec. a.C., a seguito del forzato abbandono dell'abitato preromano: ${ }^{153}$ una operazione che fa del centro una vera e propria "città di fondazione", nata in un contesto storico segnato dal consolidamento della presenza romana nella regione. La precoce ingerenza di Roma negli sviluppi locali può per altro spiegare, sempre in Umbria, anche il caso più meridionale di Carsulae, centro esso stesso sorto apparentemente ex novo nel corso del II sec. a.C. lungo il ramo occidentale della via Flaminia, dove il duovirato risulta già documentato intorno alla metà del I sec. a.C.. ${ }^{154}$ anche in questo caso, non è da escludere che il centro fosse in origine non già una civitas foederata ma un conciliabulum nato ai fini della strutturazione amministrativa di un nucleo coloniario dedotto in loco. ${ }^{155}$

Rispetto all'area di maggior diffusione, hanno collocazione eccentrica anche i municipia duovirali della civitas Aequiculorum e di Superaequum. La prima entità giuridica -con sede amministrativa a Cliternia- abbracciava l'intero territorio equicolo, ${ }^{156}$ unico segmento superstite del nomen Aequorum dopo la conquista romana del 304 a.C. Non vi è a mio avviso alcuna ragione per postulare una precoce inclusione di questo distretto nella civitas romana, ${ }^{157}$ che dovette essere concessa ai suoi abitanti solo nel 90 a.C.; la constitutio municipale è invece certamente più tarda, non anteriore -come denuncia appunto l'assetto duovirale- all'età cesariana. ${ }^{158} \mathrm{La}$

149 Qualche dubbio grava sull'assetto magistratuale di Attidium: l'unica attestazione magistratuale relativa al centro è restituita dall'iscrizione frammentaria CIL XI 5676, con menzione di un II[- - -] quinq(uennalis), dove l'integrazione II[IIvir] parrebbe comunque imposta dall'impaginato. Da cassare la supposta attestazione di un duovir a Sarsina (CIL XI $6539+A E$ 1980, 417: cf. EDR 77837): il titolo magistratuale inciso sulla lapide è infatti da restituire come [II]IIVir.

150 CIL XI 5646 (del 132 d.C.).

151 CIL XI 5802 (della prima età imperiale), rinvenuta lungo il percorso della via Flaminia al confine tra gli agri iguvino e tadinate ed ora attribuita ad Arna (cf. SupplIt 27 (2013), nr. 3, 229-230), ma unicamente in virtù dell'ascrizione del magistrato alla tribù Clustumina. La provenienza del testo, eccessivamente eccentrica, risulta tuttavia difficilmente conciliabile con questa ipotesi: non andrà semmai del tutto esclusa una sua attribuzione ad un municipium non identificato della regio VI (cf. Sisani 2007, 76-79).

152 Cf. Sisani 2007, 218-224.

153 Sulla nascita e lo sviluppo dell'abitato si veda in sintesi Sisani 2012; sulla funzione eminentemente amministrativa dell'insediamento cf. Sisani 2013 b.

154 AE 2014, 409: [-] Coelius L. f. Titianus, / [-] Egnatius C. f. Apicula / [I]Ivir(i) quinq(uennales) ex d(ecreto) $d$ (ecurionum) f(aciundum) c(uraverunt), dove l'integrazione [I]Ivir $(i)$ è assicurata dall'ampiezza postulabile per la lacuna; le altre attestazioni del duovirato risalgono alla prima età augustea (CIL XI 4575) e al pieno I sec. d.C. (AE 2017, 396): cf. Roscini 2018. Sulla successiva introduzione del quattuorvirato cf. infra, in appendice.

155 Cf. Sisani 2007, 168-171.

156 Sull'assetto amministrativo dell'area, strutturata su un unico municipium (come assicura Plin. HN 3.106), cf. Sisani 2011a, 694-701.

157 Contrariamente a quanto postulato, tra gli altri, da Humbert 1978, 219.

158 Le attestazioni epigrafiche relative a duoviri (CIL IX 4127, 4128, 4169) non sono anteriori all'età imperiale. A favore di una costituzione del municipium in età pre-augustea può comunque orientare l'iscrizione 
natura "territoriale" del municipium, esplicitata dalla sua peculiare denominazione, tradisce la lunga sopravvivenza in quest'area di un assetto insediativo di tipo paganicovicano: ed è appunto in questo carattere non urbano del distretto che andranno rintracciate le ragioni stesse del ritardo nella sua strutturazione istituzionale. Diverso è il caso di Superaequum, il cui assetto duovirale -documentato a partire dall'età augustea e fino almeno al II sec. d.C. ${ }^{159}$ - contrasta con quello adottato dagli altri municipia di area peligna (Corfinium e Sulmo), retti da quattuorviri. Certo è che il distretto superequano, collocato ai margini nord-occidentali del comparto peligno, manifesta indubbie peculiarità, che prospettano uno sviluppo storico in certo modo distinto da quello dei centri vicini. Alludo alle attestazioni cronologicamente risalenti di una epigrafia pubblica in lingua latina che potrebbero tradire, più che una precoce spinta all'auto-romanizzazione, la presenza nell'area di enclaves coloniali a partire almeno dal II sec. a.C. ${ }^{160}$ In questo caso si potrebbe allora postulare, per il periodo subito successivo alla guerra sociale, una iniziale sopravvivenza della separazione amministrativa tra le due componenti -coloniale e locale- della popolazione del distretto, superata nel tempo grazie al loro accorpamento in un unico municipium, tardivamente costituito.

I casi finora analizzati, come si vede, fanno ciascuno storia a sé: né le loro peculiari vicende storico-istituzionali paiono inficiare il postulato in base al quale il quattuorvirato rappresenta di regola la magistratura tipica dei municipia sorti nelle aree che ricevettero la cittadinanza romana solo a seguito della guerra sociale. La regola dovrebbe in astratto valere anche per il settore meridionale della penisola, dove tuttavia la frequenza di municipia duovirali - una quindicina quelli finora accertati- è tale da sollecitare la ricerca delle ragioni storiche sottese alla diffusione del fenomeno.

In questo settore il duovirato è magistratura tipica, innanzi tutto, dei municipia di area sannitica: sia nel Sannio pentro (Aufidena, ${ }^{161}$ Fagifulae, Saepinum, Terventum), sia nel Sannio occidentale (Caiatia, Cubulteria). ${ }^{162}$ Tolto il caso di Aesernia -colonia

-apparentemente di età tardo-repubblicana-CIL I ${ }^{2}$ 1829: T. Statius T. f. St. n. / aed(ilis), q(uaestor) / Annia An. f. uxo(r).

159 Le menzioni più antiche della carica sono offerte da CIL IX 3307 e 7387. Si registra anche una isolata attestazione del quattuorvirato (CIL IX 3314, del 271 d.C.), forse da attribuire al contermine municipium di Corfinium, a meno di non postulare un tardo adattamento costituzionale eventualmente motivato dalla volontà di uniformarsi agli assetti quattuorvirali degli altri municipia peligni (così Buonocore 2002 [1985]): ma per tale prassi -il caso di Carsulae è di altra natura: cf. infra, in appendice- non si offrono di fatto paralleli.

160 Sisani 2011a, 620-624.

161 L'idea di Humbert 1978, 244-250, che il centro sia stato naturalizzato già nel 268 a.C. non poggia su alcuna base concreta.

162 Contrariamente alla prospettiva da me abbracciata in precedenti lavori (ma si veda ora, per un riesame globale della questione, Sisani 2021b), non esistono elementi per postulare una precoce inclusione nella cittadinanza romana delle comunità di Caiatia e Cubulteria, che dovettero restare federate fino alla guerra sociale. L'ager Caiatinus venne in ogni caso certamente interessato dagli interventi della commissione agraria graccana (LC 233 L.: cf. Sisani 2015, 84-88): a tali interventi sarà da imputare il parziale assoggettamento di questo territorio alla iurisdictio pretoria, documentato per i decenni finali del II sec. a.C. da CIL I 825 (cf. Sisani 2011a, 715-716). $\mathrm{Nel}$ caso dell'ager Cubulterinus, un testo epigrafico su lastrina bronzea di provenienza locale $-A E 2001,856$

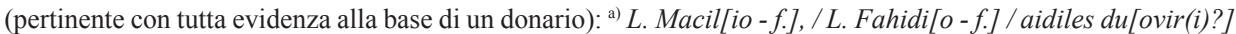
/ dedere aire [d] / moltatic[od] // ${ }^{\text {b) }}$ Luco Lania / dato dono- sembrerebbe in effetti documentare già per il pieno III sec. a.C. l'adozione di lingua e istituti di marca indubitabilmente romana: ma occorrerà tener conto delle tortuose vicende antiche del manufatto (cf. Sisani 2011a, 624-625: la lastrina, originariamente pensata per il testo a, è stata successivamente ritagliata e riutilizzata sul verso per l'incisione del testo b), forse giunto a 
latina promossa come di norma a municipium quattuorvirale ${ }^{163}$ - il quadro non conosce di fatto eccezioni, dal momento che non conosciamo l'originario assetto amministrativo né del municipium di Bovianum, ${ }^{164}$ né di quello (per altro ipotetico) di Telesia, entrambi precocemente cancellati entro l'età cesariana dalla deduzione in loco di coloniae. ${ }^{165}$ Nella gran parte dei casi, le attestazioni cronologicamente risalenti di duoviri ${ }^{166}$ consentono di datare la constitutio municipale in quest'area già all'età cesariana: attribuzione apparentemente confermata, nel caso di Aufidena, dalla titolatura di Municipium Iulium assunta dal centro. ${ }^{167}$

Più a sud, le attestazioni di municipia duovirali si mantengono numericamente significative ma risultano meno concentrate, diluite come sono in un contesto istituzionale locale dove gli assetti quattuorvirali -almeno allo stato attuale delle nostre conoscenze ${ }^{168}$ - appaiono senza dubbio maggioritari. Le attestazioni si

Cubulteria -durante i concitati anni della seconda guerra punica, quando il centro defezionò dall'alleanza con Roma (cf. Liv. 23.39.6; 24.20.5) - da altra area (ad esempio dall'assai prossimo ager Falernus).

163 Durante la fase transitoria a cavallo tra la concessione della cittadinanza romana nel 90 a.C. e l'introduzione del quattuorvirato (intorno all'80 a.C.), il municipium di Aesernia sembrerebbe aver perpetuato l'assetto magistratuale della precedente fase coloniaria latina, come fanno sospettare alcune attestazioni di praetores risalenti al principio del I sec. a.C. (CIL I ${ }^{2} 1754$ e CIL IX 6769: cf. Sisani 2018, 62-63, nota 149). Tale parentesi istituzionale è per altro postulabile anche nei casi di Alba Fucens (CIL IX 7938: cf. Letta 2016, nr. 5, 285-286, che tuttavia vuole rintracciare in questo testo la menzione non di un pr(aetor) ma di un pr(inceps), attribuendo erroneamente l'iscrizione agli ultimi decenni del I sec. a.C.), Beneventum (CIL $\mathrm{I}^{2}$ 1748: cf. infra, nota 165), Paestum (HNI 1238-1240: cf. Sisani 2018, 63, nota 155) ed eventualmente Praeneste (CIL I² 1467, 3091: cf. Sisani 2018, 63, nota 152) -tutti centri in cui si registrano attestazioni di praetores databili negli anni a cavallo della guerra sociale- ed è presupposta dalla titolatura di quattuorviri praetores (da ritenere equivalente a quella, canonica, di quattuorviri iure dicundo) di cui si fregiano a Cales, nei primissimi anni del municipium, i magistrati giurisdicenti locali (CIL I² 1574; CIL X 4657; AE 1973, 135: cf. Camodeca 2017, 56, che immotivatamente pretende di abbassare l'inquadramento cronologico di tutte queste testimonianze agli anni 50-30 a.C.).

164 Già costituito (e ancora esistente) nel 48-46 a.C.: cf. CIL I $\mathrm{I}^{2} 787$.

165 La colonia di Bovianum venne inizialmente dedotta a beneficio dei veterani di Cesare tra il 47 e il 44 a.C. e fu successivamente rinforzata in età augustea (cf. Keppie 1983, 161-163). Non posso affrontare in questa sede la spiniosa questione delle due Bovianum (su cui si veda da ultimo Soricelli 2017, 89-90), sollevata dalla peculiare menzione del centro nell'elenco pliniano (Plin. HN 3.107: colonia Bovianum Vetus et alterum cognomine Undecumanorum): anticipo solo che l'uso del singolare colonia (così in tutti i codici) costituisce a mio avviso un forte indizio per postulare l'esistenza di un'unica comunità. Nel caso di Telesia (da escludere, a fronte del silenzio pliniano, la deduzione triumvirale prospettata da $L C 238$ L.), una deduzione cesariana -ma del 59 a.C.- è indiziata dal titolo di praetores duoviri di cui si fregiano i magistrati locali già dal pieno I sec. a.C. (cf. CIL I $\mathrm{I}^{2}$ 1747, 3200): un tratto ignoto alle deduzioni sillane, che ricorre invece nelle coloniae di Grumentum e Privernum, almeno la prima delle quali certamente dedotta nel contesto delle leges Iuliae agrariae del 59 a.C. (cf. Buonopane 2017). Non va tuttavia escluso che a Telesia la deduzione cesariana sia andata ad impiantarsi su una precedente colonia sillana, come suggerisce la diversa titolatura del magistrato telesino menzionato in CIL I 1748 (perduta): [-] Visellius L.f. / Fal(erna) Flaccus / Beneventan(us) / heic sepultus e(st) / duovir Tele[s(iae)], / [p]r(aetor) Benev[enti]. L'iscrizione è certamente da datare nei decenni iniziali del I sec. a.C., come assicura il cursus honorum del personaggio, che poté rivestire la pretura a Beneventum o precedentemente alla guerra sociale (durante gli ultimi anni della fase coloniaria latina) o negli anni immediatamente successivi al 90 a.C. (prima dell'introduzione del quattuorvirato municipale): si tratta, senza dubbio, della più antica attestazione magistratuale riferibile a Telesia, all'epoca evidentemente già colonia. Il duovir telesino di CIL IX 2232, della fine del II sec. d.C., va invece attributo ad epoca successiva al rinnovamento della veste coloniaria, a titolo onorifico, sotto Commodo (come suggerisce l'assunzione della nuova titolatura di Colonia Herculanea Telesia: cf. Buonocore 2014, 5-6).

166 Aufidena: CIL IX 2809; Caiatia: CIL I² 1576; Fagifulae: CIL IX 6662; Terventum: CIL IX 2602.

167 Documentata da una iscrizione inedita di cui dà notizia Letta 2017, 23.

168 Si tenga conto che nell'ambito del centinaio di comunità dotate di autonomia locale presenti nelle regiones II e III in età augustea (cf. Plin. HN 3.71-74, 95-105) - una trentina delle quali, per altro, non ancora identificateconosciamo l'assetto magistratuale di appena una cinquantina di centri. 
distribuiscono in due aree: da un lato il settore appenninico a cavallo tra Irpinia, Apulia e Lucania, dall'altro il versante tirrenico a cavallo tra Campania e Lucania. In area irpina il duovirato è attestato -non prima, in ogni caso, dell'età imperiale-dalla documentazione epigrafica di Frigento-Rocca San Felice, ${ }^{169}$ senz'altro da attribuire ad un altrimenti ignoto municipium che tenderei ad identificare con quello degli Abellinates cognomine Protropi menzionati da Plinio tra le comunità irpine comprese nella regio $I I,{ }^{170}$ gli unici dell'elenco privi di sicura localizzazione. A non grande distanza, sull'opposto versante della catena appenninica, sono retti da duoviri anche il municipium apulo di Ausculum e quello lucano di Bantia, come documentano due isolate attestazioni epigrafiche risalenti entrambe alla metà del I sec. a.C. ${ }^{171}$ Sul versante tirrenico, infine, hanno assetto duovirale -oltre ai municipia campani di Herculaneum e Surrentum - i municipia lucani di Tegianum, Eburum e Blanda: almeno nel caso di Tegianum, l'unica attestazione del duovirato riferibile con buona verosimiglianza al centro, risalente ai decenni finali del I sec. a.C., ${ }^{172}$ prospetta una constitutio già di età cesariana, eventualmente postulabile anche per Blanda sulla scorta del titolo Iulia di cui il municipium si fregia durante l'età imperiale. ${ }^{173}$

Analizzando la distribuzione complessiva delle occorrenze, emerge con forza la possibilità di leggere la diffusione dei municipia duovirali nell'Italia meridionale alla luce del contesto storico dei decenni a cavallo tra II e I sec. a.C., che vede l'avvio stesso del processo di municipalizzazione delle aree rimaste federate fino alla guerra sociale. È in primo luogo evidente l'addensarsi delle attestazioni in aree toccate dall'attività della commissione agraria graccana: ${ }^{174}$ è questo il caso, in particolare, del Sannio occidentale, dell'Irpinia e del Vallo di Diano, al cui interno si collocano rispettivamente i municipia duovirali di Caiatia e Cubulteria, di Abellinum Protroporum, di Tegianum. Significativa è poi la coincidenza con territori direttamente investiti dalla colonizzazione sillana: nello stesso Sannio occidentale, toccato dalle deduzioni di Allifae e Telesia, nonché in area apula e lucana, dove i municipia duovirali di Ausculum e di Eburum risultano adiacenti rispettivamente

169 Ora raccolta e discussa in Camodeca 2018, che tuttavia, nel dare per scontata l'esistenza di un municipium in quest'area, non si avvede della ricaduta che l'ipotesi necessariamente produce sulla lettura degli elenchi di comunità trasmessi da Plinio: sulla questione si veda -seppure con prospettiva in parte diversa da quella che abbraccio ora-Sisani 2011a, 716-723.

170 Plin. $H N 3.105$.

171 Ausculum: AE 1994, 474; Bantia: CIL IX 418 (cf. Supplit 31 (2019), nr. 1, 33). Nel caso di Ausculum, l'unica altra attestazione magistratuale restituita dal centro -CIL IX 668 (nota solo da tradizione manoscritta): $P$. Mamercio / P. f. Maximo / aedili Compsi/norum, IIIIvir(o) i(ure) d(icundo), / IIIIvir(o) quinquen/nali, quaestori / Satria Secunda / coniugi bene / merenti et Sabi/no et Silvanae fi/lis et vac. sibi / fecit- è invece relativa ad un quattuorvir di età imperiale, che tuttavia è probabile abbia svolto l'intero cursus honorum a Compsa.

172 CIL X 337: l'iscrizione, rinvenuta lungo la valle del Tanagro, non può essere pertinente al municipium di Atina, retto da quattuorviri, attestati dall'età tardo-repubblicana fino almeno a tutto il II sec. d.C. (fantasiosa la ricostruzione degli sviluppi amministrativi di quest'ultimo centro prospettata da Sansone 2017, che pretende di attribuire ad Atina sia CIL X 337 sia AE 1988, 409, con menzione di un praetor duovir, certamente un magistrato di Grumentum). Resta incerto se Tegianum abbia successivamente acquisito, in età neroniana, statuto coloniario, come sembra attestare il graffito pompeiano CIL IV 3525: sulla questione cf. Keppie 1984, 89-90.

173 CIL X 125. Restano in ogni caso incerte tanto l'epoca quanto le ragioni dell'attribuzione del titolo (cf. Letta 2017, 23): nel caso eventualmente parallelo di Regium Iulium, costituito a municipium all'indomani della guerra sociale, il titolo dovette essere assunto solo nel 36 a.C., a seguito di assegnazioni viritane a beneficio dei veterani di Nauloco (Keppie 1983, 71), o al più presto nel 43 a.C., come ringraziamento per l'esclusione del centro dal programma di deduzioni progettato dai triumviri (cf. App. BC 4.362).

174 Per il quadro completo si veda Sisani 2015, 80-101. 
alle coloniae di Vibinum ${ }^{175}$ e di Paestum, e in area campana, con i casi già analizzati di Herculaneum e Surrentum. Più in generale, l'intero settore risulta ampiamente interessato dalle iniziative di età cesariana, con le deduzioni coloniarie e le assegnazioni agrarie effettuate nel Sannio, in Lucania, in Apulia ${ }^{176}$-che coinvolsero direttamente, tra gli altri, i territori di Terventum, Aufidena e Ausculum ${ }^{177}$ - e forse in Irpinia. ${ }^{178}$

Se gli interventi graccani assicurano della diffusa presenza in queste aree di vaste porzioni di ager publicus, frutto verosimilmente delle confische attuate a seguito del conflitto annibalico, quelli sillani denunciano la dura repressione messa in atto dal dittatore nei riguardi di tutte quelle comunità -già pesantemente provate dalle conseguenze militari della guerra sociale- che durante la guerra civile si erano apertamente schierate, in particolare nel Sannio, con il partito mariano. ${ }^{179}$ Ciò che emerge da questi interventi, per i decenni a cavallo tra il II e il I sec. a.C., è dunque un quadro di progressiva e via via più profonda destrutturazione sociale e territoriale: ${ }^{180}$ ed è appunto alla luce di questo quadro che andrà spiegato il ritardo registrato in questi stessi settori dal processo di municipalizzazione, la cui ripresa - da fissare, virtualmente in tutti i casi, intorno alla metà del I sec. a.C.- può essere letta come il risvolto istituzionale di un vero e proprio programma di riqualificazione messo in atto da Cesare già a partire dal 59 a.C.

175 Cf. ora Silvestrini 2017, 13-18. Una precoce testimonianza epigrafica di questa deduzione -rinvenuta, in contesto di reimpiego, a pochi chilometri dall'area urbana di Ausculum- è costituita da CIL I 3186 (prima metà I sec. a.C.): [- - -]ridus, / [- - ] M.f. / IIvir(i) / [- - ]lum, tabern(as), portic(us) / [- - - de sua pecu]n(ia) coloneis Firman(is) / [deder]unt, dove la menzione dei coloni Firmani, più che indicare l'esistenza di una ulteriore colonia in quest'area, può essere intesa in riferimento allo stesso contingente coloniario vibinate.

176 Cf. Keppie 1983, 49-58: in questo settore si collocano le coloniae cesariane di Telesia e Grumentum (dedotte verosimilmente nel 59 a.C.) e di Bovianum (non anteriore al 47 a.C.), nonché le assegnazioni -attestate dal Liber Coloniarium e forse tutte da collegare alla legislazione agraria del 59 a.C.- effettuate lege Iulia o limitibus Iulianis nel Sannio (agri di Aesernia, Aufidena, Terventum) e in Apulia (agri di Arpi, Ausculum, Collatia, Herdoniae, Larinum, Salapia, Sipontum e area garganica).

177 Cf. LC 238 L.: Terventum, oppidum: ager eius (...) est adsignatus post tertiam obsidionem limitibus Iulianis; 259 L.: Aufidena, muro ducta: (...) milites eam lege Iulia sine colonis deduxerunt; 260 L.: Ager Ausculanus: lege Sempronia et Iulia est adsignatus.

178 Nel quadro delle iniziative promosse nel 59 a.C. potrebbe inserirsi l'eventuale rifondazione della colonia di Abellinum, dedotta certamente in età graccana (cf. Sisani 2015, 83-90), che almeno a partire dalla seconda metà del I sec. a.C. risulta retta da praetores duoviri: titolatura magistratuale ricorrente in Italia appunto nelle coloniae cesariane (a Grumentum, Privernum, Telesia). Analogamente al caso di Telesia, l'idea di una doppia deduzione può trovare un qualche sostegno in una epigrafe menzionante un duovir iure dicundo abellinate $-C I L$ IX 2118, ora perduta: Q. Vinius Q.f. Gal(eria) IIvir i(ure) d(icundo) Abellin[i] / Vini[ae] Q.f. sorori, / V[- - -] P. f. Tertiae matri, / [Q. Vinio -]f. Gal(eria) patri-che se risalente ai decenni iniziali del I sec. a.C. (cronologia non impropria per il supporto, decorato da un fregio dorico) potrebbe trasmettere l'originario assetto magistratuale della colonia: a fronte della provenienza eccentrica dell'iscrizione, rinvenuta in territorio beneventano, non si può tuttavia escludere che la resa del titolo sia qui più semplicemente calcata sulle magistrature coloniarie di Beneventum. Resta di lettura e cronologia incerte il bollo laterizio AE 2008, 333: P. Pl(- - -), Q. Her(- - -) /

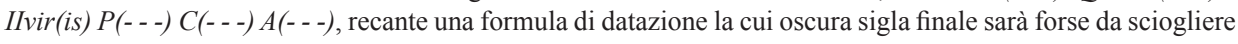
-piuttosto che in p(raetoribus) c(oloniae) A(bellinatium) - in p(ublicum) c(oloniae) A(bellinatium).

179 Santangelo 2007, 67-77.

180 Sull'aspetto demografico cf. Brunt $1987^{2}, 353-375$. 


\section{I municipia duovirali in Italia: le dinamiche storiche di un ritardo istituzionale}

Uno sguardo alla carta di distribuzione dei municipia duovirali (Fig. 1) permette di apprezzare con assoluta immediatezza il loro significativo addensarsi in un'area senza dubbio vasta ma in gran parte ricompresa all'interno dell'antico ager Romanus.

Si può anzi affermare che in questa parte della penisola il duovirato -attestato in una trentina di centri- rappresenta l'assetto amministrativo largamente più diffuso, a fronte del numero assai esiguo di municipia quattuorvirali: ciò vale, in particolare, per i settori più eccentrici, coincidenti con territori popolati dopo l'annessione da coloni viritani, laddove nelle aree di precoce municipalizzazione prevalgono come atteso forme magistratuali "anomale", che perpetuano -debitamente romanizzatele strutture della fase sovrana. Una volta ammesso il rapporto tra assetti duovirali e ritardo nella strutturazione municipale, le ragioni di questa diffusione risultano palesi: nelle aree coloniali il sistema delle praefecturae -impiantato a partire dai decenni finali del IV sec. a.C. e già al principio del II sec. a.C. esteso all'intero ager Romanus, ${ }^{181}$ ad eccezione delle aree più prossime a Roma-era risultato un espediente pienamente funzionale per la gestione dei territori periferici, tanto da sopravvivere almeno inizialmente alla ristrutturazione amministrativa attuata all'indomani della guerra sociale. ${ }^{182}$

In questi territori, complice il ritardo del processo di urbanizzazione, la legislazione municipale di età cinnana -riflessa dalle norme trasmesse dalla tabula Heracleensis- porta semmai alla codificazione di un nuovo tipo di praefecturae, che cessano di essere concepite come semplici distretti territoriali sottoposti all'autorità dei delegati del pretore, andando ora a coincidere direttamente con singole comunità paramunicipali dotate, al pari di municipia e coloniae, di organi amministrativi locali: ${ }^{183}$ la specificità di questa categoria istituzionale -implicata, in ultima analisi, dalla sua stessa denominazione- risiede nell'essere tali comunità ancora formalmente soggette alla iurisdictio pretoria, esercitata da praefecti ormai non più inviati da Roma ma nominati in loco, i quali tuttavia non costituiscono tecnicamente dei magistrati locali, discendendo la loro potestas non da elezione ma da una delega del pretore. In questa categoria di funzionari rientra senza dubbio il praefectus attestato a Casinum durante la fase finale della praefectura, ${ }^{184}$ la cui origo casinate è virtualmente certa ma che nulla obbliga ad intendere come un magistrato eletto localmente.

181 In connessione con la promozione all'optimum ius delle ultime comunità sine suffragio, da attribuire -come credo- alla censura del 189-188 a.C.: cf. Sisani 2021 b.

182 Cf. in questo senso già Laffi 2001 [1973], 121-122.

183 Cf. Sisani 2010, 175-181, e Sisani 2011a, 702-707.

184 CIL I ${ }^{2}$ 1543: [- - - ]t(- - -?) C. Futius / [- - - pra]ef(ectus) [C]asinat(ium). Si tratta certamente dello stesso personaggio menzionato in $C I L \mathrm{I}^{2} 1544$, relativa ad un monumento onorario -già smantellato entro la fine del I sec. a.C., a seguito verosimilmente di damnatio memoriae: cf. Molle 2016, 109-110- dedicatogli pubblicamente, in qualità di parens (scil. patronus) civitatis, dalla praefectura casinate. Data la convergenza delle due testimonianze, mi sembra francamente perverso continuare ad intendere questo praefectus come un semplice sostituto dei magistrati locali (come riproposto da Cerrone - Gallo 2016, 143-145). 


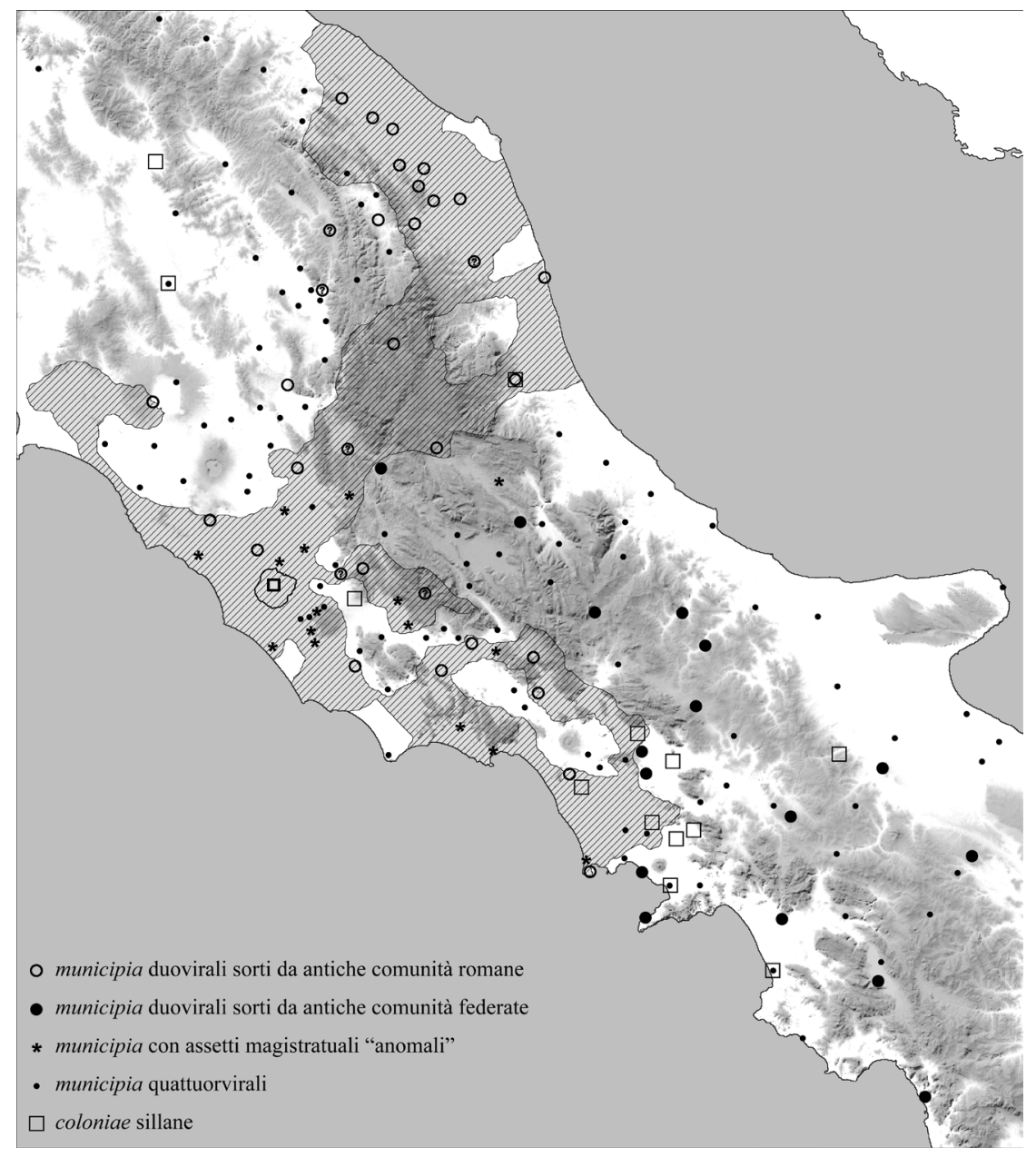

Fig. 1. Carta di distribuzione dei municipia con duovirato originario nell'Italia centrale e meridionale (il retino indica l'estensione dell'ager Romanus alla vigilia della seconda guerra punica).

La codificazione in età cinnana del nuovo assetto amministrativo della realtà municipale italica contemplava anche l'iniziale sopravvivenza di autonomie locali di rango inferiore quali fora e conciliabula, verosimilmente dipendenti a livello giurisdizionale e censitario da comunità vicine: si tratta, nuovamente, di categorie di centri diffuse principalmente all'intero dell'antico ager Romanus, dove esse rappresentano l'eredità dell'elementare forma di strutturazione di cui si erano nel tempo dotate le aree popolate da coloni viritani. Le norme della tabula Heracleensis relative a questi centri lasciano chiaramente intendere il carattere assolutamente parziale della loro autonomia, ${ }^{185}$ che possiamo immaginare in certo modo vincolata alle strutture amministrative delle municipalità maggiori. Una traccia di queste forme di subordinazione può essere colta, in area umbra, nell'apparente coesistenza

185 Sisani 2011a, 564-566, 581-586. 
intorno all'80-70 a.C. di un municipium e di una praefectura fulginati, secondo le informazioni -purtroppo frammentarie e decontestualizzate- trasmesse da Cicerone. ${ }^{186} \mathrm{Il}$ municipium di Fulginiae, regolarmente retto da quattuorviri, ${ }^{187}$ dovette essere costituito già all'indomani della guerra sociale: la contestuale esistenza di una praefectura in quest'area andrà spiegata alla luce della prossimità al centro di Forum Flaminii, il cui ritardo nello sviluppo di una compiuta autonomia poté renderne inizialmente necessaria l'aggregazione alla realtà municipale più vicina. Il caso sarebbe cioè analogo a quanto postulabile per il municipium di Peltuinum, ${ }^{188}$ polo amministrativo di una praefectura "tarda" (post guerra sociale) estesa a comprendere a fini censitari e giurisdizionali le comunità iunctae degli Aufinates e dei Vestini Cismontani, ${ }^{189}$ facenti capo ai conciliabula rispettivamente di Aufinum e di Aveia: un tipo di assetto senz'altro peculiare ma non del tutto isolato nel panorama dell'Italia municipale, come suggerisce il caso apparentemente analogo di Volcei. ${ }^{190}$

La funzionalità di questo assetto -basato sull'ampia diffusione, a fianco di municipia e coloniae, di comunità paramunicipali quali praefecturae, fora e conciliabula- è in ultima analisi assicurata dal suo perdurare fino almeno all'età cesariana, quando la ripresa del processo di municipalizzazione porterà nel giro di alcuni decenni alla scomparsa delle municipaità "minori", ora costituite a municipia dotati di organi magistratuali locali (duoviri) deputati all'esercizio della compiuta autonomia amministrativa. È pur vero che questo processo ebbe in qualche caso carattere maggiormente precoce, come fa sospettare l'esistenza anche in questo settore della penisola di municipia retti da quattuorviri, in quanto tali verosimilmente costituiti già in età pre-cesariana. ${ }^{191}$ Tolti $\mathrm{i}$ casi in cui tale assetto magistratuale viene eccezionalmente assunto, in discontinuità rispetto agli istituti di tradizione epicoria, in municipia nati prima della guerra sociale (Cures, Atella, Acerrae ed eventualmente Trebula Balliensis), all'interno dell'antico ager Romanus la diffusione del quattuorvirato pare limitata alle piccole comunità -come Bovillae, Castrimoenium e Labici- più prossime a Roma, forse prive in origine di una vera e propria autonomia municipale e ricadenti in un'area da sempre sottratta al regime delle praefecturae, al cui interno la giurisdizione era esercitata presso il tribunale centrale direttamente dal pretore: ${ }^{192}$ tale prassi doveva ormai risultare all'indomani della guerra sociale assai poco funzionale, tanto da suggerire la rapida autonomizzazione di questi centri, senza dubbio favorita dalle assegnazioni viritane attuate in quest'area durante l'età sillana.

Meno facili da giustificare sono gli esempi più eccentrici di tale precocità di sviluppi: è il caso, per altro apparentemente isolato, del municipium di Sentinum. Il centro,

186 Cic. Varen. frg. 4 P.: C. Ancharius Rufus fuit e municipio Fulginate; frg. 5 P.: [...] in praefectura Fulginate.

187 Cf. Zuddas 2019.

188 Sisani 2010, 188-191; Sisani 2011a, 586-591.

189 Cf. Plin. HN 3.107: Peltuinates quibus iunguntur Aufinates, Cismontani.

190 Plin. HN 3.98: Volcentani quibus Numestrani iunguntur. Alla luce della testimonianza pliniana, si può escludere che Numistro abbia mai assunto veste municipale, nonostante le suggestioni offerte dalle locali attestazioni di magistrati, che dovettero gerire la carica a Volcei (municipium quattuorvirale): è questo certamente il caso del quattuorvir di $A E$ 2009, 262 (fine I sec. d.C.), nonché eventualmente del magistrato attestato da CIL X 433 (II sec. d.C.), nota solo da tradizione antiquaria e malamente trascritta, dove la menzione del duovirato -del tutto inattesa: l'apparentemente convergente attestazione di un duovir Volceis nell'iscrizione puteolana CIL X 1809 andrà infatti spiegata postulando che la titolatura sia stata calcata su quella dei magistrati di Puteoli- è verosimilmente frutto di cattiva lettura.

191 Cf. infra, in appendice.

192 Cf. Sisani 2021b. 
collocato all'interno del comparto coloniale dell'ager Gallicus, dovette svilupparsi a partire dall'inizio del II sec. a.C., verosimilmente a seguito delle assegnazioni viritane a beneficio dei veterani della guerra annibalica, ${ }^{193}$ e contrariamente agli sviluppi più attesi assunse in età municipale un ordinamento quattuorvirale anziché duovirale, indice di una sua costituzione a municipium in età pre-cesariana. È difficile formulare ipotesi concrete sulle ragioni di tale precocità, nella quale si potrebbe forse leggere il riflesso istituzionale di una già realizzata strutturazione in senso urbano del centro, per altro direttamente testimoniata sul piano materiale dalla realizzazione nel corso dei decenni iniziali del I sec. a.C. di una cinta muraria monumentale: ${ }^{194}$ un tipo di intervento dalla forte valenza ideologica il quale, non casualmente, non vanta a questa quota cronologica alcun parallelo nell'area.

Nell'antico ager Romanus, la tendenzialmente tardiva trasformazione in municipia delle comunità locali era in fondo favorita dalla preesistenza in quest'area di una prassi come quella della iurisdictio mandata, già pienamente rodata durante l'età anteriore alla guerra sociale e che poté perpetuarsi con minimi aggiustamenti anche nel corso dei primi decenni del I sec. a.C. Diverso è il caso dei distretti federati, dove tale prassi non era evidentemente mai stata applicata e dove nondimeno l'esistenza di praefecturae "tarde" -posteriori cioè al 90 a.C.- è a mio avviso implicata appunto dalla diffusione anche in queste aree di municipia duovirali: mi pare infatti evidente, una volta ammesso che il duovirato come magistratura municipale è una innovazione di età cesariana, che nei centri naturalizzati a seguito della guerra sociale ma che risulteranno come municipia retti da duoviri si debba postulare una fase iniziale durante la quale il governo locale era affidato -in particolare sul piano della giurisdizione- ad altri funzionari. L'eventualità che si tratti, come nelle comunità sorte su antico ager Romanus, di praefecti nominati in loco dal pretore è ipotesi non solo astrattamente percorribile, ma che può contare sull'appoggio offerto da almeno due attestazioni epigrafiche pertinenti ai municipia duovirali di Aufidena ${ }^{195}$ e di Abellinum Protroporum ${ }^{196}$ (Frigento), entrambe databili nei decenni iniziali del I sec. a.C. -in epoca dunque certamente anteriore alla constitutio municipale dei due centrie menzionanti coppie di praefecti impegnati nella realizzazione di opere pubbliche. Mi pare francamente miope continuare ad intendere tali figure come semplici magistri paganico-vicani o come praefecti operi faciendo, categoria quest'ultima di fatto inesistente: ${ }^{197}$ si dovrà piuttosto identificarvi le coppie di funzionari locali incaricati della giurisdizione in questi centri durante la fase immediatamente anteriore alla loro promozione a municipia e alla conseguente introduzione del duovirato.

Una fase transitoria di questo tipo andrà evidentemente postulata per tutte le comunità rimaste federate fino alla guerra sociale che siano state costituite a municipia solo a partire dall'età cesariana, pur con il dubbio se tale parentesi paramunicipale sia il frutto di scelte maturate già in età cinnana-come probabilmente nel caso della res publica Aequiculorum e di Superaequum - o non piuttosto l'esito di uno sviluppo interrotto: l'esito cioè della riconversione a praefecturae di comunità inizialmente elevate a municipia e poi private della piena autonomia. Quest'ultima dinamica è

\footnotetext{
193 Sisani 2017, 187-188, 221-223.

194 CIL XI 5764: cf. Paci 2008.

195 CIL I2 1759: M. Caicilius L. f., / L. Atilius L.f. / praef(ecti) / pontem, peila[s] / faciundum / coerave[re].

196 CIL I² 1719: P. Maiu[s] M.f., / P. Allius M.f. / praef(ecti) solar(ium) f(aciundum) c(uraverint).

197 Cf. Sisani 2011a, 716-718.
} 
a mio avviso prospettabile almeno in relazione ai municipia sannitici di Fagifulae, Saepinum e Terventum, retti a partire dall'età cesariana da duoviri iure dicundo ma dove i magistrati con potestas edilitaria -secondo un ricorso apparentemente privo di paralleli nell'Italia centrale e meridionale- recano il titolo di quattuorviri (aediles), ${ }^{198}$ che potrebbe rappresentare l'eredità di una originaria fase quattuorvirale dei tre centri.

Questa eventualità-così come, più in generale, la distribuzione stessa dei municipia duovirali nati da antiche comunità federate, concentrati essenzialmente in area sannitica e lucana-spinge a postulare una frattura nel processo di municipalizzazione in queste aree da collegare con tutta evidenza alla durissima repressione messa in atto da Silla già negli anni della guerra sociale e nuovamente al ritorno dalla guerra mitridatica, quando la rappresaglia militare nei riguardi delle comunità schierate con il partito mariano si legò agli esiti profondamente destrutturanti prodotti dal programma di assegnazioni a beneficio dei veterani. È appunto in questo contesto che poterono attuarsi interventi di ridefinizione degli assetti istituzionali locali che andavano di fatto a stravolgere il programma elaborato in età cinnana: si pensi, ad esempio, all'adtributio di Calatia a Capua, che documenta una prassi prospettabile anche nei casi di Herculaneum e Surrentum, nonché eventualmente in quelli di Caiatia, Cubulteria, Ausculum ed Eburum, come suggerisce la prossimità di tutti questi centri -accomunati, appunto, dalla tardiva costituzione municipale- a coloniae dedotte con certezza o probabilità da Silla (Pompeii, Allifae, Telesia, Vibinum, Paestum). Non è per altro da escludere che gli interventi sillani abbiano prodotto analoghe ricadute anche in aree di antica municipalizzazione, ponendo eventualmente un freno agli sviluppi istituzionali di comunità quali ad esempio Casinum e Atina, entrambe praefecturae "tarde" e almeno la prima delle quali certamente coinvolta negli espropri compiuti al termine della guerra civile. ${ }^{199}$

Il risultato ultimo prodotto dalla destrutturazione sillana può essere ricostruito, ex post, a partire dalle scelte che guidarono la legislazione agraria del 59 a.C., cui va attribuita la ripresa del processo di municipalizzazione nell'Italia centrale e meridionale. La prima delle due leges Iuliae agrariae votate in quell'anno ${ }^{200}$ -elaborata principalmente, ma forse non esclusivamente, in funzione dei veterani di Pompeo e di Cecilio Metello- venne attuata grazie al sistematico recupero di terreni da destinare alle assegnazioni, operato anche tramite ricorso ad acquisti da privati in aree della penisola che all'epoca risultavano ormai spopolate. ${ }^{201}$ Quali fossero queste aree è facilmente deducibile proprio dalla distribuzione dei municipia costituiti in età cesariana, la cui strutturazione può essere letta come una diretta conseguenza della legislazione del 59 a.C., che certamente contemplava-oltre alla deduzione di vere e proprie coloniae - anche la costituzione di nuove realtà municipali. ${ }^{202}$

Per quanto attiene ai distretti anticamente federati, è difficile non cogliere un legame tra questi interventi e quanto prospettato per i decenni iniziali del I sec. a.C. da Strabone, che attingendo verosimilmente a Posidonio parla delle comunità

\footnotetext{
Degrassi 1962 [1949], 154-155.

99 Cf. Cic. Leg. Agr. 3.10-14.

200 Fonti e discussione in De Ruggiero 1892, 865-878; Brunt 1987², 312-319; Gruen 1995², 397-404.

201 Esplicitamente in questo senso D.C. 38.1.3.

202 Come si ricava dalle norme trasmesse dal corpus gromatico (263-266 L.) sotto la titolatura di lex Mamilia Roscia Peducaea Alliena Fabia, dalle quali emerge la possibilità, per i commissari incaricati delle assegnazioni agrarie, di colonias deducere e di municipia praefecturas fora conciliabula constituere. Per l'attribuzione di queste norme ad una delle due leges Iuliae agrariae del 59 a.C. si veda ora Crawford 1989.
} 
sannitiche come di realtà ormai ridotte, dopo la repressione sillana, a semplici vici: ${ }^{203}$ alludendo con ciò non solo all'effimera consistenza insediativa di questi centri, ma anche al loro mancato sviluppo in termini di strutturazione amministrativa. A fronte di questo quadro, è evidente come le iniziative cesariane possano essere lette come un globale intervento di riqualificazione demografica e istituzionale di vaste aree della penisola il quale, se nel caso in particolare dell'antico ager Romanus portò semplicemente a pieno compimento l'originario progetto di municipalizzazione elaborato in età cinnana, almeno nell'Italia meridionale andò anche di fatto a sanare le ferite prodottesi durante l'età sillana.

In termini di strutture amministrative locali, tale intervento si accompagnò all'elaborazione di una nuova forma municipale caratterizzata dal ricorso al duovirato come assetto magistratuale tipico, ${ }^{204}$ formalmente analogo a quello che aveva fino ad allora caratterizzato le sole comunità coloniarie ed ora per la prima volta sistematicamente esteso anche ai neo-costituiti municipia. Tale circostanza invita ad un'ultima riflessione, vertente proprio sulle ragioni di questa scelta, da ricercare in una differenziazione tra quattuorvirato e duovirato che non può evidentemente ridursi a mera questione di titolatura, ma che dovrà piuttosto avere carattere sostanziale.

La distinzione tra $i$ due assetti magistratuali risiedeva in primo luogo nel diverso modo di creazione: ${ }^{205}$ se nel caso del collegio dei quattuorviri l'elezione avveniva congiuntamente per tutti e quattro i magistrati e la ripartizione tra la funzione giurisdicente e quella edilitaria era operata tra gli eletti tramite sorteggio o accordi interni, il duovirato si presentava già in fase di candidatura rigidamente bipartito nei due collegi iure dicundo e aedilicia potestate, ciascuno eletto separatamente. In tali condizioni, è evidente come il modello duovirale dovesse risultare la scelta più naturale nei casi in cui il conferimento della piena autonimia amministrativa si traduceva essenzialmente nell'introduzione, a fianco di preesistenti magistrati locali aventi competenze limitate all'ordinaria amministrazione, di collegi giurisdicenti eletti in loco, che andavano ad assumere le funzioni prima rivestite dai delegati del pretore: è senz'altro questa la dinamica prospettabile per gli sviluppi del duovirato coloniario, ${ }^{206}$ da estendere per analogia anche al caso dei municipia "tardi".

$\mathrm{Al}$ di là di questo aspetto, non è però escluso che dietro questa scelta si celino anche ragioni più profonde, inerenti le stesse forme di esercizio dell'autonomia locale. Occorre innanzi tutto sgombrare il campo da quello che a me appare come un autentico fraintendimento: l'idea, cioè, che il duovirato municipale si sia imposto perché struttura "più snella e funzionale". ${ }^{207} \mathrm{E}$ infatti chiaro che, in quanto a snellezza, l'ordinamento quattuorvirale presentasse maggiori vantaggi ad esempio sul piano della semplificazione delle procedure elettorali: si trattava, in ultima analisi, del modello magistratuale più elementare, per altro ben sperimentato fin dall'età cinnana

203 Str. 5.4.11. Cf. Soricelli 2017, 98-99.

204 La tipicità di questo assetto a partire dall'età cesariana è testimoniata dal ricorso alla definizione di duoviri per indicare genericamente i magistrati municipali, quale si riscontra in Caes. Civ. 1.30.1: Itaque in praesentia Pompei sequendi rationem omittit, in Hispaniam proficisci constituit, duumviris municipiorum omnium imperat, ut naves conquirant Brundisiumque deducendas curent. Si tratta della più antica menzione letteraria di tali figure, tanto più significativa in quanto riferibile ad un contesto geografico come quello apulo dove $\mathrm{i}$ municipia sembrerebbero in massima parte retti da quattuorviri.

205 In merito a queste procedure si veda Laffi 2007 [2006], 53-55.

206 Cf. Sisani 2018, 64-67.

207 In questi termini Laffi 2007 [2006], 55. 
e che appunto per questo avrebbe potuto essere esteso senza difficoltà anche ai nuovi municipia. Mi chiedo allora se col tempo l'assetto duovirale non sia stato preferito per le intrinseche possibilità che esso offriva ai fini della fissazione di un vero e proprio cursus honorum anche in ambito locale. Se nel caso dei quattuorviri le qualifiche per la candidatura dovevano evidentemente essere le stesse per tutte e quattro le posizioni, indipendentemente dalle specifiche funzioni che gli eletti avrebbero rivestito una volta costituiti i due sottocollegi, il duovirato nel suo complesso si configurava propriamente come la somma di due magistrature distinte e separate: una circostanza che avrebbe potuto permettere la diversificazione dei criteri di eleggibilità valevoli per le due coppie magistratuali, eventualmente riservando la possibilità di candidarsi al duovirato giurisdicente solo a quanti avessero precedentemente gerito l'edilità.

È pur vero che della effettiva vigenza di tale prassi, sul piano teoretico del tutto ammissibile, non è possibile rintracciare né nelle fonti giuridiche né nella documentazione epigrafica prove certe, ${ }^{208}$ e tuttavia una sua lontana eco può forse cogliersi nella legislazione flavia dei municipia Latina delle province iberiche, anch'essi retti da ordinamenti duovirali, dove parrebbero in effetti contemplati distinti requisiti di eliggibilità per duoviri iure dicundo, aediles e quaestores. ${ }^{209}$

\section{Appendice: attestazioni "anomale" del quattuorvirato}

In appendice a questo contributo, non pare inopportuno analizzare tutte quelle attestazioni del quattuorvirato che possono a buon diritto risultare "anomale", perché relative a centri nei quali sarebbe lecito attendersi un diverso assetto magistratuale: di marca epicoria nei municipia costituiti già in età anteriore alla guerra sociale, di marca duovirale nei municipia post-cesariani e nelle coloniae civium Romanorum dedotte nel corso del I sec. a.C.

Comincerò da questi ultimi casi, che la dottrina non considera in verità anomalie, ma semplici eccezioni alla regola - che resta statisticamente valida - in base alla quale le coloniae di diritto romano, sia quelle fondate ex novo sia quelle succedute a precedenti municipia, dovrebbero sempre risultare rette da duoviri. ${ }^{210}$ Non vi è

208 Si veda in ogni caso quanto affermato in termini generali, relativamente agli honores municipali, da Callistr. Dig. 50.4.14.5: Gerendorum honorum non promiscua facultas est, sed ordo certus huic rei adhibitus est. Nam neque prius maiorem magistratum quisquam, nisi minorem susceperit, gerere potest, neque ab omni aetate, neque continuare quisque honores potest. Su questo aspetto, a partire dall'analisi dei programmata elettorali pompeiani, cf. Lo Cascio 1996, 112-116.

209 Come suggerisce il dettato del cap. 54 della lex Malacitana (cf. Rodríguez Neila 1978), dove si allude all'appartenenza a specifici genera hominum come condizione necessaria per candidarsi rispettivamente al duovirato iure dicundo, all'edilità e alla questura, con l'ulteriore limitazione imposta nel primo caso dal divieto di reiterare la stessa carica nell'arco di un quinquennio.

210 Una ulteriore eccezione è rappresentata dai centri a statuto coloniario che a partire dal I sec. a.C. risultano retti da praetores: un tratto caratteristico delle antiche coloniae civium Romanorum di area adriatica (Auximum, Castrum Novum, Potentia, Urbs Salvia), documentato anche nel caso dell'effimera deduzione coloniaria a Capua dell'83 a.C. (cf. Cic. Leg. Agr. 2.92); è invece a mio avviso da escludere il caso di Ostia, regolarmente retta da duoviri, dove l'isolata e cronologicamente risalente attestazione di praetores (AE 1983, 174: della fine del II sec. a.C.) va intesa in riferimento non a magistrati cittadini ma a sacerdoti (praetores Volkani). Ha praetores anche la colonia di Cumae, promossa nel corso dell'età imperiale (forse sotto Domiziano, e comunque entro l'età severiana): ma in questo caso la scelta -secondo un ricorso a mia conoscenza unico-si pone in chiara continuità con le istituzioni del precedente municipium (cf. Camodeca 2010a, 66-69, e Camodeca 2010b, 224- 
dubbio, infatti, che alcuni centri a statuto coloniario abbiano un assetto magistratuale di marca quattuorvirale: ${ }^{211}$ resta tuttavia aperta la questione se una tale soluzione, ben attestata in ambito provinciale, vanti effettivamente -al di fuori dei casi di Aquileia e di Parentium, almeno il primo dei quali assolutamente certo-qualche esempio anche in Italia. È quanto è stato postulato, segnatamente, in relazione alle coloniae di Sora, Teanum Sidicinum, Nola, Capua, Falerii Novi, Volaterrae e Fanum Fortunae. ${ }^{212}$

Relativamente a Sora, Teanum Sidicinum e Nola, va innanzi tutto rimarcato che le coloniae dedotte in loco, tutte succedute a precedenti municipia, documentano con certezza ordinamento duovirale: le testimonianze che potrebbero suggerire la sopravvivenza del precedente assetto quattuorvirale di marca municipale si riducono a singole attestazioni epigrafiche, di cronologia assai prossima all'epoca della deduzione. Almeno a Sora (colonia triumvirale) ${ }^{213}$ e a Teanum Sidicinum (colonia augustea), ${ }^{214}$ la natura dei documenti impedisce di fatto di appurare se i quattuorviri ivi menzionati abbiano gerito la carica negli ultimi anni del municipium o nei primi anni dalla deduzione coloniaria. Diverso è il caso di Nola, dedotta verosimilmente già in età sillana e successivamente rifondata in età augustea, ${ }^{215}$ dove l'unica attestazione

226). La titolatura “ibrida” di praetores duoviri (documentata ad Abellinum, Grumentum, Privernum e Telesia) parrebbe invece caratteristica in Italia delle coloniae fondate (o rifondate) in virtù della prima delle due leges Iuliae agrariae del 59 a.C.; una matrice cesariana è per altro postulabile anche per le occorrenze del titolo -tutte risalenti ad età pre-augustea-nelle coloniae provinciali di Narbo Martius (CIL XII 4338, 4420, 4428) e Lepida Celsa (RPC I 261-264), dedotte su progetto del dittatore negli anni a cavallo del 44 a.C., dove in ogni caso esso risulterà ben presto sostituito da quello canonico di duoviri.

211 Si veda Laffi 2007 [2002], con censimento di tutte le attestazioni: da escludere il caso di Tingi, municipium triumvirale retto da quattuorviri, che acquisirà statuto coloniario - e assetto duovirale- solo in età claudia (cf. ora Bernard - Callegarin 2017). Non rientra in questa casistica Pompeii, dal momento che le locali attestazioni del quattuorvirato sono relative da un lato alla brevissima fase municipale che precedette la deduzione sillana (nei programmata elettorali in lingua osca ST Po 40-50: cf. Crawford 2008), dall'altro alla prima fase coloniaria, in iscrizioni menzionanti interi collegi magistratuali di duoviri iure dicundo e duoviri aedilicia potestate collettivamente definiti come quattuorviri (CIL I² 1630, 1631: cf. Degrassi 1962 [1949], 107-108): quest'ultimo uso -ben attestato in ambito provinciale: cf. Sisani 2018, 42, nota 3- vanta in Italia un ulteriore esempio a Falerio (CIL IX 5420); così anche nel rescritto diretto da Alessandro Severo ai quattuorviri et decuriones Fabraternorum trasmesso da Cod. Iust. 11.40.

212 Escludo il caso di Asculum, cui si è preteso di attribuire una isolata attestazione del quattuorvirato sulla base dell'iscrizione nursina CIL IX 4547 (nota solo da tradizione manoscritta): T. Septimio T. f. [- - -] / Blasto VIII[vir(o)] / IIvir(ali) pot(estate) IIII[- - -] / coloniae A[- - -]/lanorum (etc.), dove l'integrazione IIII[vir(o)] coloniae A[scu]lanorum è del tutto ipotetica: giusta la correttezza della trascrizione, si potrebbe piuttosto intendere VIII[vir(o)] IIvir(ali) pot(estate) IIII, [aed(ili)] coloniae A[scu]lanorum, o in alternativa leggere VIII[vir(o)] IIvir(ali) pot(estate) II, II[vir(o)] coloniae A[scu]lanorum.

213 CIL X 5713 (età triumvirale): L. Firmio L.f. / prim(o) pil(o), tr(ibuno) mil(itum), / IIIIvir(o) i(ure) d(icundo), / colonia deducta / prim(o) pontifici / legio IIII Sorana / honoris et virtutis caussa. L'impaginato dell'iscrizione -che evidenzia in corpo maggiore le prime tre linee di testo, di fatto isolandole da ciò che segue- spinge decisamente a collegare l'indicazione temporale colonia deducta non al quattuorvirato (come pretende Solin 2014, 116-124) ma al pontificato. Sulla storia amministrativa di Sora si veda Solin 2014: va certamente riferita alla fase del municipium una seconda attestazione del quattuorvirato (AE 1985, 266: cf. Solin 2014, 124-125), risalente al pieno I sec. a.C.

214 AE 1908, 218 (età proto-augustea): [-] Satrius N. f. Ter(etina) Ruf[us] / [t]r(ibunus) mil(itum) a popul[o], / [I]IIIvir iur(e) dic(undo), qu[inq(uennalis)] (etc.). Sull'insieme della documentazione epigrafica si veda Camodeca 2008 [2007]: le altre attestazioni del quattuorvirato sono tutte -con buona pace del Camodeca-di età repubblicana (CIL X 4796, 4798; $A E$ 1993, 493), ad eccezione di EphEp VIII 575, rinvenuta in una località del territorio e verosimilmente da attribuire a Cales.

215 Sugli sviluppi istituzionali del centro cf. Camodeca 2012. La colonia fu anche in questo caso preceduta da un municipium, come attesta Paul. Fest. 155 L. 
di un quattuorvir sembrerebbe in effetti appartenere alla prima fase coloniaria:216 a meno di non intendere il titolo come sinonimo di aedilis ${ }^{217}$ si dovrà concludere che la colonia abbia mantenuto per brevissimo tempo l'assetto magistratuale del precedente municipium, poi sostituito dal canonico duovirato. ${ }^{218}$

Più complesso è il caso di Capua, dedotta nel 59 a.C. senza essere preceduta da alcun municipium, dal momento che fino a quella data il centro rimase nella condizione di praefectura. L'assetto magistratuale assunto dopo la deduzione è quello duovirale, documentato già a partire dall'età cesariana, ${ }^{219}$ epoca alla quale è possibile far risalire anche una isolata attestazione epigrafica del quattuorvirato. ${ }^{220}$ La mancanza di un precedente municipale impedisce in questo caso di postulare una iniziale continuità delle magistrature locali di età anteriore alla deduzione: si potrebbe al limite pensare ad una fase transitoria, anteriore al confezionamento dello statuto locale e alla conseguente introduzione del duovirato, ma non è da escludere che la carica sia stata gerita in altro centro, la cui menzione avrebbe potuto figurare nelle parti perdute del testo.

L'esempio apparentemente più sicuro di mantenimento del quattuorvirato in una colonia succeduta a un precedente municipium è quello di Falerii, che documenta assetto quattuorvirale fino almeno al II sec. d.C., ma dove in ogni caso si registra anche una isolata attestazione del duovirato risalente alla prima età imperiale. ${ }^{221}$ Come si è già visto, l'ipotesi di una colonia retta da quattuorviri discende in questo caso unicamente dall'aver confuso testimonianze relative a comunità distinte: quella di Falerii Novi, che resta municipium (retto da quattuorviri) fino all'età di Gallieno, e quella di Faliscum, colonia (retta da duoviri) dedotta nel sito di Falerii Veteres in età triumvirale.

Per quanto riguarda Volaterrae, un frustulo epigrafico di recente rinvenimento ne attesta statuto coloniario, con il titolo di Colonia [- - - ] Augusta. ${ }^{222}$ Il centro, ancora municipium nel 46 a.C., ${ }^{223}$ venne dunque elevato a colonia nel corso dell'età imperiale: certamente in età post-augustea, come assicura la mancata menzione di tale deduzione in Plinio. Il cambio statutario non ha apparentemente lasciato tracce a livello di assetto magistratuale, dal momento che la documentazione epigrafica restituisce unicamente menzioni di quattuorviri, da riferire evidentemente alla

216 CIL I 3127 (nota solo da tradizione manoscritta, ma apparentemente databile nella prima metà del I sec. a.C.): C. Catius M. f. IIIIvir campum publice / aequandum curavit, maceriem / et scholas et solarium, semitam / de s(ua) p(ecunia) f(aciunda) c(uravit) / Genio coloniae et colonorum / honoris causa / quod perpetuo feliciter utantur.

217 Così Degrassi 1962 [1949], 106-107: ma quest'uso -ben attestato in ambito provinciale: cf. Sisani 2018, 42, nota 3- non conosce esempi certi in Italia se non nella Cisalpina (nelle coloniae di Augusta Taurinorum e Mediolanum e nei municipia di Bellunum, Industria e Veleia), con l'unica eccezione rappresentata dai quattuorviri (aedilicia potestate) dei municipia duovirali di Fagifulae, Saepinum e Terventum.

218 Già attestato a Nola nel pieno I sec. a.C. (CIL I I 1619-1620: cf. EDR 156881 e 80832).

219 CIL I 1620 (cf. EDR 80832), da Puteoli: N. Cluvius M'.f. duumvir / Nolae, IIIIvir quinq(uennalis) C[- - -], / duumvir qu[inq(uennalis)] / Kapuae ma+[- - -].

220 CIL X 3921: [- - -] Fal(erna) Quartus IIIIvir [- - -?] / [- - -] us L.f. Fal(erna). Le altre attestazioni di quattuorviri attribuite in letteratura a Capua o sono frutto di lettura errata o sono pertinenti ad altri centri: cf. Solin 2014, $120-121$.

$221 \quad A E 1990,342$.

${ }_{222}$ AE 1994, 612: - - - - - / colonia [- - - / Aug(usta) Vol[- - -]. Cf. Munzi - Terrenato 1994, che postulano una prima deduzione di età triumvirale, unicamente sulla base dell'ipotesi di integrazione colonia [Iul(ia)] Aug(usta), niente affatto obbligata.

223 Cf. Cic. Fam. 13.4.1-2. 
precedente fase municipale e tutte in ogni caso concentrate in età cesariano-augustea, con una isolata attestazione di II sec. d.C. ${ }^{224}$ che per altro -stante la provenienza decisamente eccentrica dell'iscrizione- potrebbe essere pertinente ad altro centro. ${ }^{225}$

Resta infine il caso di Fanum Fortunae, ${ }^{26}$ verosimilmente nato come conciliabulum alla fine del III sec. a.C. in connessione con le assegnazioni viritane nell'ager Gallicus del 232 a.C. Il centro venne elevato a colonia in età triumviraleaugustea, ${ }^{227}$ sebbene non sia a mio avviso da escludere che una prima deduzione possa aver avuto luogo già in età cesariana. ${ }^{228}$ La documentazione epigrafica locale non restituisce menzioni certe di duoviri: ${ }^{229}$ è per contro nota almeno una attestazione relativa ad un quattuorvir risalente alla piena età imperiale, ${ }^{230}$ della quale tuttavia si è recentemente sospettata con buoni argomenti una possibile provenienza aliena. ${ }^{231}$ Esclusa questa attestazione, resta una seconda e più antica testimonianza epigrafica, risalente alla seconda metà del I sec. a.C. e certamente di provenienza locale, nella quale si è voluta rintracciare una ulteriore menzione del quattuorvirato. ${ }^{232}$ Anche in considerazione delle oggettive difficoltà sollevate dalle letture finora proposte, non sono tuttavia affatto certo che il testo sia realmente relativo ad un quattuorvir: vi vedrei piuttosto la menzione di un triumvir, intendendo l'iscrizione -coerentemente con tutti gli elementi in essa contenuti- come una dedica ad Ottaviano. ${ }^{233}$ Giusto quanto si è venuto illustrando, il centro di Fanum Fortunae resterebbe privo di attestazioni magistratuali: il che chiaramente non impedisce di postulare che la colonia sia stata retta, come di norma, da duoviri.

In conclusione, le uniche coloniae in Italia rette da ordinamenti quattuorvirali sembrerebbero essere quelle di Aquileia (triumvirale/augustea) ${ }^{234}$ e di Parentium (verosimilmente post-augustea): ${ }^{235}$ e non sarà allora casuale che entrambi questi

$224 A E$ 1982, 356. Cf. Pack 1981: l'iscrizione proviene dall'area della villa romana in loc. S. Vincenzino (Cecina), lungo la via Aurelia.

225 Segnatamente alla comunità dei Subertani (cf. Plin. HN 3.52), tuttora non identificata ma forse da localizzare -come suggerisce la toponomastica- in corrispondenza dell'odierna Suvereto, non distante dal luogo di rinvenimento dell'iscrizione.

226 Cf. Paci 2004.

227 Keppie 1983, 184-185.

228 È quanto porta a credere la menzione del centro in Pomponio Mela (2.64: Fanestris colonia), che ne rimarca la veste coloniaria. Si tenga conto che nella descrizione dell'Italia e dell'Illirico il geografo attinge -apparentemente senza aggiornarlo- ad un periplo certamente anteriore al 42-41 a.C. (Silberman 1988, xxxxliii): la fonte utilizzata -Cornelio Nepote?- ignora infatti sia lo spostamento del confine italico dal corso del Timavo a quello del Formione sia l'accorpamento all'Italia della provincia della Gallia Cisalpina (cf. Sisani 2017, 126, nota 113). In questa sezione dell'opera la notazione relativa a Fanum Fortunae costituirebbe, di fatto, l'unico dettaglio storico eventualmente successivo a tale data: una circostanza in se stessa singolare che mal si concilia, tra l'altro, con il fatto che le poche altre colonie italiche menzionate come tali sono o fondazioni "storiche" (Bononia, Mutina) o deduzioni cesariane (Pola: cf. Sisani 2017, 125-129).

229 Hanno tutte carattere frammentario le iscrizioni menzionanti magistrati locali CIL XI 6221 e EDR 15928.

$230 \quad A E 1993,623$.

231 Cf. Baldelli 2007, che postula una provenienza da Ravenna del manufatto.

232 AE 1983, 379 (reimpiegata nei sotterranei del locale convento di S. Agostino): [-] Caesarid[- - -] / IIIIvir R [- - -] / P. Scantiu [s - - -], secondo la lettura proposta dall'ultimo editore (cf. EDR 79140).

233 A fronte dell'inesistenza di gentilizi quali Caesaridius o Caesaridenus e dell'apparente mancanza sulla pietra della quarta asta nella stringa IIIIVIR, il testo andrà restituito in questa forma: [Imp(eratori)] Caesari D[ivif. - - -] /IIIvir(o) r(ei) [p(ublicae) c(onstituendae) - - - / P. Scantiu[s - - -]. Su questa nuova proposta di lettura -frutto di un accurato esame autoptico e che ritengo ragionevolmente certa- cf. Sisani 2021a.

234 Laffi 2001 [1987], 155-170.

235 Sisani 2017, 129-130. Si vedano, in ogni caso, i dubbi recentemente espressi da Matijašić 2016 in merito alla 
centri sorgano in un'area solo tardivamente inclusa, tra il 42-41 e il 18-12 a.C., entro i confini italici. Di fatto, nel resto d'Italia, le coloniae dedotte nel corso del I sec. a.C. risultano rette senza eccezioni da duoviri: le isolate e cronologicamente risalenti attestazioni di quattuorviri coloniali -a Nola, nonché eventualmente a Sora, Teanum Sidicinum e (con maggiore incertezza) Capua- sono tutte relative al brevissimo intervallo tra la deduzione e l'entrata in vigore dello statuto locale.

Per quanto riguarda i municipia anteriori alla guerra sociale, i casi di assunzione del quattuorvirato rappresentano una anomalia solo se si accoglie supinamente il paradigma "continuista" in base al quale nelle comunità di precoce naturalizzazione la conservazione della struttura magistratuale della fase sovrana è regola ferrea. ${ }^{236}$ Non voglio insistere sulla intrinseca debolezza di questo assunto, la cui meccanica applicazione ha condotto ad intendere in termini di continuità -in base ad un ragionamento che altro non è se non un classico esempio di petitio principii- anche alcune attestazioni del duovirato: ad esempio quelle di Trebula Suffenas, Atina e Casinum. Il paradigma va in realtà riformulato in termini più sfumati: è senz'altro vero che per tutti i municipia i quali conservano magistrature superiori di marca palesemente epicoria ${ }^{237}$-dittatura unica (Aricia, Caere, Lanuvium) o collegiale (Fidenae, ${ }^{238}$ Nomentum), pretura unica (Capena) o collegiale (Anagnia, Capitulum Hernicum, Cumae, Lavinium), edilità duplice (Tusculum) o triplice (Arpinum, Formiae, Fundi)- si deve postulare una constitutio in età anteriore alla guerra sociale, ma è altrettanto vero che nelle comunità di vecchi cives le quali siano rimaste praefecturae fino all'età cesariana la tardiva trasformazione in municipia non conduce al recupero delle forme magistratuali della precedente fase sovrana, adeguandosi invece all'ormai canonico schema duovirale. Si può inoltre affermare che almeno in alcuni casi la discontinuità rispetto agli istituti di tradizione locale ha carattere maggiormente precoce, traducendosi fin dagli anni subito successivi al 90 a.C. nell'assunzione di regolari assetti quattuorvirali.

È questo, apparentemente, il caso di Cures Sabini, la cui constitutio a municipium deve con tutta evidenza risalire già al 290 a.C., al momento stesso della concessione della civitas sine suffragio (dal 268 a.C. optimo iure) ai Sabini. ${ }^{239}$ Il quattuorvirato è attestato epigraficamente a partire dall'età neroniana ${ }^{240}$ e fino almeno all'inizio del III sec. d.C. ${ }^{241}$ Tale assetto, di norma ritenuto il prodotto di una fantomatica

possibile provenienza aliena delle iscrizioni parenzane con menzione di quattuorviri (AE 1966, 145-146).

236 Il paradigma della continuità tra gli istituti della fase sovrana e quelli municipali è alla base dello studio di Letta 1979, i cui postulati sono ora ribaditi - con qualche aggiustamento- in Letta 2017.

237 Censimento in Letta 1979, 34-42: da escludere i supposti municipia retti da praetores di Suessula (dove la pretura locale, semplicemente, non vanta alcuna attestazione) e di Velitrae (il praetor di CIL X 6554 non è infatti un magistrato cittadino ma un praetor iuventutis: cf. Panciera 2006 [1960]). Non vanno evidentemente considerati di tradizione epicoria né gli assetti magistratuali di Trebula Mutuesca (octoviri) e di Peltuinum (praefecti iure dicundo ed aediles), non omologati allo schema quattuorvirale/duovirale ma di marca chiaramente romana,

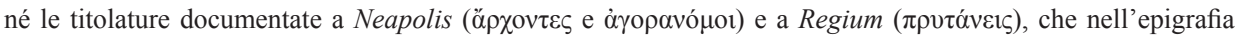
pubblica in lingua greca dei due municipia mascherano l'allusione a regolari collegi quattuorvirali (cf. Sartori 1953, 48-55, 136-142), come assicurano le contestuali attestazioni nel primo caso di un collegio di $\tau \varepsilon ́ \sigma \sigma \alpha \rho \varepsilon \varsigma$

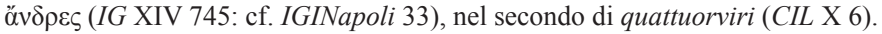

238 Sul caso di Fidenae -dove sono attestati, ma in età verosimilmente anteriore alla guerra sociale, anche duoviri (CIL I $\mathrm{I}^{2}$ 1502, 2664)- cf. Sisani 2018, 65-66.

239 Humbert 1978, 233-235.

240 CIL IX 4968.

${ }^{241}$ CIL IX 4958, 4970, 4972, 4975, 4976, 4978. 
"evoluzione" da altra forma magistratuale, ${ }^{242}$ dovette a mio avviso essere assunto già al principio del I sec. a.C., quando al centro -per altro apparentemente mai inquadrato nel sistema delle praefecturae-poté essere riconosciuta piena autonomia giurisdizionale, svincolata dalla soggezione alla iurisdictio pretoria che in origine, nel caso delle comunità romane più prossime all'Urbe, doveva essere amministrata direttamente presso il tribunale centrale. ${ }^{243}$

Gli stessi sviluppi sono postulabili anche per le piccole comunità latine di Bovillae, Castrimoenium e Labici, certamente incluse nell'ager Romanus al più tardi dal 338 a.C. e anch'esse rette in età municipale da quattuorviri. ${ }^{244}$ In questi casi, tuttavia, è possibile che la constitutio municipale - già realizzatasi entro il 54 a.C. ${ }^{245}$ - giunga a pieno compimento solo negli anni subito successivi alla guerra sociale, come fanno sospettare le notizie relative agli interventi sillani in quest'area, ${ }^{246}$ apparentemente collegati al programma di assegnazioni viritane a beneficio di veterani, che poterono condurre alla nascita di nuovi municipia in settori dell'ager Romanus fino ad allora privi di un assetto istituzionale pienamente definito e forse originariamente subordinati alle strutture amministrative di comunità vicine (Aricia e Tusculum).

Ulteriori esempi sono quelli di Atella e di Acerrae, comunità che ottennero la cittadinanza romana (inizialmente sine suffragio) rispettivamente nel 334 e nel 332 a.C. ${ }^{247}$ e che vennero successivamente incluse -a partire al più tardi dal 211 a.C.- nella praefectura campana. ${ }^{248}$ L'assetto magistratuale dei due centri, di marca quattuorvirale, è documentato da isolate attestazioni epigrafiche risalenti ad età imperiale. ${ }^{249}$ È difficile credere che in entrambi i casi il quattuorvirato sia subentrato -secondo un ricorso, come vedremo, affatto inusuale- ad un originario assetto magistratuale di marca duovirale o eventualmente epicoria: tanto più che tra le comunità ricadenti nella praefectura campana solo per Cumae (retta da praetores) è dimostrabile la continuità con le magistrature della fase sovrana, mentre la precoce elevazione degli altri centri a coloniae -Suessula verosimilmente in età sillana, ${ }^{250}$ Capua nel 59 a.C., Casilinum e Calatia tra il 47 e il 44 a.C. ${ }^{251}$ - ci priva di

242 Come postulato da Letta 1979, 46-47: sulla debolezza di questa ipotesi cf. Sisani 2010, 215-219.

243 Su questo aspetto rimando nuovamente a Sisani $2021 \mathrm{~b}$.

244 Bovillae: CIL XIV 2413; CIL VI 1851. Castrimoenium: CIL XIV 2454. Labici: AE 1900, 133.

245 Cf., in relazione a Bovillae e a Labici, Cic. Planc. 23.

246 LC 230 L.: Aricia, oppidum: lege Sullana est munita (...) ager eius in praecisuris est adsignatus; 231 L.: Bovillae, oppidum: lege Sullana est circumducta (...) agrum eius ex occupatione milites veterani tenuerunt in sorte; 233 L.: Castrimoenium, oppidum: lege Sullana est munitum (...) ager eius ex occupatione tenebatur; 238 L.: Tusculi oppidum muro ductum: (...) ager eius mensura Sullana est adsignatus. Cf. Laffi 2001 [1973], 121122.

247 Humbert 1978, 195-204.

248 Cf. Fest. 262 L. Sulla nascita della praefectura si veda ora Sisani 2021b.

249 CIL X 3736, da Atella (nota solo da tradizione manoscritta e apparentemente da datare nella prima età imperiale): Cn. Monnio Cn. [f.] Tro(mentina) C[ele]ri, v(ixit) a(nnis) XXI, / [in se]n(atum) copt(ato) Atella[e], / [pro?] III[I]viro praef(ecto) / [M]onnia Rufa mater, / C[n.] Monnius Cn. l. Faustus. CIL X 3759, da Acerrae (III sec. d.C.): Gn. Stennio Egnatio Gn. Stenni / Egnati Rufi fil(io) Fal(erna) Primo IIIIvir(o) / II q(uin)q(uennali) (etc.).

250 Lo statuto coloniario, pur se non altrimenti attestato, è ricavabile da LC 237 L.: Suessula, oppidum muro ductum: lege Sullana est deducta, ager eius veteranis limitibus Sullanis in ingeribus est adsignatus, ed è confermato dall'assunzione di un assetto magistratuale di marca duovirale (documentato, in ogni caso, solo per l'età imperiale: $C I L$ X 3764, 3765). Non prova la condizione municipale del centro una iscrizione inedita (notizia in Camodeca 2017, 55, nota ix) dal foro di Suessula, nella quale si potrebbe rintracciare la menzione di un q(uaestor) m(unicipii): ma la sigla sarà da intendere piuttosto come q(uaestor) m(unerarius).

251 Keppie 1983, 143-147. 
fatto di possibili conferme. Si dovrà piuttosto postulare, per entrambi i centri, uno svincolamento dall'autorità dei praefecti Capuam Cumas realizzatosi già al principio del I sec. a.C., che non farebbe problema coniugare con una contestuale introduzione del quattuorvirato, all'epoca canonico per i municipia.

L'ipotesi, come è chiaro, coinvolge la questione più generale della durata nel tempo della prassi della iurisdictio mandata in area campana. Se è infatti certo che i quattro praefecti Capuam Cumas sopravvissero come magistratura fino al 16-13 a.C. ${ }^{252}$ è difficile credere che essi abbiano mantenuto così a lungo effettive funzioni di governo: soprattutto dopo il 59 a.C., quando anche Capua poté riacquisire, una volta assunto statuto coloniario, la piena autonomia amministrativa. Nel caso specifico di Atella e Acerrae, non va comunque escluso che il precoce distacco dalla praefectura si debba ad una concreta iniziativa di Silla: si tratterebbe dell'ennesimo intervento attuato dal dittatore nell'ager Campanus, che a questo punto sembrerebbe fatto oggetto nel suo complesso -testi l'adtributio di Calatia a Capua, le assegnazioni di terre al santuario di Diana Tifatina e le deduzioni coloniarie di Suessula e Urbanadi un globale progetto di ridefinizione territoriale e amministrativa. ${ }^{253}$

Nella stessa area, ma al di fuori della praefectura campana, un ultimo possibile caso è infine rappresentato da Trebula Balliensis, qualora si accetti l'idea di riferire a questo centro -e non a Trebula Suffenas - la notizia liviana relativa alla concessione ai Trebulani, nel 303 a.C., della civitas sine suffragio. ${ }^{254}$ Giusta la bontà di questa ipotesi, il caso risulterebbe di estremo interesse, a fronte della cronologia postulabile per il quattuorvirato trebulano, già attestato nel pieno I sec. a.C. ${ }^{255}$ e dunque senz'altro da considerare l'assetto magistratuale originario del municipium, almeno dagli anni subito successivi alla guerra sociale.

Sulle ragioni della mancata continuità con gli istituti della fase sovrana è impossibile -e forse inutile, in mancanza di dati- formulare ipotesi. Si dovrà semplicemente ammettere che in tutti questi centri l'ingresso nella cittadinanza romana condusse ad un precoce abbandono delle forme amministrative locali almeno per quanto atteneva alla giurisdizione, ${ }^{256}$ nel tempo interamente rimessa a quella centrale, amministrata o direttamente dal pretore o dai praefecti suoi delegati: un processo che almeno nei casi di Atella e di Trebula Balliensis -anch'essa schieratasi durante la guerra annibalica sul fronte anti-romano, ${ }^{257}$ al pari dei Campani- va forse inteso come l'esito dell'applicazione di misure punitive, ${ }^{258}$ e che più in generale poté essere accelerato da sopraggiunti fenomeni di crisi demografica e di conseguente contrazione insediativa, postulabili ad esempio per le piccole realtà municipali più

252 Cf. Sisani 2010, 177; Sisani 2011a, 725-727.

253 Sull'interessamento di Silla nei confronti di questo territorio cf. Franciosi 2002, 243-248, e Minieri 2002, 254256.

254 Liv. 10.1.3. Cf. in questo senso De Sanctis 1953-1964 [1907-1923], II, 322, nota 134.

255 CIL I² 3119; cf. CIL X 4561.

256 Le funzioni magistratuali inferiori avranno per contro potuto sopravvivere secondo le forme locali, come può eventualmente suggerire nel caso di Trebula Balliensis la conservazione di magistrati con potestas edilitaria -tríbúns plíf(ríkús) - di chiara tradizione epicoria, attestati da una iscrizione osca (ImIt Campania/Trebula Balliensis 1) databile in base al formulario nella seconda metà del II sec. a.C.: sulla questione cf. da ultimo Guadagno 2013.

257 Liv. 23.39.6.

258 Si veda, relativamente alle comunità campane secessioniste, Humbert 1978, 366-372. Nel caso specifico di Atella, nel 210 a.C. gli abitanti furono deportati a Calatia e la città venne (temporaneamente) assegnata ai Nucerini: cf. Liv. 27.3.6-7. 
prossime a Roma ${ }^{259}$ e per la stessa Cures. ${ }^{260}$ La piena autonomia locale, in tutti questi casi, dovette essere riacquisita solo nel contesto della generalizzata promozione municipale attuata all'indomani della guerra sociale, che coincise con un globale riassetto delle strutture giurisdizionali e censitarie locali dell'intera penisola: un contesto nel quale la forma quattuorvirale si configurava come la soluzione canonica per gli organi magistratuali municipali, in alternativa all'eventuale conservazione di istituti di marca epicoria che tuttavia, nei casi ora illustrati, avrebbe piuttosto assunto i contorni di un artificioso recupero antiquario, per l'epoca del tutto inatteso.

Una ulteriore eccezione alla regola, pur se di segno diverso rispetto ai casi ora analizzati, potrebbe eventualmente essere costituita da Statonia, comunità alla quale Vitruvio sembra ancora attribuire lo status di praefectura: ${ }^{261}$ dal momento che il municipium risulta retto già nella prima età imperiale da quattuorviri, ${ }^{262}$ saremmo portati a credere che tale assetto magistratuale sia stato introdotto a seguito di una constitutio municipale augustea, prospettando uno sviluppo amministrativo di fatto senza paralleli. Tutto ruota, a ben vedere, intorno alla corretta interpretazione da dare alla definizione vitruviana, che va forse più semplicemente intesa in senso gromatico, ad indicare cioè lo statuto giuridico non già della comunità in sé ma di una sua pertinenza territoriale, qualificabile come ager ex alienis territoriis sumptus: ${ }^{263}$ è quanto in fondo suggerisce lo stesso passo del De Architectura, che parrebbe ricomprendere la praefectura Statoniensis all'interno dei fines Tarquiniensium.

Resta infine da trattare un'ultima "anomalia" relativa al quattuorvirato municipale: i casi in cui la forma quattuorvirale è introdotta a seguito di riassetto amministrativo, andando a sostituire una originaria e distinta struttura magistratuale. L'unico esempio certo di questa prassi riguarda Carsulae, municipium costituito in età cesariana e inizialmente retto -come di norma per l'epoca- da duoviri, poi sostituiti nel corso del I sec. d.C. da quattuorviri, attestati con continuità fino al IV sec. d.C. ${ }^{264}$ L'idea che si tratti semplicemente di uno spontaneo adeguamento formale agli assetti magistratuali dei municipia circostanti non convince: il cambio di titolatura, apparentemente da datare in età flavia, ${ }^{265}$ deve con tutta evidenza discendere da una effettiva ricostituzione istituzionale del municipium, che non è escluso vada letta alla luce del peculiare legame -tradito da diverse testimonianze- tra il centro e la dinastia dei Flavi, inaugurato dall'appoggio fornito a Vespasiano nel 69 d.C. ${ }^{266}$ e

259 Cf. Cic. Planc. 23: (...) nisi forte te Labicana aut Gabina aut Bovillana vicinitas adiuvabat, quibus e municipiis

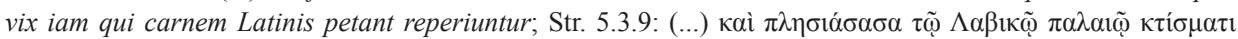
$\kappa \alpha \tau \varepsilon \sigma \pi \alpha \sigma \mu \varepsilon \dot{v} \omega$ (...). Quanto mai indicativa di questi fenomeni (cf. Brunt 1987², 345-350) è la stessa scomparsa, nel corso al più tardi del I sec. a.C., di antiche realtà municipali: è il caso di Pedum, assente dalla lista augustea delle civitates della regio I trasmessa da Plinio, la cui autonomia amministrativa parrebbe ormai già estinta in età cesariana (Cic. Att. 9.18.3; cf. Hor. Ep. 1.4.2).

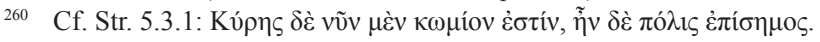

261 Vitr. 2.7.3: Sunt vero item lapidicinae complures in finibus Tarquiniensium quae dicitur Anicianae (...) quarum officinae maxime sunt circa lacum Vulsiniensem, item praefectura Statoniensi; cf. Plin. HN 36.168: Nigri silices optimi, quibusdam in locis et rubentes; nonnusquam vero et albi, sicut in Tarquiniensi Anicianis lapidicinis circa lacum Volsiniensem et in Statoniensi. Il centro - che si riteneva situato nel distretto vulcente (abbracciavo questa ipotesi in Sisani 2011a, 617-618, nota 212)- è da localizzare nell'Etruria tiberina, nei pressi di Bomarzo (cf. Stanco 1994 e Munzi 1995).

262 AE 1990, 338.

263 Su questa categoria gromatica cf. Sisani 2011a, 705-706.

264 Roscini 2018.

265 La più recente attestazione del duovirato $(A E 2017,396)$ risale infatti ai decenni centrali del I sec. d.C.

266 Tac. Hist. 3.60 . 
forse tradottosi nella riattribuzione di fette di territorio sottratte alla comunità in occasione della deduzione della contermine colonia triumvirale di Tuder ${ }^{267}$

L'ipotesi non solo è astrattamente percorribile, ma può contare sul sostegno fornito da una vicenda istituzionale assolutamente parallela: quella di Reate. Il centro fa parte, insieme a Nursia e Amiternum, del gruppo di praefecturae istituite poco dopo il 290 a.C. e destinate a strutturare sul piano amministrativo le assegnazioni viritane nell'alta Sabina, che in quest' area andarono integralmente a sostituire il popolamento locale. ${ }^{268}$ In tutti e tre i casi, la trasformazione in municipia si verifica, assai tardivamente, solo nel corso dell'età augustea. Fino ad allora, almeno le praefecturae di Nursia e Amiternum continuano ad essere rette da octoviri, poi sostituiti a seguito della constitutio municipale da canonici assetti di marca duovirale. ${ }^{269} \mathrm{Nel}$ caso di Reate, non abbiamo invece alcuna informazione relativa all'assetto magistratuale locale durante la fase della praefectura, mentre come municipium il centro risulta inaspettatamente retto da quattuorviri, le cui attestazioni epigrafiche non sono tuttavia anteriori al tardo I sec. d.C. ${ }^{270}$ Non è inverosimile ipotizzare che anche nel municipium di Reate il quattuorvirato sia stato introdotto -in sostituzione di un originario assetto magistratuale di marca eventualmente duovirale-solo in età flavia, a seguito di una ristrutturazione amministrativa e territoriale da collegare con tutta evidenza alla deduzione in loco di veterani sotto Vespasiano, ${ }^{271}$ per altro originario del centro.

Almeno a giudicare da questi casi, il quattuorvirato sembrerebbe dunque conoscere, al principio dell'età flavia, una nuova fortuna, che segna una vera e propria inversione di tendenza rispetto alla prassi adottata in età cesariano-augustea. Non è forse un caso se l'apparente rivitalizzazione di questo assetto magistratuale - che incarnava in certo modo la forma archetipica dei municipia - si verifichi sotto Vespasiano, protagonista di una rinnovata attività legislativa in ambito municipale tanto nelle province quanto in Italia. ${ }^{272}$ Dietro questi casi verrebbe quasi da scorgere, se non l'elaborazione di una vera e propria riforma, quanto meno l'applicazione consapevole di una nuova prassi, che in occasione di eventuali interventi di riassetto istituzionale portava a privilegiare il quattuorvirato come segno distintivo della realtà municipale italica, riservando il duovirato ai municipia (romani e latini) di ambito provinciale. ${ }^{273}$

\footnotetext{
Cf. Roscini 2018, 252-253.

268 Sisani 2013a.

269 Sisani 2010, 199-207.

270 Quattuorviri: CIL IX 4753, 4754; AE 2016, 379. Aediles: CIL IX 4169.

271 Keppie 1984, 91-104.

272 Per l'ambito provinciale, risale ai primi anni di regno la legge destinata a regolare la concessione dello ius Latii alle comunità dell'universa Hispania (Zecchini 1990). Per quanto riguarda 1'Italia, l'esistenza di una lex Flavia di interesse municipale (lato sensu) è assicurata da AE 1984, 188 (da Forum Popilii): C. Messio C. f. Q. n. Scaev(ae) / IIvir(o) tert(ium), / cui lege Flavia datum est / primus sententiam sui ordinis / interrogaretur cuique / post mortem publice funus / locusque sepulturae decretus / est, Scaeva f(ilius) (cf. Demougin 1986 e Camodeca 2003, 180-181). Si obietterà che a Forum Popilii non si registra un analogo passaggio al quattuorvirato, ma in questo caso la conservazione di un assetto duovirale può spiegarsi postulando l'elevazione del centro a colonia, nel quadro del vasto programma di deduzioni vespasianee, concentrato proprio nel settore tirrenico a cavallo tra Campania e Lucania (i casi certi riguardano Capua, Puteoli, Nola, Paestum): una deduzione flavia è del resto indiziata da una notizia del Liber Coloniarum-233-234 L.: Forum Popili, oppidum muro ductum: (...) Imperator Vespasianus postea lege sua agrum censiri iussit- e risulterebbe definitivamente confermata qualora si volesse attribuire a questo centro, piuttosto che alla vicina Sinuessa, l'iscrizione CIL X 4735 (dedica a Pertinace da parte di una [Colo]nia Flavia).

273 Cf. Sisani 2018.
} 


\section{Bibliografia}

Baldelli, G. (2007): "La prima ritrovata segnalazione e la vera provenienza di un'epigrafe fanese", Picus 27, 229-237.

Bellomo, M. (2020): “Aspetti e problemi della gestione dell'ager publicus all'inizio del II secolo a.C.: il caso dei veterani di Scipione Africano", [in] M. Faraguna - S. Segenni (edd.), Forme e modalità di gestione amministrativa nel mondo greco e romano: terra, cave, miniere (=Consonanze 23), Milano, 253-268.

Beloch, K. J. (1926): Römische Geschichte bis zum Beginn der Punischen Kriege, BerlinLeipzig.

Bernard, G. - Callegarin, L. (2017): "La titulature des magistrats et le statut de la cité de Tanger d'après l'épigraphie monétaire", [in] Evangelisti - Ricci (edd.), 2017, 183-192.

Brunt, P. A. (19872): Italian manpower (225 B.C. - A.D. 14), Oxford.

Buonocore, $\mathrm{M}$.

(2002 [1985]): “Munera e venationes: una risposta pagana all'infiltrazione del cristianesimo nell'Abruzzo romano?", [in] L'Abruzzo e il Molise in età romana tra storia ed epigrafia (=Studi e Testi 21), L'Aquila, 193-208.

(2014): "Un nuovo praetor duovir da Telesia", [in] M. Chiabà (ed.), Hoc quoque laboris praemium. Scritti in onore di Gino Bandelli (=Polymnia 3), Trieste, 1-17.

Buonocore, M. - Firpo, G. (1998): Fonti latine e greche per la storia dell'Abruzzo antico II (=Documenti per la Storia dell'Abruzzo 10), L'Aquila.

Buonopane, A. (2017): "I magistrati della colonia di Grumentum (Italia, regio III): aspetti e problemi", [in] S. Segenni - M. Bellomo (edd.), Epigrafia e politica. Il contributo della documentazione epigrafica allo studio delle dinamiche politiche nel mondo romano (=Consonanze 4), Milano, 119-145.

Burnett, A. - Amandry, M. - Ripollès, P. P. (1998): Roman Provincial Coinage I, London² $(=R P C \mathrm{I})$.

Camodeca, G.

(2003): "L'attività dell'ordo decurionum nelle città della Campania dalla documentazione epigrafica", CahGlotz 14, 173-186 (https://doi.org/10.3406/ccgg.2003.1584).

(2008 [2007]): "Il primo frammento dei Fasti Teanenses (8-7 a.C.) e la colonia augustea di Teanum Sidicinum", [in] I ceti dirigenti di rango senatorio equestre e decurionale della Campania romana I, Napoli, 325-352.

(2010a): "Il patrimonio epigrafico e l'élite municipale di Cumae", [in] L. Chioffi (ed.), Il Mediterraneo e la storia. Epigrafia e archeologia in Campania: letture storiche, Napoli, 47-72. (2010b): "Sull'élite e l'amministrazione cittadina di Cuma romana", [in] L. Lamoine C. Berrendoner - M. Cébeillac-Gervasoni (dirs.), La praxis municipale dans l'Occident romain, Clermont-Ferrand, 219-244.

(2012): "Nola: vicende sociali e istituzionali di una colonia romana da Silla alla tetrarchia", [in] L. Lamoine - C. Berrendoner - M. Cébeillac-Gervasoni (dirs.), Gérer les territoires, les patrimoines et les crises. Quotidien municipal II, Clermont-Ferrand, 295-328.

(2017): "Magistrature cittadine in Campania fra la tarda repubblica e l'età severiana", [in] Evangelisti - Ricci (edd.), 2017, 53-60.

(2018): "Frigento e il suo territorio in età romana attraverso la documentazione epigrafica", [in] A. Famiglietti (ed.), San Marciano. Primo vescovo di Frigento tra storia e fede, Frigento, 25-46.

Cappelletti, L. (2011): Gli statuti di Banzi e Taranto nella Magna Graecia del I secolo a.C., Frankfurt am Main. 
Caracciolo, G.

(2018a): Chiusi romana. Ricerche di prosopografia e di storia socio-economica (Inaugural-Dissertation zur Erlangung des Doctorgrades der Philosophischen Fakultät der Universität zu Köln im Fach Alte Geschichte, Historisches Institut), Köln. (2018b): "Inediti dagli scavi Maetzke nel duomo di Chiusi", ZPE 206, 255-266.

Cerrone, F. - Gallo, A. (2016): "Vicende istituzionali ed epigrafia a Casinum", [in] Epigrafia e territorio. Politica e società. Temi di antichità romane X, Bari, 141-161.

Chelotti, M.

(2015): "Una vicenda istituzionale: il caso di Aceruntia", SCO 61, 177-185.

(2019): “Bantia”, [in] Supplementa Italica 31, Roma, 9-42 (=SupplIt 31).

Crawford, M. H.

(1989): "The lex Iulia agraria", Athenaeum 67, 179-190.

(2008): “The IIIIviri of Pompei”, [in] C. Berrendoner-M. Cébeillac-Gervasoni-L. Lamoine (dirs.), Le quotidien municipal dans l'Occident romain, Clermont-Ferrand, 171-181.

(2011): Imagines Italicae. A corpus of Italic inscriptions (=BICS Supplement 110), London (=ImIt).

Curchin, L. A. (2016): "The octovirate and decemvirate in Italian municipal politics", Latomus 75, 27-54.

De Ruggiero, E.

(1892): “Agrariae leges", [in] Enciclopedia giuridica italiana I/2.1, Milano, 733-910.

(1896): Le colonie dei Romani, Spoleto.

De Sanctis, G. (1953-1964 [1907-1923]): Storia dei Romani, Firenze.

Degrassi, A.

(1947): Inscriptiones Italiae XIII. Fasti et elogia I. Fasti consulares et triumphales, Roma (=InscrIt XIII/1).

(1962 [1949]): "Quattuorviri in colonie romane e in municipi retti da duoviri", [in] Scritti vari di antichità I, Roma, 99-177.

(1962 [1960]): “Sul duovirato nei municipi italici”, [in] Scritti vari di antichità I, Roma, 185-192.

(1971 [1959]): “L'amministrazione delle città”, [in] Scritti vari di antichità IV, Trieste, 67-98.

Demougin, S. (1986): "La lex Flavia dans une inscription campanienne", [in] B. Rémy [ed.], Recherches épigraphiques. Documents relatifs à l'histoire des institutions et de l'administration de l'empire romain, Saint-Etienne, 41-47.

Di Stefano Manzella, I. (1990): "Lo stato giuridico di Falerii Novi dalla fondazione al III sec. d.C.", [in] La civiltà dei Falisci, Firenze, 341-367.

Evangelisti, S. - Ricci, C. (edd.), (2017): Le forme municipali in Italia e nelle province occidentali tra i secoli I a.C. e III d.C. (=Insulae Diomedeae 28), Bari.

Filippi, G. (1989): "Forum Novum", [in] Supplementa Italica 5, Roma, 145-238 (=Supplit 5). Firpo, G. (2009): “Colonia Arretium: da Silla a Cesare”, RendIstLomb 143, 87-118.

Franciosi, G. (2002): "I Gracchi, Silla e l'ager Campanus", [in] G. Franciosi (ed.), La romanizzazione della Campania antica I, Napoli, 229-248.

Galli, L. - Gregori, G. L. (1998): “Aletrium”, [in] Supplementa Italica 16, Roma, 13-90.

Garofalo, P. (2017): "Ulubrae: locus in Italia, in quo nutritus est Caesar Augustus (Porph., ad Hor. Ep. I 11, 30)”, MEFRA 129, 399-411 (https://doi.org/10.4000/mefra.4427).

Giovagnoli, M. (2018): "Epigrafia, storia e istituzioni locali: una rimeditazione su Cereatae Marianae", [in] S. Antolini - S. M. Marengo - G. Paci (edd.), Colonie e municipi nell'era digitale. Documentazione epigrafica per la conoscenza delle città antiche (=Ichnia 14), Tivoli, 235-248. 
Granino Cecere, M. G.

(1988): "Trebula Suffenas", [in] Supplementa Italica 4, Roma, 117-240 (=SupplIt 4).

(2007): “L. Cornelius L. f. Balbus: qualche riflessione sul suo cursus honorum”, [in] P. Desideri - M. Moggi - M. Pani (edd.), Antidoron. Studi in onore di Barbara Scardigli Forster, Pisa, 229-244.

Gruen, E. S. (1995²): The last generation of the Roman Republic, Berkeley.

Guadagno, G. (2013): "Vasto: tribuf prifliks. Presunti tribuni della plebe in area italica", Considerazioni di Storia ed Archeologia 6, 46-49.

Humbert, M. (1978): Municipium et civitas sine suffragio. L'organisation de la conquête jusqu'à la guerre sociale (=Collection de l'École française de Rome 36), Rome.

Jones, G. B. D. (1963): "Southern Etruria 50-40 B.C.: an attack on Veii in 41 B.C.", Latomus 22, 773-776.

Keppie, L.

(1983): Colonisation and veteran settlement in Italy. 47-14 B.C., London.

(1984): "Colonisation and veteran settlement in Italy in the first century A.D.", PBSR 52, 77-114.

Laffi, U.

(2001 [1973]): "Sull'organizzazione amministrativa dell'Italia dopo la guerra sociale", [in] Studi di storia romana e di diritto (=Raccolta di Studi e Testi 206), Roma, 113135.

(2001 [1987]): "L'amministrazione di Aquileia nell'età romana", [in] Studi di storia romana e di diritto (=Raccolta di Studi e Testi 206), Roma, 143-171.

(2007 [2002]): "Quattuorviri iure dicundo in colonie romane", [in] Colonie e municipi nello stato romano (=Raccolta di Studi e Testi 239), Roma, 129-148.

(2007 [2004]): "Osservazioni sulla lex municipii Tarentini”, [in] Colonie e municipi nello stato romano (=Raccolta di Studi e Testi 239), Roma, 191-231.

(2007 [2006]): "La struttura costituzionale nei municipi e nelle colonie romane. Magistrati, decurioni, popolo", [in] Colonie e municipi nello stato romano (=Raccolta di Studi e Testi 239), Roma, 49-79.

Lasserre, F. (1967): Strabon. Géographie, livres V et VI, Paris.

Letta, C.

(1979): "Magistrature italiche e magistrature municipali: continuità o frattura?", [in]

E. Campanile - C. Letta, Studi sulla magistrature indigene e municipali in area italica (=Orientamenti Linguistici 11), Pisa, 33-88.

(2016): "Novità epigrafiche dai territori di Marruvium e Alba Fucens", [in] Il Fucino e le aree limitrofe nell'antichità: archeologia e rinascita culturale dopo il sisma del 1915. Atti del IV convegno di archeologia, Avezzano, 281-287.

(2017): "Magistrature indigene e municipali in area italica: trentasei anni dopo", [in] Evangelisti - Ricci (edd.), 2017, 15-28.

(2019): "Mutamenti istituzionali nei municipi dell'Italia nella prima età imperiale: il duovirato a Marruvium e l'emissario claudiano del Fucino", [in] N. Andrade - C. Marcaccini - G. Marconi - D. Violante (eds.), Roman imperial cities in the East and in central-southern Italy (=Ancient Cities 1), Roma, 349-363.

Letta, C. - D’Amato, S. (1975): Epigrafia della regione dei Marsi (=Monografie CeSDIR 7), Milano.

Liverani, P. (1984): “L'ager Veientanus in età repubblicana”, PBSR 52, 36-48.

Lo Cascio, E. (1996): "Pompei dalla città sannitica alla colonia sillana: le vicende istituzionali”, [in] Les élites municipales de l'Italie péninsulaire des Gracques à Néron 
(=Collection du Centre Jean Bérard 13 / Collection de l'École française de Rome 215), Naples-Rome, 111-123.

Marengo, S. M. (2000): “Trea", [in] Supplementa Italica 18, Roma, 155-188 (=SupplIt 18).

Matijašić, R. (2016): "L'iscrizione di Acerrentino (Inscr. It. X, 2, 22) e lo status giuridico di Parentium", [in] F. Mainardis (ed.), Voce concordi. Scritti per Claudio Zaccaria (=Antichità Altoadriatiche 85), Trieste, 475-482.

Mello, M. - Voza, G. (1968): Le iscrizioni latine di Paestum, Napoli.

Minieri, L. (2002): “La colonizzazione di Capua tra l'84 e il 59 a.C.”, [in] G. Franciosi (ed.), La romanizzazione della Campania antica I, Napoli, 249-267.

Miranda, E. (1990-1995): Iscrizioni greche d'Italia. Napoli, Roma (=IGINapoli).

Molle, C. (2016): "Varia epigraphica dalla Valle del Liri", [in] H. Solin (ed.), Le epigrafi della Valle di Comino. Atti del dodicesimo convegno epigrafico cominese, San Donato Val di Comino, 91-116.

Munzi, M. (1995): "La nuova Statonia", Ostraka 4/2, 285-299.

Munzi, M. - Terrenato, N. (1994): "La colonia di Volterra: la prima attestazione epigrafica ed il quadro storico e archeologico", Ostraka 3/1, 31-42.

Paci, G.

(2004): "Fanum Fortunae: note storiche ed epigrafiche", Picus 24, 29-67.

(2004): “S. Vittore di Cingoli”, [in] Supplementa Italica 22, Roma, 153-159 (=SupplIt 22).

(2008): "Le iscrizioni delle mura repubblicane di Sentinum", [in] M. Medri (ed.), Sentinum 295 a.C. - Sassoferrato 2006. 2300 anni dopo la battaglia. Una città romana tra storia e archeologia, Roma, 235-245

Pack, E. (1981): “M. Anaenius Phanianus”, ZPE 43, 249-270.

Pack, E. - Paolucci, G. (1987): “Tituli Clusini: nuove iscrizioni e correzioni all'epigrafia latina di Chiusi”, ZPE 68, 159-191.

Pais, E.

(1923): "Serie cronologica delle colonie romane e latine dalla età regia fino all'impero", MemLinc 5/17, 311-355.

(1925): "Serie cronologica delle colonie romane e latine dall'età dei Gracchi a quella di Augusto", MemLinc 6/1, 345-412.

Panciera, S. (2006 [1960]): "Sulla pretura in Velitrae", [in] Epigrafi, epigrafia, epigrafisti. Scritti vari editi e inediti (1956-2005) con note complementi e indici (=Vetera 16), Roma, 591-593.

Reddé, M. (1986): Mare Nostrum. Les infrastructures, le dispositif et l'histoire de la marine militaire sous l'empire romain (=Bibliothèque des Écoles françaises d'Athènes et de Rome 260), Rome (https://doi.org/10.3406/befar.1986.1238).

Rix, H. (2002): Sabellische Texte. Die Texte des Oskischen, Umbrischen und Südpikenischen, Heidelberg $(=S T)$.

Rodríguez Neila, J. F. (1978): "Las elecciones municipales en la Bética romana. Una aproximación a la lex Flavia Malacitana", Revista de Estudios de la Vida Local 199, 581-632.

Roscini, E. (2018): "Un nuovo Furius, magistrato a Carsulae”, ZPE 207, 249-253.

Rosi Bonci, L. - Spadoni, M. C. (2013): “Arna”, [in] Supplementa Italica 27, Roma, 201-236 (=Supplit 27).

Ruffo, F. (2015): “La piana del Sarno (ager Nucerinus, ager Pompeianus, ager Stabianus): fonti archeologiche e (ri)letture cartografiche per lo studio delle centuriazioni e della viabilità in età romana", Agri Centuriati 12, 9-40. 
Rutter, N. K. (2001): Historia Numorum. Italy, London (=HNI).

Sansone, A. (2017): "Le dinamiche istituzionali di Atina (regio III): dal periodo postannibalico alla municipalizzazione", [in] Evangelisti - Ricci (edd.), 2017, 75-87.

Santangelo, F. (2007): Sulla, the elites and the empire. A study on Roman policies in Italy and the Greek East (=Impact of Empire 8), Leiden-Boston (https://doi.org/10.1163/ ej.9789004163867.i-300).

Sartori, F. (1953): Problemi di storia costituzionale italiota (=Pubblicazioni dell'Istituto di Storia Antica 1), Roma.

Sciarretta, F. (1996): "Rinvenimenti archeologici nelle aree trebulana e tiburtina", Atti e Memorie della Società Tiburtina di Storia e d'Arte 69, 93-104.

Silberman, A. (1988): Pomponius Mela. Corographie, Paris.

Silvestrini, M. (2017): "Le guerre civili nel Mezzogiorno adriatico", [in] La Puglia nel mondo romano. Storia di una periferia. L'avvio dell'organizzazione municipale (=Pragmateiai 29), Bari, 9-63.

Sisani, S.

(2002): "Lucius Falius Tinia: primo quattuorviro del municipio di Hispellum", Athenaeum 90/2, 483-505.

(2007): Fenomenologia della conquista. La romanizzazione dell'Umbria tra il IV sec. a.C. e la guerra sociale (=Quaderni di Eutopia 7), Roma.

(2009): "Dirimens Tiberis? I confini tra Etruria e Umbria", [in] F. Coarelli - H. Patterson (eds.), Mercator placidissimus. The Tiber Valley in antiquity (=Quaderni di Eutopia 8), Roma, 45-85.

(2010): "Dalla praefectura al municipium: lo sviluppo delle strutture amministrative romane in area medio-italica tra il I sec. a.C. e l'età imperiale", RendLinc 9/21, 173 226.

(2011a): "In pagis forisque et conciliabulis. Le strutture amministrative dei distretti rurali in Italia tra la media repubblica e l'età municipale", MemLinc 9/27, 543-780.

(2011b): "Perusia restituta: le vicende istituzionali del municipium dopo il 40 a.C.", Bollettino della Deputazione di Storia Patria per l'Umbria 108, 273-294.

(2011c): "L'ultimo dei Volumni: P. Volumnius Violens e le vicende istituzionali del municipium di Perusia tra il 40 a.C. e l'età augustea", [in] L. Cenciaioli (ed.), L'Ipogeo dei Volumni. 170 anni dalla scoperta, Perugia, 211-230.

(2012): "Il municipium romano di Tadinum", [in] A. Bravi (ed.), Aurea Umbria. Una regione dell'Impero nell'era di Costantino (=Bollettino per i Beni Culturali dell'Umbria 10), Viterbo, 307-308.

(2013a): "Da Curio Dentato a Vespasio Pollione: conquista e romanizzazione del distretto nursino", [in] S. Sisani (ed.), Nursia e l'ager Nursinus. Un distretto sabino dalla praefectura al municipium, Roma, 9-15.

(2013b): "Città senza case: la domus come spazio pubblico nei municipia dell'Umbria", [in] S. Gutiérrez Lloret - I. Grau Mira (eds.), De la estructura doméstica al espacio social. Lecturas arqueológicas del uso social del espacio, Alicante, 191-206.

(2015): L'ager publicus in età graccana (133-111 a.C.). Una rilettura testuale, storica e giuridica della lex agraria epigrafica, Roma.

(2016): "Le istituzioni municipali: legislazione e prassi tra il I secolo a.C. e l'età flavia", [in] L. Capogrossi Colognesi - E. Lo Cascio - E. Tassi Scandone (edd.), L'Italia dei Flavi (=Acta Flaviana 3), Roma, 9-55.

(2017): "Tergeste e le 'colonie' cesariane della Gallia Togata (in margine a b.g. 8.24.3)", [in] A. Giovannini (ed.), Trieste e l'Istria, Trieste, 105-152. 
(2018): "Le magistrature locali delle comunità municipali di ambito provinciale: uno studio sulla diffusione del quattuorvirato e del duovirato tra l'età tardo-repubblicana e l'età imperiale", Gerión 36/1, 39-75 (http://dx.doi.org/10.5209/GERI.60293).

(2021a): "Una ignorata dedica a Ottaviano triumviro da Fanum Fortunae", ZPE 217, 247-252.

(2021b): "Tra autonomia e integrazione: diritti locali e giurisdizione prefettizia nelle comunità di cives sine suffragio", [in] M. Tarpin (ed.), Settlement systems: structures, hierarchies and territories. New approaches, Besançon (in corso di stampa).

Solin, H.

(2007): "Sull'amministrazione di Atina in età romana", [in] H. Solin (ed.), Le epigrafi della Valle di Comino. Atti del terzo convegno epigrafico cominese, San Donato Val di Comino, 85-93.

(2013): "Sulla storia costituzionale e amministrativa della Casinum romana", [in] H. Solin (ed.), Le epigrafi della Valle di Comino. Atti del nono convegno epigrafico cominese, San Donato Val di Comino, 105-117.

(2014): "Appunti sulla storia amministrativa di Sora", [in] H. Solin (ed.), Le epigrafi della Valle di Comino. Atti del decimo convegno epigrafico cominese, San Donato Val di Comino, 115-125.

(2016): "Sulle trasformazioni amministrative di Casinum", [in] F. Mainardis (ed.), Voce concordi. Scritti per Claudio Zaccaria (=Antichità Altoadriatiche 85), Trieste, 667-686.

Soricelli, G.

(2007): "Intramurani / extramurani", [in] E. Lo Cascio - G. D. Merola (edd.), Forme di aggregazione nel mondo romano (=Pragmateiai 13), Bari, 59-69.

(2017): "Città e magistrature nel Sannio pentro tra tarda repubblica e prima età imperiale", [in] Evangelisti - Ricci (edd.), 2017, 89-102.

Spadoni, M. C. - Cenciaioli, L. - Benedetti, L. (2018): "Perusia - Ager Perusinus", [in] Supplementa Italica 30, Roma, 9-328 (=SupplIt 30).

Stanco, E. A. (1994): "La localizzazione di Statonia: nuove considerazioni in base alle antiche fonti”, MEFRA 106, 247-258 (https://doi.org/10.3406/mefr.1994.1847).

Taylor, L. R. (1960): The voting districts of the Roman republic (=Papers and Monographs 20), Rome.

Zecchini, G. (1990): "Plinio il Vecchio e la lex Flavia municipalis", ZPE 84, 139-146.

Zuddas, E.

(2017): "Dal quattuorvirato al duovirato: gli esiti del bellum Perusinum e i cambiamenti costituzionali in area umbra", [in] Evangelisti - Ricci (edd.), 2017, 121-132.

(2019): "I quattuorviri di Fulginiae", ZPE 211, 250-256.8 
LE MAGISTRATURE LOCALI DELLE COMUNITÀ MUNICIPALI E COLONIALI DELL'ITALIA CENTRALE E MERIDIONALE IN ETÀ SUCCESSIVA ALLA GUERRA SOCIALE

\begin{tabular}{|c|c|c|c|c|c|}
\hline REGIO I & colonia & praefectura & municipium & $\begin{array}{r}>\text { colonia post } 90 \\
\text { (usque ad Augusti aet.) }\end{array}$ & $\begin{array}{l}\text { a.C. } \\
\text { (imp.) }\end{array}$ \\
\hline Abella & & & $\bullet$ & SVLL.? IIViri & \\
\hline Abellinum & IIviri? & & & CAES.? (?) pr. IIviri & $\bullet$ \\
\hline *Acerrae & & {$[\bullet]$} & IIIViri & & \\
\hline${ }^{(* *)}$ Aefula (?) & & & IIviri & & \\
\hline Aletrium & & & IIIIviri & & \\
\hline${ }^{(*)}$ Allifae & & {$[\bullet]$} & $?$ & SVLL.? / CAES.? IIviri & \\
\hline "Anagnia & & {$[\bullet]$} & praetores-aediles & & \\
\hline Antium & $\begin{array}{l}<\text { IIviri } \\
\text { IIviri }\end{array}$ & & & TRIVM. / AVG. ? IIviri & - \\
\hline Aquinum & & & IIIIviri? & TRIVM. IIViri & \\
\hline Ardea & & & $\bullet$ & & IIviri \\
\hline *Aricia & & & dictator-aediles & & \\
\hline "Arpinum & & {$[\bullet]$} & II aediles & & \\
\hline *Atella & & {$[\bullet]$} & IIIIviri & & \\
\hline *Atina & & $\bullet$ & IIviri & & \\
\hline${ }^{(*)}$ Bovillae & & & IIIViri & & \\
\hline Caiatia & & & IIviri & & \\
\hline$\underline{\text { Cales }}$ & & & $\begin{array}{c}\text { IIIIviri praetores } \\
\text { IIIIviri }\end{array}$ & & IIviri \\
\hline "Capitulum Her. & & & praetores & & \\
\hline "Capua & & $\bullet$ & & \begin{tabular}{|c|}
{$[[83$ A.C. $]]$} \\
praetores \\
IIIViri ??? \\
CAES. IIviri \\
TRIVM. (>AVG.?) IIviri \\
\end{tabular} & $\bullet$ \\
\hline${ }^{(*)}$ Casinum & & praefecti & IIviri & & IIviri \\
\hline${ }^{(*)}$ Castrimoenium & & & IIIViri & & \\
\hline Cereatae Marianae & \multicolumn{2}{|c|}{ (ager Arpinas) } & IIviri & & $?$ \\
\hline Circeii & & & IIIIviri & & \\
\hline Cora & & & IIIIviri & & \\
\hline Cubulteria & & & IIviri & & \\
\hline *Cumae & & {$[\bullet]$} & praetores & & pr. \\
\hline Fabrateria Nova & IIviri & & & & \\
\hline${ }^{(*)}$ Fabrateria Vetus & & & $\begin{array}{c}\text { dictatores ??? } \\
\text { IIviri }\end{array}$ & & \\
\hline
\end{tabular}




\begin{tabular}{|c|c|c|c|c|c|}
\hline Ferentinum & & & IIIIviri & & \\
\hline *Formiae & & {$[\bullet]$} & III aediles & & IIviri \\
\hline "F* Forum Popilii & & $(?)$ & IIviri & & $?$ \\
\hline${ }^{(*)}$ Frusino & & {$[\bullet]$} & $\bullet$ & & IIviri \\
\hline "Fundi & & {$[\bullet]$} & III aediles & & \\
\hline Gabii & & & IIIIviri & & \\
\hline Herculaneum & & & IIviri & & \\
\hline Interamna Lirenas & & & IIIIviri & & \\
\hline${ }^{(*)}$ Labici & & & IIIIviri & & \\
\hline "Lanuvium & & & dictator-aediles & & $\bullet$ \\
\hline "Lavinium & & & praetores-aediles & & \\
\hline Minturnae & IIviri & & & AVG. IIviri & \\
\hline Misenum & \multicolumn{2}{|c|}{ (ager Cumanus) } & IIviri & & IIviri \\
\hline Neapolis & & & archontes (IIIViri) & & IIviri \\
\hline Nola & & & $\bullet$ & $\begin{aligned} \text { IIIIViri } & \\
& \text { SVLL.? IIviri } \\
& \text { AVG. IIviri } \\
& \end{aligned}$ & $\bullet$ \\
\hline Nuceria & & & IIIIviri & TRIVM. IIviri & $\bullet$ \\
\hline Ostia & $\begin{array}{c}<\text { pr. ??? } \\
\text { IIviri }\end{array}$ & & & & \\
\hline Pompeii & & & IIIIviri & SVLL. IIViri & \\
\hline Praeneste & & & $\begin{aligned}<\text { praetores } & \\
& >\text { IIviri }\end{aligned}$ & [[SVLL.]] IIviri & IIviri \\
\hline *Privernum & & {$[\bullet]$} & (?) & ${ }^{\text {CAES.? }}$ pr. IIviri & \\
\hline Puteoli & $\begin{array}{r}<\text { IIviri } \\
\text { IIviri }\end{array}$ & {$[\bullet]$} & & TRIVM. (>AVG.?) IIViri & $\bullet$ \\
\hline Salernum & IIviri & & & & \\
\hline Setia & & & IIIIviri & & $\bullet$ \\
\hline Signia & & & IIIViri & & \\
\hline Sinuessa & IIviri & & & & $?$ \\
\hline Sora & & & IIIVviri & $\begin{array}{ll}\text { IIIViri ? } & \\
& \text { TRIVM. IIviri }\end{array}$ & \\
\hline Suessa & & & $\bullet$ & TRIVM. IIViri & \\
\hline *Suessula & & {$[\bullet]$} & (?) & ${ }^{\text {SVLL.? } ? \text { IIViri }}$ & \\
\hline Surrentum & & & IIviri & & \\
\hline Tarracina & IIviri & & & & \\
\hline Teanum Sidic. & & & IIIIviri & $\begin{array}{l}\text { IIIViri ? } \\
\\
\end{array}$ & \\
\hline Telesia & & & (?) & $\begin{array}{r}\text { SVLL.? IIViri } \\
\text { CAES.? pr. IIviri }\end{array}$ & IIviri \\
\hline
\end{tabular}




\begin{tabular}{|c|c|c|c|c|c|}
\hline Tibur & & & IIIIviri & & \\
\hline${ }^{(*)}$ Treba (?) & & & IIviri & & \\
\hline${ }^{(*)}$ Trebula Ball. & & & $\begin{array}{l}\text { IIIIViri } \\
\\
>\text { IIViri }\end{array}$ & & (?) \\
\hline *Tusculum & & & II aediles & & \\
\hline "Velitrae & & & $\bullet$ & & IIviri \\
\hline${ }^{(*)}$ Venafrum & & {$[\bullet]$} & $?$ & $\begin{array}{r}\text { CAES.? IIViri } \\
\text { AIVir. } \\
\text { AIviri }\end{array}$ & \\
\hline Verulae & & & $\begin{array}{r}\text { IIIIviri } \\
\text { >IIviri }\end{array}$ & & \\
\hline${ }^{(* *)}$ Vlubrae & & & IIviri & SVLL.? / CAES.? (?) & \\
\hline Volturnum & $\begin{array}{r}<\text { IIviri } \\
\text { IIviri }\end{array}$ & {$[\bullet]$} & & & \\
\hline
\end{tabular}

> colonia post 90 a.C.

\begin{tabular}{|c|c|c|c|c|c|}
\hline REGIO II & colonia & praefectura & municipium & (usque ad Augusti aet.) & (imp.) \\
\hline Abellinum Pro. (?) & & praefecti & IIviri & & \\
\hline Aeclanum & & & IIIIViri & & IIviri \\
\hline Aquilonia & & & IIIIviri & & \\
\hline Ausculum & & & $\begin{array}{l}\text { IIviri } \\
\text { >IIIViri ??? }\end{array}$ & & \\
\hline Barium & & & IIIIviri & & \\
\hline Beneventum & & & $\begin{array}{l}<\text { praetores } \\
\text { IIIIviri }\end{array}$ & TRIVM. (>AVG.?) IIviri & $(?)$ \\
\hline$\underline{\text { Brundisium }}$ & & & IIIIviri & & \\
\hline Butuntum & & & IIIIviri? & & \\
\hline Caelia & & & IIIIviri & & \\
\hline Cannae (?) & & & IIIIviri & & \\
\hline Canusium & & & IIIIviri & & IIviri \\
\hline Caudium & & & IIIIviri & & \\
\hline Compsa & & & IIIIviri & & \\
\hline Genusia & & & IIIIviri & & \\
\hline Gnatia (?) & & & IIIVviri & & \\
\hline Herdoniae & & & IIIIviri & & \\
\hline Larinum & & & IIIIviri & & \\
\hline Ligures Baebiani & & & IIIIviri & & \\
\hline Luceria & & & IIIIViri & AVG. IIviri & \\
\hline Lupiae & & & IIIVviri & & IIviri \\
\hline Rubi & & & IIIIviri? & & \\
\hline Rudiae & & & IIIIviri & & \\
\hline
\end{tabular}




\begin{tabular}{|c|c|c|c|}
\hline Salapia & & IIIIviri & \\
\hline Sarmadium (?) & & IIIIviri & \\
\hline Sipontum & IIviri & & \\
\hline Tarentum & & $\begin{array}{l}\text { IIIVviri } \\
\text { >IIviri }\end{array}$ & \\
\hline Teanum Apulum & & IIIIviri & \\
\hline Venusia & & $\bullet$ & TRIVM. IIviri \\
\hline Vibinum & & $(?)$ & ${ }^{\text {SVLL.? IIviri }}$ \\
\hline Vria Apula (?) & & IIIIviri & \\
\hline Vria Messapica & & IIIIviri & \\
\hline
\end{tabular}

$>$ colonia post 90 a.C.

\begin{tabular}{|c|c|c|c|c|c|}
\hline REGIO III & colonia & praefectura & municipium & (usque ad Augusti aet.) & (imp.) \\
\hline Aceruntia & & & $\begin{array}{r}\text { IIIViri } \\
\text { >IIviri }\end{array}$ & & \\
\hline Atina & & & IIIIviri & & \\
\hline Bantia & & & IIviri & & \\
\hline Blanda & & & IIviri & & \\
\hline Buxentum & IIviri & & & & \\
\hline Copia & & & IIIIViri & & \\
\hline Croto & $\begin{array}{r}<\text { IIviri } \\
\text { IIviri }\end{array}$ & & & & \\
\hline Eburum & & & IIviri & & \\
\hline Grumentum & & & (?) & CAES.? pr. IIviri & \\
\hline Locri & & & IIIIviri & & \\
\hline$\underline{\text { Paestum }}$ & & & $\begin{aligned}<\text { praetores } & \\
\text { IIIIviri } & \\
& >\text { IIViri }\end{aligned}$ & [[SVLL.?]] (?) IIviri & IIviri \\
\hline Petelia & & & IIIIviri & & \\
\hline Potentia & & & IIIIviri & & \\
\hline Regium & & & prytanes (IIIViri) & & \\
\hline Tegianum (?) & & & IIviri & & $?$ \\
\hline Velia & & & IIIIviri & & \\
\hline Vibo & & & IIIIviri & & \\
\hline Volcei & & & IIIVviri & & \\
\hline
\end{tabular}

$>$ colonia post 90 a.C.

REGIO IV colonia praefectura municipium (usque ad Augusti aet.) (imp.)

\begin{tabular}{|l|r|r|r||l|c|}
\hline Aesernia & & & $\begin{array}{c}\text { <praetores } \\
\text { IIIViri }\end{array}$ & & $\bullet$ \\
\hline
\end{tabular}




\begin{tabular}{|c|c|c|c|c|}
\hline Alba Fucens & & $\begin{array}{r}<\text { praetores } \\
\text { IIIIviri }\end{array}$ & & IIviri \\
\hline Amiternum & VIIIViri & $\begin{array}{l}\text { VIIIviri } \\
\text { IIviri }\end{array}$ & & \\
\hline Antinum & & $\begin{array}{l}\text { IIIIviri } \\
\quad>\text { IIviri ??? }\end{array}$ & & \\
\hline Anxa & & IIIIviri & & \\
\hline Anxanum & & IIIIviri & & \\
\hline Aufidena & praefecti & IIviri & & \\
\hline Bovianum & & $\bullet$ & \begin{tabular}{|l} 
CAES.? (?) \\
AVG. IIviri \\
\end{tabular} & $(?)$ \\
\hline Carseoli & & IIIIviri & & $\bullet$ \\
\hline Cliternia & & IIviri & & \\
\hline Cluviae & & IIIIviri & & \\
\hline Corfinium & & IIIIviri & & \\
\hline "Cures & & IIIIviri & & \\
\hline Fagifulae & & IIviri & & \\
\hline "Fidenae & & $\begin{array}{l}\text { IIviri ? } \\
\quad \text { dictatores }\end{array}$ & & \\
\hline${ }^{* *}$ Forum Novum & (?) & IIviri & & \\
\hline Histonium & & IIIIviri & & \\
\hline${ }^{(* *)}$ Interamnia Pr. & VIIIviri & IIviri & SVLL.? IIViri & \\
\hline Iuvanum & & IIIIviri & & \\
\hline Lucus Angitiae & & $\begin{array}{l}\text { IIIIviri } \\
\qquad>\text { IIviri ? }\end{array}$ & & \\
\hline Marruvium & & $\begin{array}{l}\text { IIIIviri } \\
\text { >IIviri }\end{array}$ & & \\
\hline *Nomentum & & dictatores-aediles & & \\
\hline Nursia & VIIIviri & VIIIviri IIvir. pot. & {$[$ [TRIVM.]] $\bullet$} & \\
\hline Peltuinum & $?$ & praefecti-aediles & & \\
\hline Pinna & & IIIIViri & & \\
\hline${ }^{* * *}$ Reate & $\bullet$ & >IIIViri & & \\
\hline Saepinum & & IIviri & & \\
\hline Sulmo & & IIIIviri & & \\
\hline Superaequum & & $\begin{array}{l}\text { IIviri } \\
\text { >IIIIviri ??? }\end{array}$ & & \\
\hline Teate & & IIIIviri & & $\bullet$ \\
\hline Terventum & & IIviri & & \\
\hline Trebula Mutuesca & (ager Curensis?) & VIIIviri & & \\
\hline
\end{tabular}




\begin{tabular}{|l|l|l|l||l|l|}
\hline${ }^{(*)}$ Trebula Suffenas & & & IIviri & & \\
\hline
\end{tabular}

$>$ colonia post 90 a.C.

\begin{tabular}{|c|c|c|c|c|c|}
\hline REGIO V & colonia & praefectura & municipium & (usque ad Augusti aet.) & (imp.) \\
\hline Ancona & & & $\bullet$ & ${ }^{\text {TRIVM. IIViri }}$ & \\
\hline Asculum & & & $\bullet$ & TRIVM. IIViri & \\
\hline Auximum & praetores & & & & \\
\hline Castrum Novum & praetores & & & & \\
\hline Cingulum & & $\bullet$ & IIviri & & \\
\hline Cupra Maritima & & $(?)$ & IIviri & & \\
\hline "** Cupra Montana & & $(?)$ & IIviri & & \\
\hline${ }^{* *}$ Falerio & $(?)$ & $(?)$ & (?) IIviri & & IIviri \\
\hline Firmum & & & $\bullet$ & TRIVM. IIViri & \\
\hline Hadria & & & $\bullet$ & TRIVM. IIviri & \\
\hline ***Planina (?) & & $(?)$ & IIviri & & \\
\hline Potentia & praetores & & & & \\
\hline ***ina & & $(?)$ & IIviri & & IIviri \\
\hline *** Septempeda & & $(?)$ & IIviri & & IIviri \\
\hline${ }^{* * * *}$ Trea & & $(?)$ & IIviri & & \\
\hline Vrbs Salvia & praetores & & & & $(?)$ \\
\hline
\end{tabular}

$>$ colonia post 90 a.C.

\begin{tabular}{|c|c|c|c|c|c|}
\hline REGIO VI & colonia & praefectura & municipium & (usque ad Augusti aet.) & (imp.) \\
\hline Ameria & & & IIIIviri & & \\
\hline Arna & & & >IIviri & & \\
\hline Asisium & & & IIIIviri & & \\
\hline Attidium & & & IIIIviri? & & \\
\hline Camerinum & & & IIIIviri & & \\
\hline Carsulae & & (?) & $\begin{array}{l}\text { IIviri } \\
\qquad>\text { IIIIviri }\end{array}$ & & \\
\hline${ }^{* * *}$ Fanum Fortunae & & (?) & (?) & $\begin{array}{r}\text { IIIViri ??? } \\
\text { CAES.? }\end{array}$ & • \\
\hline Fulginiae & & $?$ & IIIIviri & & \\
\hline${ }^{* * *}$ Forum Flam. (?) & & (?) & IIviri & & \\
\hline F*orum Semp. & & (?) & IIviri & & \\
\hline Hispellum & & & IIIIViri & TRIVM. IIViri & $\bullet$ \\
\hline Iguvium & & & IIIIviri & & \\
\hline Interamna Nahars & & & IIIIviri & & \\
\hline Matilica & & $(?)$ & IIviri & & \\
\hline
\end{tabular}




\begin{tabular}{|c|c|c|c|c|c|}
\hline Mevania & & & IIIIviri & & \\
\hline Mevaniola & & & IIIIviri & & \\
\hline Narnia & & & IIIIviri & & \\
\hline Ocriculum & & & IIIIviri & & $\bullet$ \\
\hline Ostra & & (?) & IIviri & & \\
\hline Pisaurum & $\bullet$ & & & ${ }^{\text {TRIVM. }}$ IIViri & \\
\hline Pitinum Mer. & & & IIIIviri & & \\
\hline Pitinum Pis. & & & IIIIviri & & \\
\hline Plestia & & & IIIIviri & & \\
\hline Sarsina & & & IIIIviri & & \\
\hline Sentinum & & {$[(?)]$} & IIIIviri & & \\
\hline Spoletium & & & IIIIviri & & \\
\hline${ }^{* * *}$ Suasa & & (?) & IIviri & & \\
\hline Tifernum Tib. & & & IIIIviri & & \\
\hline Tadinum (?) & & (?) & IIviri & & \\
\hline Trebiae & & & IIIIviri & & \\
\hline Tuder & & & IIIIviri & TRIVM. IIviri & \\
\hline Tuficum & & & IIIIviri & & \\
\hline Vettona & & & >IIviri & & \\
\hline Vrvinum Hor. & & & IIIIviri & & \\
\hline Vrvinum Mat. & & & IIIIviri & & \\
\hline
\end{tabular}

$>$ colonia post 90 a.C.

\begin{tabular}{|c|c|c|c|c|c|}
\hline REGIO VII & colonia & praefectura & municipium & (usque ad Augusti aet.) & (imp.) \\
\hline Alsium & IIviri & & & & \\
\hline Arretium & & & $\bullet$ & $\begin{array}{r}\text { SVLL.? }(?) \\
\text { CAES.? IIviri }\end{array}$ & \\
\hline Blera & & & IIIIviri & & \\
\hline *Caere & & {$[\bullet]$} & dictator-aedilis & & \\
\hline "Capena & & & praetor-aedilis & & \\
\hline Castrum Novum & IIviri & & & CAES.? IIviri & \\
\hline Clusium & & & $\begin{array}{l}\text { IIIViri } \\
\quad>\text { IIviri }\end{array}$ & SVLL.? IIviri & $(?)$ \\
\hline Cortona & & & IIIIviri & & \\
\hline Faesulae & & & IIIIViri & & \\
\hline Falerii & & & IIIIviri & & $\bullet$ \\
\hline Faliscum & & (ager Fal & us) & ${ }^{\text {TRIVM. IIviri }}$ & \\
\hline Ferentium & & & IIIIViri & & \\
\hline Florentia & & & $\bullet$ & CAES.? IIviri & \\
\hline${ }^{* * *}$ Forum Clodii & & $\bullet$ & IIviri & & \\
\hline
\end{tabular}




\begin{tabular}{|c|c|c|c|c|c|}
\hline Graviscae & IIviri & & & & \\
\hline Heba & IIviri & & & & \\
\hline Luca & & & - & TRIVM. IIViri & \\
\hline Lucus Feroniae & \multicolumn{3}{|c|}{ (ager Capenas) } & $\begin{array}{l}\text { CAES.? IIViri } \\
\text { AVG. IIviri }\end{array}$ & \\
\hline Luna & $\begin{array}{r}<\text { IIviri } \\
\text { IIviri }\end{array}$ & & & & \\
\hline Nepet & & & IIIIviri & & \\
\hline Perusia & & & $\begin{array}{l}\text { IIIViri } \\
\text { >IIviri }\end{array}$ & & $\bullet$ \\
\hline Pisae & & & $\bullet$ & TRIVM. IIViri & \\
\hline Pistoriae & & & IIIIviri & & \\
\hline Populonia & & & IIIIviri & & \\
\hline Rusellae & & & $\bullet$ & AVG. IIviri & \\
\hline Saturnia & IIviri & {$[\bullet]$} & & & \\
\hline Statonia & & $?$ & IIIIviri & & \\
\hline Subertanum (?) & & & IIIIviri & & \\
\hline Sutrium & & & $\bullet$ & TRIVM. IIviri & \\
\hline Tarquinii & & & IIIIviri & & \\
\hline Tuscana & & & IIIIviri & & \\
\hline${ }^{* *}$ Vei & & & IIviri & & \\
\hline Visentium & & $(?)$ & IIviri & & \\
\hline Volaterrae & & & IIIIviri & & $\bullet$ \\
\hline Volci & & & IIIIviri & & \\
\hline Volsinii & & & IIIIviri & & \\
\hline
\end{tabular}




\section{Legenda:}
* (*) municipi anteriori alla guerra sociale; tra parentesi i casi incerti
** (**) comunità di coloni romani dedotti in forma viritana anteriormente al II sec. a.C.; tra parentesi i casi incerti
Abellinum colonie di diritto romano dedotte anteriormente al I sec. a.C.
$\underline{\text { Ardea }}$ colonie di diritto latino fino al 90 a.C.
(ager ...) pertinenza territoriale del centro in età anteriore al conferimento della piena autonomia amministrativa
$<$ IIviri nel caso delle colonie, attestazioni magistratuali anteriori con certezza o probabilità al I sec. a.C.
$<$ praetores nel caso dei municipi, attestazioni magistratuali riferibili alla primissima fase municipale (se non al momento finale della precedente fase sovra- na), anteriori al confezionamento dello statuto locale e all'introduzione del quattuorvirato

IIviri; IIIVviri assetto magistratuale originario, assunto all'atto del confezionamento dello statuto locale (in neretto gli assetti "anomali" rispetto allo schema quattuorvirale/duovirale)

>IIviri nel caso dei municipi, indica cambio di titolatura magistratuale a seguito di riassetto istituzionale

IIIIviri nel caso delle colonie "militari", attestazioni magistratuali riferibili alla primissima fase coloniaria (se non al momento finale della precedente fase municipale), anteriori al confezionamento dello statuto locale e all'introduzione del duovirato

status documentato o virtualmente certo (assetto magistratuale ignoto) status documentato ma da riferire con certezza o probabilità al periodo anteriore al I sec. a.C.

? $\quad$ status documentato da testimonianze di natura o attribuzione ambigua

(?) status non documentato ma postulabile

(?) dopo il toponimo, attribuzione incerta dell'attestazione

? ??? dopo il titolo magistratuale, attestazione incerta o assai incerta

[[SVLL.]] colonie "militari" successivamente ricondotte allo status di municipi 